University of San Diego

Digital USD

1988-04-01

\title{
Naturalistic Inquiry: An Appropriate Method for Evaluating Customer Training A Case Study of a Computer System Value- Added Reseller
}

Barbara Coulter Broderick EdD

University of San Diego

Follow this and additional works at: https://digital.sandiego.edu/dissertations

Part of the Leadership Studies Commons

\section{Digital USD Citation}

Coulter Broderick, Barbara EdD, "Naturalistic Inquiry: An Appropriate Method for Evaluating Customer Training A Case Study of a Computer System Value-Added Reseller" (1988). Dissertations. 511.

https://digital.sandiego.edu/dissertations/511

This Dissertation: Open Access is brought to you for free and open access by the Theses and Dissertations at Digital USD. It has been accepted for inclusion in Dissertations by an authorized administrator of Digital USD. For more information, please contact digital@sandiego.edu. 


\title{
NATURALISTIC INQUIRY: AN APPROPRIATE METHOD FOR EVALUATING CUSTOMER TRAINING
}

A Case Study of a Computer System Value-Added Reseller

$$
\text { by }
$$

Barbara Coulter Broderick

A dissertation submitted in partial fulfillment of the requirements for the degree of

\author{
Doctor of Education \\ University of San Diego \\ April, 1988 \\ Dissertation Committee \\ Patricia A. Lowry, Pk.Dr, Director \\ Susan M. Zgliczynski, Ph.D. \\ Fred R. Bahr, D.B.A.
}


Copyright 1988

by

\section{Barbara Coultex Broderick}

All rights reserved. 
For my mom and dad, who gave me a love of learning and the motivation to succeed. And to my children, for whom I hope to do the same. 


\section{ACKNOWLEDGEMENTS}

Over the past six years, I have had the good fortune of working with some very special people. I cannot possibly thank all of them here, but I do want to acknowledge a few.

First, Dr. Ed DeRoche was instrumental in my enrolling in the doctoral program. He has continued to be very supportive of my efforts and has provided me with valuable advice and insights. I have learned a great deal from him, not only professionally, but personally as well. His sensitivity and concern have always been appreciated.

I would also like to thank $\mathrm{Dr}$. Pat Lowry who has helped me in various capacities. As teacher, she gave me opportunities to think creatively and to develop new insights in the field of curriculum. These have served me well in the business world. As chair of my dissertation committee, she provided valuable guidance, editorial advice, and support. As friend, she always had an available ear and has made me feel confident of my abilities.

Dr. Susan Zgliczynski has served as my advisor, teacher, and committee member. I have learned a great deal from her and would like to thank her for being so patient and understanding -- and so smart! 
Seven years ago I took a management course from Dr. Fred Bahr in the School of Business. He impressed me then as being a fine professor and having one of the sharpest business minds I had ever encountered. My decision to ask him to serve on my committee was a good one, and my initial impressions have been confirmed. Dr. Bahr has been a source of information and insight and has provided me with a new perspective on the role of education in the business world.

I want to add a special note of thanks to Barbara Wegener for being so helpful and supportive throughout the past few years. Her sense of humor has frequently brightened up an otherwise dull day. Her efficiency is admirable.

It is also important that I thank my fellow doctoral students who have been a constant source of encouragement, advice, and support. Susan Sargent, Nan Haugen, and June Scopinich helped me through everything -especially statistics - and I've enjoyed their friendship.

Jeff Glenn-Levin has watched and Iistened as I took classes, studied for comps, and wrote my dissertation. He has been a terrific business associate, and without him I would never have developed my interests and skills in the training field. I thank him for the many opportunities he has given me and, more important, for being my friend. 
Finally, I want to thank my husband, Paul, for giving me his constant love and support. Ever since he's known me I've been going to school. My ability to stick with this program was very much due to him. And without him I wouldn't have been blessed with my three wonderful children who have never allowed me to become too wrapped up in intellectual pursuits! 
TABLE OF CONTENTS

vi 
Pilot study .. . . . . . . . . . .65

Case Study Procedures . . . . . . . . .67

A Guide to Naturalistic Evaluation . . . . . .94

Researcher Training . . . . . . . . .96

IV. PILOT STUDY. • . . . . . . . . . . . . .98

Site selection . . . . . . . . . . .99

Review of Procedures . . . . . . . . 101

Sample Responses . . . . . . . . . 109

Lessons Learned . . . . . . . . . 120

Implications of Pilot Study on Development of Guide ............. . . 130

V. FINDINGS . . . . . . . . . . . . 133

Proposition one . . . . . . . . . . . 134

Proposition Two . . . . . . . . . . 145

Proposition Three .. . . . . . . . 168

Summary of Findings . . : . . . . . . . 178

VI. SUMMARY, CONCLUSIONS AND RECOMMENDATIONS • 179

Research Questions . . . . . . . . 179

Implications of the Research . . . . . . 197

Recommendations for Future Research . . . 199

Summary . . . . . . . . . . . 201

VII. A GUIDE TO EVALUATING CUSTOMER TRAINING: A NATURALISTIC APPROACH . . . . . . . 202

Foreward . . . . . . . . . . . . 202

Introduction . . . . . . . . . . 202

Why Evaluate Customer Training . . . . 205

vii 
A Naturalistic Approach to Evaluation . . 206

TBM Computer Systems: An Evaluation of

Customer Training . . . . . . . . . 210

APPENDICES . . . . . . . . . . . . . . 239

REFERENCES . . . . . . . . . . . . . . 272

viii 


\section{LIST OF TABLES}

Table 1 Proposition \#1: Role-ordered Matrix

(Company Management) ........ 136

Table 2 Proposition \#2: Summary Matrix

Merit/Worth of Training . . . . . . . 147

Table 3 Proposition \#3: Summary Matrix

Trainer Effectiveness . . . . . . . 155

Table 4 Multiple Sources of Evidence . . . . 189 


\section{LIST OF FIGURES}

Figure 1 Sample of Codes Used For Sorting Data . . 86

Figure 2 Units of Analysis . . . . . . . . 88

Figure 3 Sample of Coded Observation Notes . . . 89

Figure 4 Example of a Checklist Matrix . . . . 90

Figure 5 Example of a Role-Ordered Matrix . . . 91

Figure 6 Sample of Course A Training Manual . . 159

Figure 7 Sample of Course B Training Manual . . .160

Figure 8 Interview Guide For Trainers . . . . .216

Figure 9 Interview Guide For Class Participants. .219

Figure 10 Interview Guide For customers Attending

Previous Classes . . . . . . . . .221

Figure 11 Interview Guide For Company Management. .224

Figure 12 Interview Guide For Sales Reps . . . . .225

Figure 13 Training Observation Guide . . . . . .227

Figure 14 Sample Page of Observation Guide. • . .228

Figure 15 Guide for Evaluating Training Materials .229

Figure 16 List of Codes for Analysis . . . . . . 230

Figure 17 Example of a Checklist Matrix . . . . .233

Figure 18 Example of a Role-Ordered Matrix. • . . 234 


\section{I.IST OF APPENDICES}

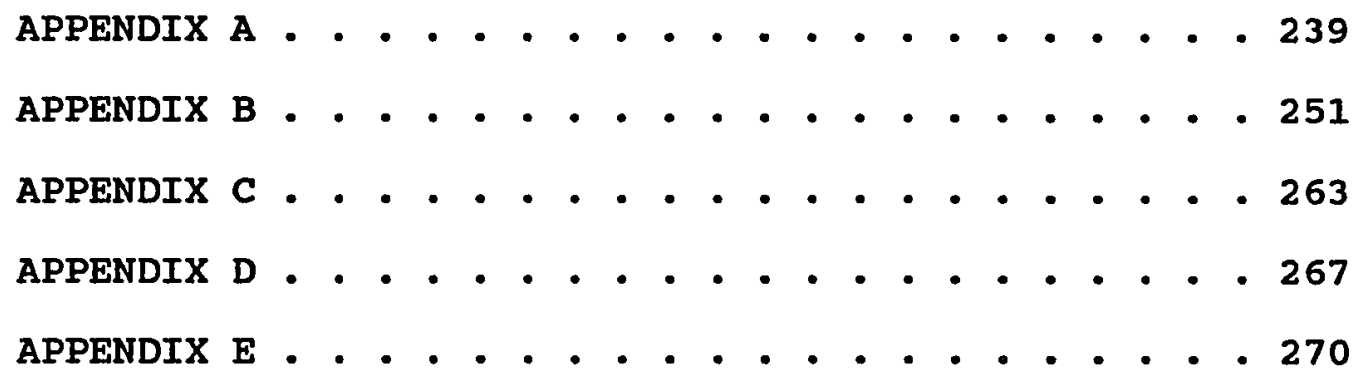

$\mathbf{x i}$ 


$$
\begin{aligned}
& \text { "Those who refused to look through Galileo's } \\
& \text { telescope knew what they were about: if they did } \\
& \text { not see the moons of Jupiter, then they would } \\
& \text { be forced to believe what they did not wish } \\
& \text { to believe. Therefore, it was wiser not to look." } \\
& \text { (Zinman, 1966, in van Maanen, 1973) }
\end{aligned}
$$

xii 
Chapter one

Introduction

Corporate training is big business in America. Estimates vary as to the amount of money spent each year, but it is certain that the business is at least a multibillion dollar a year proposition (Delaney, 1987, Hales, 1986). This training is offered to all types of employees, including managers, supervisors, professionals, support staff -- even CEOs. In addition to employee training, professionals in this field also address another audience -- the customer, or end-user. However, the multi-billion dollars spent annually are not necessarily enough money -- or money well spent. In Tom Peters' (1987) most recent book, Thriving on chaos, he remarks :

our investment in training is a national disgrace. That should come as no surprise. Despite lip service about people-as-our-mostimportant-asset, we value hardware assets over people, and have done so for the last century" (p.324)

with the tremendous growth in the computer industry over the past two decades, there has been an increase in demand for training users of both computer hardware and software. Many companies which sell computer systems have assumed the responsibility of training their 
customers in how to operate the system. Peters (1987) states that "Training your customers' employees becomes yet one more opportunity to redefine responsiveness and make it an offensive marketing strategy". Delaney (1987) suggests that this is another major dimension of a company's involvement in training, "another reality which often makes such involvement absolutely necessary: to support the purchase and use of company products or services" (p. 43). Companies such as IBM, Xerox, and Burroughs have highly developed training programs for their customers. other companies, however, operate training programs that are not well planned. Instead, these programs have evolved as the company has grown. With the dramatic increase in computer use and the acquisition of new systems, the amount of requisite training has also increased. However, quantity in this case is not necessarily related to quality. Instead, the growth of these programs has frequently resulted in a decrease in the quality of the training. A recent survey by the Manpower Services Commission and the National Economic Development Office of the United Kingdom (in an effort to better understand U.S. training programs) showed "a general view that training is an important, perhaps even essential, element of corporate human resource strategies. This, however, does not appear to bring about highly structured planning, budgeting, 
monitoring. Instead, training exists largely as an ad hoc and reactive function" (Olson, 1986, p.32).

This is not to say that all corporate training programs are ineffective. It is important, however, to recognize that training is an important factor in a company's growth and profitability and should not be taken lightly. As a company grows and its user base expands, management needs to step back and take an objective look at how it trains both its employees and its customers. Is the company addressing their appropriate needs and concerns? Do their trainers teach the technical skills required by the people who use the firm's products? Are end-users learning to be independent users? These questions cannot be answered unless a concerted effort is made to find the answers. Making this effort involves performing a well-planned evaluation of existing training.

A study recently sponsored by the American Society of Training and Development found that the first step in the textbook approach to training programs, that of formal evaluation, is ignored by about half the training executives most or all of the time ("Employee Training in America"). A 1985 survey of TRAINING magazine subscribers found that $62 \%$ of the respondents do not assess the need for or evaluate their training projects (Bowman, 1985, p.30). This indicates the failure of 
many companies to look at what they are doing and why they are doing it. There may be many reasons for neglecting this important task.

First, there may be insufficient time and/or personnel to carry out an evaluation. The process requires training staff time and the cooperation of other employees. Management may have other priorities. There are sales to be made, capital goods to be purchased, employees to be hired, and transactions to be negotiated.

second, training is frequently neglected or given a lower status within the company than that of other departments such as marketing or engineering -departments viewed as potential money makers.

Third, evaluating a training program is something that must be done by skilled personnel. It requires an understanding of many aspects of the business -organizational goals, related technology, end-user needs, and trainer effectiveness.

Fourth, the task of evaluating a training program can be intimidating to a company's management. It has been said that evaluations are often neglected because they require the evaluator -- a role frequently assigned to the training manager -- to be sophisticated in evaluation concepts, including statistical procedures (Randall, 1975). This is a qualification in short supply among many training staffs, and one which non-research oriented 
people tend to avoid.

Evaluation also requires that strategic decisions must be made. What exactly will be evaluated? Who will participate in the evaluation process? How will the results be analyzed? What type of recommendations should follow? Yet if training is not taken seriously, or if training is not a priority of management, the evaluation process will be either shortchanged or totally neglected. The lack of positive means of evaluation leaves many managers in the position where they see training as a greater financial risk than other options for investment of the organization's stretched financial resources... one of the highest priorities for training specialists today is to find a means of evaluating training activities which will convince their managements of the contribution that training can make to the success of the business (Robinson, p. 21). In order for a training program to have a positive effect on the success of a business, it must be designed with the company's strategic plan in mind. Peters (1987) believes that you must "treat your training assessment as the essence of strategic opportunity" (p. 329). It follows, therefore, that evaluating training requires the ability to look into the future. It is not only important to look at what the customer needs now, but 
what he will need as his business grows and as the product develops. Training must be more than reactive -it must be proactive.

Effective training requires dual vision. It is crucial that we anticipate, that we not simply react...but that we proact. As agents of change, we are looked upon to be visionary: to have our eyes on distant gates; to be prophets of tomorrow's needed skills, knowledge and insights (Bell, 1984, p.51).

Training programs are change agents. They act to develop skills, shape attitudes, motivate workers and improve productivity. They can also be tools for people who want to orchestrate change within an organization. In the December 20, 1986 issue of Economist magazine, it was reported that

Two things are certain. One is that, over the coming five years, four out of five people in the industrial world will be doing jobs differently from the way they have been done in the previous 50 years. The other is that, outside of a tiny group of technocrats, most people are going to have to go back to school, sooner or later, to learn how (p.93).

Customer training is important as both a change agent and a tool. As a change agent, it can have a 
significant impact on a company's bottom-line. When a new customer is well-trained on a new system, the word spreads to other potential customers who then may decide to purchase their equipment from the same company. As a tool for management, customer training allows the enduser to become independent. When a customer is not welltrained on a system, he must rely on help from the people who sold it to him. "The number of information-system experts to users is usually less than 1 to 100. The only way to combat the obvious problem of this imbalance is to focus, right from the start, on making users proficient and independent... Creative users go beyond applying the tool to specified jobs; their confidence pushes them to strive for new applications." (Sokol and Bulyk) This desire for new applications may result in the need for additional hardware or enhanced software; both result in more sales. If sales are up and customer support costs are down, both management and employees will benefit. It follows, then, that customer training can be a critical factor in a company's growth and success. If it does play such a vital role, then it would be wise for every company involved in customer training to look objectively at how it is performing. Evaluating customer training is especially important for a company which has experienced a period of rapid growth. What used to be adequate training for new customers may now be 
inadequate. Tom Peters, author of In Search of

Excellence suggests that a company "evaluate the content of every course every six months relative to market opportunities and changes in the marketplace" (1987). McDonald (1987) notes that "training effectiveness is defined by the value of the actions taught which learners use within the functions that they serve. Ideally, such value should be expressed in terms of increased profitability."

The question remains as to how this evaluation should take place. Much has been written about assessing a company's need for management development and employee training. There are models for evaluating existing training programs and models for developing new ones. However, evaluating end-user training requires a special approach because it involves the customers. so much hinges upon their satisfaction and independence. Therefore, it is important to look at the program being evaluated from two different viewpoints.

First, does the program have "merit". Merit is described by Guba (1981) as having intrinsic, contextfree value. This means that the program has "value of its own, implicit, inherent, independent of any possible applications." (Guba, 1981) The program should also be evaluated for its "worth". Worth refers to extrinsic value, value within some context of use or application 
(Guba, 1981). Customer training should be evaluated for its merit -- the accuracy of its content, the design of its presentation, and the quality of its materials. But a program should also be judged for its worth on the basis of how well it produces learning on the part of the trainees. Do they leave training with the ability to apply what they have learned back at their jobs? Can the trainees work independently with the information they have been taught? Is the material designed so that it can be effectively taught by the company's trainers? Is the program structured appropriately for the ability level of the trainees? In order to assess the merit and worth of a training program, it is critical that the evaluator look closely at various aspects of the program. This involves a careful review of all related documentation and training materials. It requires observation of classes and workshops. It also involves feedback from all concerned parties - trainers, trainees, and management. These people can be considered part of the "stakeholding audience." "A stakeholding audience is a group of persons having some common characteristics that has some stake in the performance (or outcome or impact) of the evaluand, that is, is somehow involved in or affected by the entity being evaluated" (Guba, 1981, p. 304). This type of evaluation requires extensive interaction with the stakeholding audience, which "is 
sufficient to cause evaluators seriously interested in being responsive to seek some other methodology than the conventional experimental, pre-post control-group approach." (Guba, 1981, p. 52) One type of evaluation which is very appropriate for assessing the merit and worth of end-user training is a responsive, naturalistic approach that relies on field study and allows the evaluator to become totally immersed in the training experience. As a result of such an evaluation, a company can gauge just how successful it is at training its customers and transforming them into independent users of its products. It can determine the quality of its materials, the effectiveness of its trainers, and the degree to which training is positively (or negatively) affecting the profitability of the company.

\section{The Purpose of the study}

The purpose of this study was to demonstrate the effectiveness of naturalistic inquiry as an appropriate method for evaluating end-user training in today's business environment. In order to do this, the researcher identified the characteristics of this method that contribute to its value and practicality within this setting. This involved defining naturalistic inquiry and describing the assumptions and postures of this technique. It also involved a discussion of the major components of 
end-user training and information-gathering techniques for each component. Before beginning the study, the researcher identified propositions regarding both the evaluation process and customer training.

The researcher chose case study methodology in order to demonstrate the effectiveness of naturalistic evaluation for end-user training and to either support or refute the propositions of the study. Qualitative data analysis methods were employed to organize the data and draw meaningful conclusions. The final step in the research was to design a practical guide for companies interested in performing a naturalistic evaluation of their own training program(s). This guide outlines steps to follow in planning for the evaluation and provides suggested interview questions for customers, trainers, and management. It provides guidelines for evaluating trainer effectiveness, documentation and training materials. Suggested methods for analyzing the data, including coding and categorizing techniques, are also provided. These may be used to draw conclusions about various components of a customer training program as well as conclusions about the overall program. 


\section{Research Questions}

The following research questions have been

identified:

1. What characteristics of naturalistic evaluation make

it an appropriate method for assessing end-user system training?

2. How can this method be used to evaluate the major components of an end-user training program?

3. Which naturalistic techniques are most appropriate for gathering information about each component?

4. How can this information best be presented to companies interested in performing naturalistic evaluation of their training program(s)?

Need For The Study

Many of the companies who currently market computer systems have experienced rapid growth over the past few years. Recent advancements in computer technology, coupled with a decrease in the cost of both hardware and software, have made computerization of businesses less of a luxury and more of a necessity. In order to fare well in the competitive business environment, companies must do all they can to streamline their information processing. This typically entails purchasing and implementing a computer system. Once a comp.ny purchases such a system, its employees must be trained in using it effectively. Customer training is an important factor in 
the degree of success a company has with the new system. Customer training also plays a key role in the decision to purchase the system in the first place. With the rapid growth in the customer base of computer companies, little time is spent on evaluating training. Yet evaluation is so important because it allows a company to respond to the needs of its customers. Naturalistic evaluation of customer training is a very appropriate method for conducting such a study, yet there is little information available to business personnel who should be responsible for this task. An understanding of the naturalistic evaluation process and a practical guide to conducting such an evaluation would be of great value to training professionals and/or company managers who are not skilled in research techniques but who must take the time to look objectively in order to offer customers quality training. If they cannot do this, customers will not experience the degree of success otherwise possible. The customers will not be satisfied, and the company may not be as profitable as it might have been.

\section{Propositions}

In order to limit the scope of the study, the following propositions reflect those issues most relevant to the researcher's analysis of customer training.

1. Training programs designed for end-users of computer systems generally evolve as the company's customer base grows. These programs are rarely planned. 
2. Training can be evaluated for both merit and worth. Each play an important role in the overall success of the program.

3. The majority of trainers in end-user training programs come from an industry background with little or no training in educational methods. Training them to be good teachers is a critical step in the development of a successful training program.

Definition of Terms

Merit: Guba (1981) describes merit as the intrinsic, context-free value of an entity.

Worth: Guba (1981) describes worth as the extrinsic value of an entity; its value within some context of use or application.

Evaluation: In this study, evaluation will be considered as it relates to training. Goldstein's (1986) definition is most appropriate: "Evaluation is the systematic collection of descriptive and judgmental information necessary to make effective training decisions related to the selection, adoption, value, and modification of various instructional activities."

Naturalistic Evaluation: A naturalistic approach to evaluation is both holistic and dynamic, occurring within the natural setting of the evaluand and requiring 
interaction of the evaluator with the program and its stakeholders. It allows for feedback through qualitative research methods, such as interviews and observation and calls for the use of intuition and experience by the evaluator (Guba, 1981).

\section{Responsive Evaluation: Responsive evaluation is} described by stake (1975) as being oriented directly to program activities, responding to audience requirements for information, and considering the different value perspectives of stakeholders when reporting the success and failure of the program.

Customer (End-user) Training: This type of training is designed specifically to teach technical skills to users in order to support the purchase and use of the company's products (Delaney, 1987). In this study, the customers have purchased a new computer system consisting of hardware and application software.

Value-Added Reseller: A Value-Added Reseller (VAR) is a company that buys a computer system from a manufacturer, packages it with application software, and then sells the product.

Trainer: A trainer is a person who engages in the design, development and delivery of training (Spaid, 1986). In this study, the trainer is responsible for teaching either technical or non-technical skills to an individual or group of employees. 
Trainee: A trainee is a person who is receiving instruction in some technical or non-technical skill (Margolis and Bell, 1986).

Andragogy: Andragogy refers to the art and science of helping adults learn and is based on self-directedness, experience, readiness to learn and problem centeredness (Knowles, 1984) .

\section{Limitations of the study}

1. The study involves the evaluation of two companies who are actively conducting customer training. The first company will serve as a pilot study for the research. Both companies are valueadded resellers who meet the criteria for site selection, and the study was designed specifically for use with these two companies.

2. Various components of customer training were identified for inclusion in this study (e.g., formal classes and training materials). Customer training in other companies may be comprised of a different set of components.

3. It may not be possible to observe every training class or evaluate every piece of training material. Interviews will be conducted with as large a group of employees and customers as possible. 
4. Interview, observation and evaluation guides were designed for use during the pilot study and the case study research. There are endless variations of training, and every company differs in its approach to this process. Therefore, use of these guides in other settings will require their modification based upon the structure and make-up of the training program being evaluated. 


\section{Chapter Two}

\section{Review of the Literature}

There have been a large number of books and articles written concerning training and evaluation of training programs both in the United states and in the major industrial centers of the world. A majority of these, however, deal with the field of human resource development and focus on employee and/or management training. The area of customer training, and particularly customer training in the computer industry, has received little attention. For this reason, much of the background reading for this study has involved literature about training and evaluation in general. The literature reviewed in this chapter is organized in the following manner. The first section focuses on various definitions of training and evaluation. Both terms are defined for the purpose of this study. The second section explores the topic of naturalistic evaluation, outlining its major characteristics and showing its appropriateness as a technique for evaluating customer training. The third section addresses the propositions of this study and reviews the literature relevant to each one.

Definitions of Training and Evaluation Various definitions of training have been offered in the literature. Some of these are very simplistic. Margolis and 
Bell (1986) define training as "helping adults learn to learn" (p.1). Others are far more complex. "Training is defined as the systematic acquisition of skills, rules, concepts, or attitudes that result in improved performance in another environment" (Goldstein, 1986, p.3). Most definitions focus on the end result of the process, a change in the behavior of the person being trained. Laird (1978) states that "Training may be defined as an experience, a discipline, or a regimen which causes people to acquire new, predetermined behaviors" (p.9). Mayo and DuBois (1987) cite McGehee's definition of training as "the formal procedures which a company utilizes to facilitate learning so that the resultant behavior contributes to the attainment of the company's goals and objectives" (p.3). Other definitions are more job or task related training. Hamblin (1976) sees training as "any activity which deliberately attempts to improve a person's skill in a job" (p.6). Although all of these definitions are similar in many respects, they differ in their scope. For the purpose of this study, a definition offered by Mayo and Dubois (1986) will be adopted. "The term 'training' emphasizes (1) the development of a skill and (2) learning for a definite purpose, characteristically associated with the goals of an organization" (p.2). This definition is appropriate because it stresses the 
development of a skill as well as learning within an organization. This study will look specifically at customer training designed to teach a skill -- use of a computer system -- as it relates to the needs of the company implementing the new system.

Evaluation has also been described in a number of ways. Webster (1985) provides two simple definitions, "to determine or fix the value of", and "to examine and judge". Stake (1983) describes it as "an observed value compared to some standard" (p. 291). The literature reviewed for this study focuses primarily on the evaluation of training programs, which Kirkpatrick (1976) defines simply as the determination of the program's effectiveness. Meyers (1981) defines it as "the effort to understand the functioning and effects of a program, which is a planned sequence of activities intended to achieve some goal" (p.1). Other authors offer less simplistic descriptions. Goldstein (1986) states that "evaluation is the systematic collection of descriptive and judgmental information necessary to make effective training decisions related to the selection, adoption, value, and modification of various instructional activities" (p.141). Hamblin (1974) focuses on both the collection of the data being evaluated as well as the actual assessment process. 
The act of evaluating training is simply the act of judging whether or not it was worthwhile in terms of some criterion of value, in the light of the information available. However, in the training field, evaluation has traditionally been taken to include, not only the assessment of value, but also the collection and analysis of the information on the basis of which the assessment is made (p.11).

Sauer (1981) also addresses the collection of data in his description. "Evaluation requires making value judgments about performance, quality, congruence with objectives. Good evaluation is based on feedback, and it mainly planned for, sought through some instrument or 'formal' means, distilled and summarized. Analysis and judgments may then be made" (p.154).

The literature reflects a sincere interest in evaluating training programs in order to make them more effective. Hamblin (1974) believes that "evaluation should be an integral feature of the training system, rather than a tacked-on addition" (p.12). She explains that "A well controlled training programme is one in which weaknesses and failures are identified and corrected by means of negative feedback, and strengths and successes are identified and amplified by means of positive feedback" (p.11). However, in his preface to 
the book Evaluating Training Programs, Kirkpatrick (1976) discusses one problem facing evaluators. "All training professionals agree evaluation should be done. That is as far as the agreement goes. When we try to define 'evaluation' or determine how to do it, opinions and recommendations vary tremendously."

In addition to differences in opinion on what evaluation is or how to do it, studies have shown that although there is a general acceptance of the worth of training evaluation, people may not practice what they preach. On one hand, Russ-Eft (1985) states that "there is an increasing recognition that evaluation is critical to training. Basically, all parties gain through evaluating training: The programs, the training departments, and the training specialists" (p. 57). On the other hand, when it comes to performing training evaluation, there appears to be more talk than action. A student at the University of New York conducted a study of 83 corporations in 10 industries. He found fewer than 1 in 10 organizations conducted formal program evaluation. (Phillips, p.4). The literature also shows that the importance of evaluation is often overlooked and opportunities for improving training programs are frequently missed because evaluation is not given the attention it deserves (Mayo and DuBois, Hamblin, Margolis and Bell). One author goes so far as to state that "the literature has been void of useful and practical information on evaluation" (Phillips, p.5). 


\section{Qualitative Evaluation}

In recent years, there has been a flood of publications dealing with evaluation of training. These publications encompass a broad spectrum of approaches to the field. Some are highly theoretical, while others direct the reader through systematic, step-by-step procedures. Although the importance of evaluation is established, there are varying views on how this process should take place. Randall (1976) recognizes three groups of people with differing attitudes about the performance of training evaluation. First, he identifies the "negativists", those who claim that evaluation of formal training is either impossible or unnecessary. Second, he describes "positivists" who believe that scientific evaluation of training results is the method of choice. Third, he identifies a group he calls the "frustrates" who recognize that evaluation is necessary but have not yet decided what method will be best for performing this task. Kirkpatrick (1976) emphasizes the importance of evaluation when he states that "the future of training directors and their programs depends to a large extent on their effectiveness" (p.13). Like the positivists, he believes that "To determine effectiveness, attempts must be made to measure in scientific and statistical terms" (p.13). Yet over the past decade, other approaches to evaluation are receiving 
a great deal of attention. Stake (1982) discussed the evaluation of an arts program using a responsive approach, one that provides contrast with the scientific, positivist approach. This is

an approach that trades off some measurement precision in order to increase the usefulness of the findings to persons in and around the program. Many evaluation plans are more preordinate, emphasizing: (1) statement of goals, (2) use of objective tests, (3) standards held by program personnel, and (4) research-type reports. Responsive evaluation is less reliant on formal communication than on natural communication" (p.27) Most of what has been written about evaluation focuses on the use of quantitative methods. What is lacking in the literature is more emphasis on a qualitative approach to training evaluation. This is not to say that quantitative techniques are inappropriate, or that qualititative methods are better. It can be argued, however, that both approaches are legitimate and that neither method should be discounted. Rogers (1983) explains that "Both approaches can be rigorous, systematic forms of empirical inquiry... Neither is inherently good or bad, superior or inferior." (p.89) Downey and Ireland (1983) express a similar viewpoint. 
Methodologies are neither appropriate nor inappropriate until they are applied to a specific research problem....each inquiry requires careful selection of the proper tools. Having the wrong tool for the task may be no better than having no tools at all...Thus, both qualitative data and quantitative data have their place in organizational research" (p.179).

Van Maanen (1983) states that Qualitative researchers in contrast to their quantitative colleagues claim forcefully to know relatively little about what a given piece of observed behavior means until they have developed a description of the context in which the behavior takes place and attempted to see that behavior from the position of its originator. That such contextual understandings and empathetic objectives are unlikely to be achieved without direct, firsthand, and more or less intimate knowledge of a research setting is a most practical assumption that underlines and guides most qualitative study (p.10) . Yet there are certainly contrasting views on the value of qualitative research. Reynolds (1983) believes The naturalistic perspective upon social and educational matters seems to reflect a temporary disillusionment with such conventional modes of 
scholastic enquiry as positivism. Yet there is no evidence that our understanding of social and educational matters has been dramatically increased by this new, unscientific, idealist, and micro-sociological paradigm (p.87) . on the other hand, Miles and Huberman (1984) speak strongly in defense of this type of data. Qualitative data are attractive. They are a source of well-grounded, rich description and explanation of processes occuring in local contexts. With qualitative data, one can preserve chronological flow, assess local causality, and derive fruitful explanations. Serendipitous findings and new theoretical integrations can appear. Finally, qualitative findings have a certain undeniability that is often far more convincing to a reader than pages of numbers (p.2).

Light (1983) discusses his preference for qualitative evaluation as it relates specifically to training programs. with analytic methods, the investigator attempts to isolate the various elements in a complex situation, such as professional training. To do this, the evaluator usually knows (or assumes he or she knows) what the elements are, and to separate them out he or she usually employs 
predeveloped instruments and analyzes the results quantitatively. He or she then identifies the dependent, independent, and intervening variables, and assesses the links between them. A lot can be missed by such analytic methods partly because predeveloped instruments are used which may not suit the particular situation and partly because these methods cut reality up into discrete fragments of surface behavior which are then recombined into statistical clusters. By contrast, the holistic method considers a complete activity like training as an interrelated system with a deep structure...By focusing on the system as a whole, the method obtains a better sense of how the training program works (p.58).

MacDonald and Walker (1983) also stress the value of qualitative, non-statistical research.

Many of the quite legitimate questions that are put to evaluators, especially by teachers, cannot be answered by the experimental methods and numerical analyses that constitute the instrumental repertoire of conventional educational research. There seems to be a need to find ways of portraying this experience and this milieu so that prospective users of new 
programs can relate them to their own experience, circumstances, concerns and preferences" (p. 1). The purpose of this study is to show that one qualitative approach, naturalistic evaluation, is an appropriate method for evaluating training, specifically customer training.

\section{Naturalistic Evaluation}

Man is by nature an evaluator. We evaluate everything we come in contact with, whether it be for its value, its relevance to our lives, the degree of pleasure or displeasure it gives us, or its relative importance. It has been said that "Man is apparently so constituted that he cannot refrain from evaluating, judging, appraising or valuing almost everything which comes within his purview" (Hamblin, p.9). Although evaluation is not new to us, the practice of educational evaluation as we know it is less than 100 years old.

In Guba and Lincoln's book Effective Evaluation (1981), the authors outline the history of evaluation and the evolution of the field called naturalistic inquiry. originally evaluation dealt with individual differences among students as determined by intelligence tests. During the early 1950s, focus shifted to the evaluation of student behaviors based on their ties to instructional objectives. As time went on, other new ideas were introduced and new models proposed. In an article in 
1963, Cronbach stressed the importance of decision-making as part of the evaluation process. Several years later, Scriven introduced the concepts of formative and summative evaluations and called for the professional evaluator to render judgments of the evaluand. stake proposed his "countenance" model in 1967, a model involving both description and judgment. stufflebeam followed shortly thereafter with his CIPP (Context-InputProcess-Product) model, where evaluation is a continuing process that leads the evaluand to be both proactive and reactive, to "service decisions still to be made or to provide accountability data for decisions made in the past" (p.15). In 1972, Scriven suggested that evaluators no longer rely on objectives as the focus of their work, but instead avoid them. He believed that evaluation should be goal-free, that it should "evaluate actual effects against a profile of demonstrated needs..." (Guba and Lincoln, 1981, p.17).

As new problems emerged and new questions arose, "it was becoming more and more evident that life in a multivalued, pluralistic society was not well served by modes of evaluation that persisted in the belief that consensus was possible and that value congruence was a worthwhile aim" (Guba and Lincoln, 1981, p.22). Stake introduced his responsive model to address this concern. 
Responsive evaluation is

based on what people do naturally to evaluate things: they observe and react... An educational evaluation is responsive evaluation if it orients more directly to program activities than to program intents, if it responds to audience requirements for information, and if the different value perspectives of the people at hand are referred to in reporting the success and failure of the program (Stake, 1975, p.14). stake suggests various steps for conducting this type of evaluation, including talking with clients, making personal observations, identifying the concerns of the audiences, conceptualizing the issues and problems, selecting data collecting procedures, reporting this information in various "natural ways", and where necessary, presenting formal reports to appropriate audiences. Guba and Lincoln (1981) believe that "responsive evaluation as proposed by stake...offers the most meaningful and useful approach to performing evaluations" (p.33). They elaborate on this belief by stressing that "responsive evaluation produces information that audiences want and need... it takes its cues from those matters that local audiences find interesting or relevant" (p.38). Naturalistic evaluation, as described by Guba and Lincoln (1981), is 
responsive evaluation.

Before exploring the use of naturalistic evaluation as a technique for evaluating training, it is important to understand what is meant by a naturalistic approach in research. Guba and Lincoln (1983) state that naturalistic inquiry is a "paradigm of inquiry" (p.311). They go on to explain this statement by describing paradigms as "axiomatic systems characterized by their differing sets of assumptions about the phenomena into which they are designed to inquire" (p.311). The naturalistic paradigm is one which relies on "field study as a fundamental technique, which views truth as ineluctable, that is, as ultimately inescapable. sufficient immersion in and experience with a phenomenological field yields inevitable conclusions about what is important, dynamic, and pervasive in that field" (Guba and Lincoln, 1981, p.55). These authors take the position that "the naturalistic paradigm is the more useful for all social-behavioral inquiry and certainly for responsive naturalistic evaluation" (p.56). An understanding of the basic assumptions of the naturalistic paradigm should aid in an understanding of naturalistic inquiry. The following are five basic assumptions outlined by Guba and Lincoln (1983). 
1. There are multiple, intangible realities which can be studied only holistically. Prediction and control are unlikely outcomes of naturalistic inquiry.

2. The inquirer and the object interact to influence one another, especially when the object of inquiry is another human being.

3. The naturalistic inquirer focuses on differences rather than similarities, and subtle differences may be seen as more important than gross similarities.

4. Although actions may be explainable in terms of multiple interacting factors, events, and processes that shape it, inquires can, at best, establish plausible inferences about the patterns and webs of such shaping in any given case.

5. Inquiry is value-bound in a number of ways, including the following: Inquiries are influenced by inquirer values, by choice of paradigm guiding the investigation, and by choice of data collection and analysis methods.

In addition to the assumptions outlined here, Guba and Lincoln (1983) identify some characteristic postures which provide important insights into naturalistic 
inquiry. Six of the most common postures are described. Preferred data collection methods: "Qualitative methods are normally preferred by a human using himself or herself as a prime data collection instrument. Techniques such as interview, observation, use of non-verbal cues and unobtrusive measures, and documentary and records analysis seem more appropriate in that case" (p.323).

Source of theory: Unlike rationalists who prefer a priori theory, naturalists believe that it is not theory but the inquiry problem that guides and bounds an inquiry. The naturalist would prefer "to develop the theory as his or her collection of facts grew and his or her insights into their possible meanings matured" (p.324).

Instruments: Naturalistic inquiry has as its preferred instrument the human being, "because of their greater insightfulness, their flexibility, their responsiveness, the holistic emphasis they can provide, their ability to utilize tacit knowledge, and their ability to process and ascribe meaning to data simultaneously with their acquisition" (p.324). Knowledge types used: With humans acting as the prime data collection instrument, "naturalists admit 
and build upon intuitions, apprehensions, 'vibes', which while not expressible at any given moment, nevertheless occur to the inquirer by virtue of his or her training and experience" (p.324).

Design: The naturalist is not able to specify any but the broadest design of the final report because "he or she anticipates that the design will emerge as the inquiry proceeds" (p.325).

Setting: Natural settings are preferred for all inquiry. Studies are not conducted in laboratory settings or in controlled or contrived environments (p.325) .

Naturalistic evaluation is a dynamic, holistic approach built on assumptions and postures that make it an effective technique for evaluating training programs. It allows the evaluator to become involved in the training process and to interact with the various stakeholding audiences. It allows for feedback through personal interviews, observations within a natural setting, examination of related materials, and use of both experience and intuition on the part of the evaluator. Van Maanen (1983) endorses this type of evaluation in the preface to his book Qualitative Evaluation. "I am convinced that the richest and most useful studies grow from situations in which the 
evaluator deeply enmeshes himself in the everyday activities of the program he investigates." Guba and Iincoln (1981) cite a description of naturalistic inquiry by Wolf and Tymitz in their book, An Introduction To Judicial Evaluation and Natural Inquiry: Naturalistic inquiry is an inquiry mode aimed at understanding actualities, social realities, and human perceptions that exist untainted by the obtrusiveness of formal measurement or preconceived questions... Naturalistic inquiry attempts to present 'slice-of-life' episodes documented through natural language and representing as closely as possible how people feel, what they know, and what their concerns, beliefs, perceptions, and understandings are. The literature reflects a growing interest in naturalistic evaluation, especially in the social sciences. Reynolds (1983) cites a variety of such studies in the field of education.

over the last decade, it is easy to trace the growing popularity of so-called "naturalistic" methods of social enguiry... One can see such methods being applied to the study of contemporary educational issues and problems, particularly to curriculum (Stenhouse, 1980) and to within-school educational processes (Woods \& Hammersley, 1971; Chanan and Delamont, 1975; Woods, 1979) (p. 77). 
Reynolds (1982) also addresses the wide variety of issues which have been studied using this approach. The great volume of material that has accumulated since the development of the new society of educators in the early 1970s has almost exclusively been collected by naturalistic forms of ethnography. The information bears upon a wide range of important issues. We have information on the rich variety of teacher and pupil strategies (Woods, 1980; Eggleston, 1974), upon the nature of students' within-school subcultures (Woods, 1979), upon teacher decision making or strategy formation (Eggleston, 1979), and upon the nature and quality of classroom interaction (Delamont, 1976; Stubbs \& Delamont, 1976) (p. 82). Hatch (1985) believes that naturalistic inquiry should be used in educational research because it offers enriched understanding of schools and the people who inhabit them. Williams (1983) extends the focus on this type of inquiry to any situation where a process is evaluated.

Naturalistic inquiry is particularly suited to process evaluation. Observation of the evaluand (or its related participants) in action by a naturalistic evaluator can reveal critical processes as they occur naturally. Interactions, 
relationships, strategies, and skills can be studied as they take place (p. 87).

The literature shows an increasing amount of attention being focused on naturalistic inquiry. Yoong (1986) believes that its popularity will continue to increase in the future. Lincoln and Guba (1985) view naturalistic inquiry as providing "a better degree of fit with substantive paradigms in the areas of social/behavioral research" (p. 66).

\section{Propositions}

In addition to a review of the literature in the areas of training, evaluation, and naturalistic research, materials relating to the study's three propositions was also reviewed. These propositions reflect the issues most relevant to the research and are based upon literature in the fields of business, training, adult learning and evaluation. The scope of this literature is broad, covering topics which range from principles of adult education to trends in the computer industry. In order to review this literature and present it in an organized manner, each proposition was addressed individually. 
Training programs designed for end-users of computer systems generally evolve as the company's customer base grows. They are rarely planned.

The world is in the middle of a technological revolution. In his best selling book, Megatrends (1984), John Naisbitt states that "We now mass-produce information the way we used to mass-produce cars. In the information society, we have systematized the production of knowledge and amplified our brainpower. To use an industrial metaphor, we now mass-produce knowledge and this knowledge is the driving force of our economy" (p. 7). We are experiencing an information explosion. Economist magazine reports that "the machinery that has been midwife to this explosion in knowledge -- computers, databases, decision-making software, modems, video equipment, CAD terminals... is all lumped together under the banner of information technology (IT). Already IT is the fastest growing service industry in most industrial countries" (December 20,1986, p. 93)

Due to the growth of information technology, the computer industry has experienced a tremendous growth over the past decade. Computer systems are being installed in every type of business. It is not only the large corporations or complex industrial organizations that require computerized information networks. Even the 
smallest mom and pop retail stores are turning to the computer for assistance in inventory control, accounting, planning, and sales tracking. Vendors involved in the sale of computer systems to these businesses may have started out on a small scale, with only a few customers. These customers required training on these systems, and thus was born the vendors' training departments. As the customer base grew, so did the training departments -- but it is likely that there was no real planned growth, no strategy for assessing the needs of the customers and developing programs to meet these needs.

Effective training requires...dual vision. It is crucial that we anticipate, that we not simply react...but that we proact. As agents of change, we are looked upon to be visionary: to have our eyes on distant gates; to be prophets of tomorrow's needed skills, knowledge and insights" (Bell, p. 50).

Yet in spite of this need for vision, for planning, Olson (1986) believes that training exists largely as an ad hoc and reactive function. As growth in the computer industry continues, it becomes even more important that companies develop a proactive stance toward their training programs. Goldstein (1986) notes that Advances in computer technology and work techniques have already led to changes in 
training requirements for many jobs in

industrial enterprises. Each new advance has the potential to change job requirements as well as to create or abolish entire job categories. Automation generally requires higher levels of skill from the operators who desire to continue in their present jobs... (p.10).

Two of the technology training truths described by Sokol and Bulyk (1986) also address the issue of computer training. First, "Training is crucial to all stages of automation...Training is a necessary tool throughout the automation process, from introduction to advanced use of the equipment" (p. 43). And second, "Automation training needs are complex and must be made manageable. A structured, written plan is necessary" (p. 44).

For a company to take a truly proactive stance toward training, and to devote adequate time and energy to planning this training, it is vital that management recognize its importance. Peters (1987) recommends that a company's management view training as a means for teaching the organization's vision and values.

The best training programs, at all levels, from beginner to brush-up, must be seen as a prime opportunity to underscore these values. Top management must be involved in every training program, using the opportunity to discuss and transmit the vision that holds the firm together in turbulent times (p. 328). 
In order to manage automation training needs, to think proactively and plan accordingly, existing training programs must be evaluated. Kaufman (1980) explains that "evaluation is a process of helping to make things better than they are, of improving the situation...evaluation tells us how we are doing compared with what we set out to do, and will suggest what might be done to achieve our objectives" (p.9). Kirkpatrick (1976) states that "The most common reason for evaluation is to determine the effectiveness so future programs can be improved" (p.88). Companies interested in providing their customers with quality service and training must take the time to look to the future -- to accommodate the growth in their customer bases and the enhancements to their products. They must evaluate what they are doing and plan what they will do next.

Training can be evaluated for both merit and worth. Each play an important role in the overall success of the program.

Guba and Lincoln (1981) identify two senses in which an entity may have value. "...it may have value of its own, implicit, inherent, independent of any possible applications... we shall apply the term 'merit' to this kind of intrinsic, context-free value" (p.39). Evaluation of 'merit' in a training program might involve evaluating 
the materials for the professional look, the training facilities for their comfort and functionality, and the content of the coursework for its accuracy, completeness, and appropriateness for each audience. These all contribute to a quality training program. Mayo and DuBois (1987) address one of these factors, the environment.

Some training environments are more conducive to learning than others... If a training space is specifically designed for training and the lighting and noise in this space can be controlled, the trainees are more likely to feel that the training is important to management and therefore should be important to them. On the other hand, if training is conducted in an outdated or inappropriate space, the trainees may conclude -- perhaps correctly -- that training is not seen as a high priority in the organization (p.28).

Margolis and Bell (1987) share this view and believe that a good training site should meet several basic requirements, including: comfort and accessibility; quiet, privacy, and freedom from interruptions; ample space; and proper temperature control and ventilation. Luckett (1985) addresses other important factors. He suggests that a successful training program should be well executed, "appealing to the trainee accustomed to 
sophisticated print, radio, television and movie production" (p.80). Content and delivery should be geared to the trainee's skill level and should provide the trainee with a safe, enjoyable experience. All of these are important. They reflect the vendor's commitment to customer training. They make the customer feel appreciated and important. They contribute to the marketability of the product.

But merit by itself is not enough. A training program must also have worth. Worth refers to the extrinsic or context-determined value. Does the training program actually prepare the trainees to use the product? Roman (1984) points out that in order for training to be effective, it must be directed toward a task or project that the students will actually be completing when they return to work. And Robinson (1985) states that "If training carried out away from the job cannot be transferred effectively to the job, it will be abortive and a total waste of everybody's time" (p. 181). Sokol and Bulyk (1986) explain several aspects of training which further reflect the importance of "worth". Training is more than skills development... A training program aimed at user development must anticipate shifting needs and provide supportive training. Such a developmental training program has three components: sensitization -- activities 
that prepare users emotionally for the automation and the changes it will bring; education -activities that prepare the user intellectually for the automation; and training -- activities that prepare the user to actually operate the automated tools (p. 43). Luckett (1985) outlines the important qualities of a successful training program. Although several focus on the program's merit, many deal with its worth. He suggests that the program should be lasting, anticipating and dealing with the obstacles to long-term behavior change. It should be useful to the trainee, limiting its contents to what's been proven to help most on the job. It should also be persuasive, overcoming any objections which the trainee might have had and motivating new behaviors.

If a training program doesn't meet the needs of its customers, then no matter how much merit the program has, it will not have much worth. 
The majority of trainers in end-user training programs come from an industry background with little or no training in educational methods. Training them to be good teachers is a critical step in the development of a successful training program.

Trainers who are hired by computer system vendors are typically hired because of their industry background, not because they are experienced teachers.

Most of those who deliver training have not prepared themselves academically for the job. Instead, they have found themselves in the role more or less by accident. Often people are "drafted" into the job of training because they have become knowledgeable about particular subjects or proficient in particular skills (Margolis and Bell, 1986, p.ix).

It is a trainer's expertise in a particular applications field -- such as retail, energy, health services, or finance -- that contributes to success. Customers are more willing to work with a person who can speak their language and who understands their problems than someone who is a data processing expert or a skilled teacher. For this reason, very few trainers responsible for customer training on computer systems have any education in teaching methods or adult learning theory. "Many trainers focus primarily on their own content 
specialty... and only secondarily on the participants' needs, wishes, level of skill, or past experience" (Esty, p. 75)

The literature shows, however, that a high degree of proficiency in a skill does not make a person competent to teach that skill. Kliem asks that we understand "that the most technically proficient person in the company may not be the best instructor. Just because an employee can perform his or her job well does not qualify him or her to teach. In many respects, the skills and orientation of both functions are 'poles apart'" (p.51). Hahne (1986) asks an important question addressing the same issue.

Who else but an expert in a certain field is better qualified to teach that material to others? Well, frankly, expertise in an area does not guarantee that an individual will be able to impart that knowledge to others. Certain techniques -- training techniques -- must be used if one is to be sure that trainees are learning what they're supposed to and will be able to apply that information once they're back on the job (p.16).

Janov (1986) concurs with his thinking when she states, "There's a real difference between a professional trainer who has terrific communication skills and knows what 
makes for effective classroom instruction, and a technical person who has all the background in the world but doesn't have skills in front of a group" (p.18). Bezdek (1985) states that "Many technical instructors mistakenly believe that content is all important... Acquiring facts is important, of course, but learning also involves understanding concepts, seeing relationships, and applying knowledge" (p.73).

Can technical people learn how to be effective trainers? Laird and Belcher (1984) believe that this is very possible. "After many years of observing both the ordinary and the masterful, we have seen that the really great ones use some special skills. It is heartening that these special skills are learnable, and are thus available to all who actively seek excellence in the class or conference room" (p.73). Current literature also reflects the view that people can learn to be good trainers, as many books and articles have been published with that goal in mind (Margolis and Bell, 1987; Mayo and Dubois, 1987; Laird and Belcher, 1984).

If this is the case, what type of education is necessary for trainers? First, they need to understand that every customer is different. Each person that sits in their classroom or participates in their training program comes to that training with different experiences, attitudes, motivations, and learning styles. 
Trainers also need help in becoming familiar with each audience -- the specific group of people with whom they will be interacting. Technical experts may be too involved with the subject matter to think about the people they will be teaching. Bezdek (1985) recommends that trainers understand the learners' backgrounds and needs, their familiarity with the subject matter, and any material which they should understand before beginning the training at hand.

Trainers should also be familiar with adult learning theory. Adults do not learn the same way children learn. A trainer cannot teach a class of adults in the same manner he or she was taught in elementary or high school. Yet most trainers have no other role model to learn from. They teach the way they were taught, and they frequently fail. Malcolm Knowles (1984) discusses two contrasting approaches to education, pedagogy and andragogy. "The pedagogical model is the one we have all had the most experience with. In fact, it is the only way of thinking about education that most of us know, for it has dominated all of education -- even adult education until recently -- since schools started being organized in the seventh century" (p.8). The pedagogical model assumes that the learner is dependent on the teacher who is fully responsible for what should be learned, how and when it should be learned, and whether it has been learned. 
students are responsible only for being taught and carrying out the teacher's directions. The model also assumes that the learner enters the activity with little experience in the field and that the teacher's experience is of value to them. The pedagogical model also assumes that students are motivated primarily by external pressures, such as competition for grades, demands of parents or other adults, or consequences of failure. The andragogical model takes a very different approach to adult education. The following are four assumptions which provide a basis for this model.

First, the learner is self-directing and that "when we find ourselves in situations where we feel that others are imposing their wills on us without our participating in making decisions affecting us, we experience a feeling, often subconciously, of resentment and resistance" (Knowles, p.9). Hall (1987) emphasizes the importance of self-direction.

A lot of us are reluctant to accept change, especially if it is imposed on us in an arbitrary manner. You and I want to know about any change which is going to make a difference in how we perform our duties. We normally can accept change with a bit more grace when we know about it in advance, and we will accept it even better if it is pointed out to us how the change will 
work to our advantage. We'll be still more committed to making the change work if we have been given the opportunity to play a part in the planning for the change and have had our ideas taken into consideration" (p.4).

Knowles' second assumption is that adults have a great deal of experience to build on, and that for many kinds of learning, adults are a great resource for each other. "So, if in an educational situation an adult's experience is ignored, not valued, not made use of, it is not just the experience that is being rejected, it is the person. Hence the great importance of using the experience of adult learners as a rich resource for learning" (p.11).

A third assumption of this model is that adults are ready to learn when they need to know or do something in order to be more effective in some aspect of their lives. "Recognize that the best training is one oriented toward applications the individual will experience daily. The key is relevance. If the training does not provide the tools to help employees in their duties, they will soon forget what they learned and the company will have fruitlessly expended money and energy" (Kliem, p. 51). Knox (1986) explains that "For the most part, adults do not learn for the sake of learning; they learn in order to be able to perform a task, solve a problem, or live in a more satisfying way" (p.12). 
And finally, adults respond better to intrinsic motivators than to extrinsic ones. "The andragogical model predicates that the more potent motivators are internal -- self-esteem, recognition, better quality of life, greater self-confidence, self-actualization, and the like" (Knowles, 1986, p.12).

Why is an understanding of adult learning theory important? Knox (1986) states that "Effective instructors recognize that there are some general characteristics associated with adult learning that enable them to be especially helpful to learners in each instance" (p.15). He goes on to say that "...a more fundamental understanding of adults as active learners can enable you to enhance their motivation, achievement, application and continued inquiry" (p.39). This knowledge can assist trainers in the design of training programs and materials as well as the methods used in training. For instance, Kliem (1985) explains that "nontechnical people tend to think in terms of tasks and problems, whereas technical types are more likely to think in terms of functions" (p.74). A technical trainer might have difficulty teaching a non-technical audience unless he or she was able to approach the subject in a manner acceptable to the trainees. Kliem (1985) provides another example of how an understanding of learning theory might enhance training. 
Adult learners are task oriented. They are usually interested in solving a particular problem or learning a specific skill. They need to understand what they are going to learn and why it is important. Set learning objectives based on what the audience needs to know. Be sure participants understand what they are going to learn and why" (p. 74).

In addition to an awareness of adult learning theory, it is also important that trainers recognize their role in the training process. Margolis and Bell explain this role as follows: "The trainer guides the learners in determining the relevance of the learning for their own lives and work; the learners are encouraged to use their own judgment and decision-making capabilities" (p.8). In order to be effective in this role, the trainer must know how to facilitate learning. A variety of basic activities are involved, including: 1) setting and maintaining a learning climate; 2) Making presentations;

3) Giving instructions; 4) Monitoring group and individual tasks. Trainers need the tools required to do these things. They need to understand how to set up a classroom, how to listen and ask questions effectively, how to work successfully with groups and individuals, and how to speak clearly. Other forms of instruction are also extremely helpful, such as how to work with 
audiovisual equipment, how to write objectives or lesson plans, and how to judge the degree to which the trainees are actually learning. The literature is full of practical guides to training. Many (Custer, 1986; Mayo and DuBois, 1987; Goad, 1987; Sauer and Holland, 1987) include specific techniques and step-by-step instructions which can be extremely valuable for subject-matter experts who find themselves in the role of trainer.

Subject matter experts have the potential for being excellent trainers, but their knowledge of the industry is not enough. They must also be trained in teaching techniques. This involves practical skills in communication and classroom management, as well as an understanding of the characteristics of the adult learner. Conclusion

Little has been written on naturalistic evaluation of training. In fact, an overwhelming majority of the literature regarding training evaluation adopts a quantitative approach. In order to defend the use of a qualitative, naturalistic approach as an appropriate method for evaluating customer training, literature was reviewed in the following areas: training, evaluation, naturalistic inquiry, and qualitative research. The case study designed to illustrate the use of naturalistic inquiry for evaluating customer training addresses three 
propositions. The review of literature was extended to support these propositions.

The literature encourages the use of naturalistic inquiry for evaluating education programs. Corporate training is in itself a form of education, and therefore may also be evaluated using this technique. companies may be more motivated to evaluate their training programs using this method because the process takes place within the natural environment and does not require the rigid controls of a quantitative study. This technique also encourages interaction between the evaluator and the stakeholders in the program. This interaction provides very valuable information to the evaluator and, in the end, to the company.

The review of the literature was extremely valuable in planning the pilot study, carrying out the evaluation process, and completing the final step of this research, the compilation of a practical guide to naturalistic evaluation designed for companies designated as valueadded resellers (VARs). 
Chapter Three

Methodology

Naturalistic evaluation of end-user training was explored through the use of case-study methodology. This methodology was selected for two reasons. First, case study requires "intensive investigation of the particular unit represented" (Good and Scates, 1954, p. 729). In this research, the unit being investigated was the enduser training program of a company that markets computer systems. The focus of the study was naturalistic evaluation, which occurs within a natural setting and involves extensive interaction with the various stakeholders. Therefore, case study methodology was particularly appropriate because it "allows an investigation to retain the holistic and meaningful characteristics of real-life events..." (Yin, 1984, p. 14). It also allows the researcher to consider a wide variety of information collected from multiple sources. "The essential procedure of the case-study method is to take account of all pertinent aspects of one thing or situation, employing as the unit for study an individual, an institution, a community, or any group considered as a unit" (Good \& Scates, 1954, p.726).

Case study methodology can be especially valuable when program evaluation is involved. Yin (1984) described four different applications of the case study to evaluation. 
The most important is to explain the causal links in real-life interventions that are too complex for the survey or experimental strategies. A second application is to describe the real-life context in which an intervention has occurred. Third, an evaluation can benefit, again in a descriptive mode, from an illustrative case study... of the intervention itself. Finally, the case study strategy may be used to explore those situations in which the intervention being evaluated has no clear, single set of outcomes" (p. 25) .

An additional strength of the case study is "its ability to deal with a full variety of evidence - documents, artifacts, interviews, and observations" (Yin, 1984, p. 20) - This research study involved all of these. stake (1978) added further justification to the selection of this methodology when he stated the following: Most case studies feature: descriptions that are complex, holistic, and involving a myriad of not highly isolated variables; data that are likely to be gathered at least partly by personalistic observation; and a writing style that is informal, perhaps narrative, possibly with verbatim quotation, illustration, and even allusion and metaphor" (p. 75). 
Yin (1984) identified two types of single case studies. The first is holistic, where only the global nature of a program is studied. The second is the embedded case study. "Even though a case study might be about a single ...program, the analysis might include outcome from individual projects within the program... Such a design would be called an embedded case study." Yin went on to warn the researcher of a pitfall of the embedded design, "... when the case study focuses only on the subunit level and fails to return to the larger unit of analysis." This study used an embedded case study design where the researcher focused on both the subunit level (e.g., training materials, trainer competence, workshop content) and the global nature of the customer training.

This particular research study was well suited to this methodology. Research techniques included interviews, observation, and examination of relevant documents. The description of the evaluation process dealt with a number of variables. The final report was written in a narrative style and accompanied by illustrations and quotations. Finally, the use of subunits added "significant opportunities for extensive analysis, enhancing the insights into the single case" (Yin, 1984, p.47). For all of these reasons, case study was selected as the one methodology best suited for the research. 
There are, however, prejudices against the case study. Yin (1984) identified three of the primary concerns. First, there is a lack of rigor in this type of research. Second, the case-study may provide little basis for generalization. And third, case-study reports are sometimes presented in the form of massive, unreadable documents. These are limitations, but they do not minimize the value of doing case study research.

Lincoln and Guba (1985) addressed the first concern, that of rigor and the assertion that "rigor is not the hallmark of naturalism" (p.289). They responded to that assertion by suggesting techniques which may increase a study's rigor. These parallel four criteria of the conventional, quantitative paradigm: credibility as an analog to internal validity; transferability as an analog to external validity; dependability as an analog to reliability; and confirmability as an analog to objectivity.

Specific techniques which may be used in order to achieve the four criteria include the following. For credibility, they suggest prolonged engagement, persistent observation, triangulation of data, peer debriefing, and member checks. All of the above require intensive contact with the phenomena or respondents, the use of different sources and data collection methods, and the assistance of a disinterested professional peer to, 
in Guba's (1985) terms, keep the inquirer honest. For transferability, they recommended the generation of thick descriptive data. This narrative allows others to make judgments about the degree of fit or similarity of the findings to another site. For dependability and confirmability, an external audit by a competent external disinterested party was recommended.

The second concern, that of the difficulty in generalizing from a case-study, has also been addressed in the literature (Lincoln and Guba, 1985; Bogdan and Biklan, 1982). They note that scientific experiments may also lack rigor, as it is very difficult to generalize from a single experiment. However, Lincoln and Guba (1985) stress that "the naturalist cannot specify the external validity of an inquiry; he or she can provide only the thick description necessary to enable someone interested in making a transfer to reach a conclusion about whether transfer can be contemplated as a possibility" (p. 316). Walker (1983) stated that It is common in research to use the term reliability to refer to a further difficulty and one which dominates discussion of case study research: the problem of replicability. Would another researcher entering the same situation produce similar results? We suggest that in our emphasis on procedures... we are moving to a kind 
of case study research that has high reliability in this sense. Educational situations are rarely replicable and this proposition would be difficult to test, but in theory it would seem that where procedures are clear and explicit then reliability in this sense would be higher than it would given a free hand to the researcher in the design and conduct of the case study (p.45). Walker elaborated on this point.

The problem for the case study is not whether it is worth studying individual events, but whether he can do so in a way that captures the attention of his audience. When only one instance is studied it does not really matter which instance is studied. The sampling problem is not really a problem at all; one instance is likely to be as typical and as atypical as another. The problem of generalizing ceases to become a problem for the author. It is the reader who has to ask what is there in this study that I can apply to my own situation, and what clearly does not apply (p.49). In response to Yin's third concern, there is no reason for a case-study report to be massive and unreadable. Instead, the report can be well written, concise, and interesting to read. In fact, Biklen and Bogdan (1985) believe that the qualitative researcher has 
a special obligation to write up the data in an interesting and well-written manner (p. 99).

Stake (1978) was optimistic about the future of this form of research. He noted that "...because of the universality and importance of experiential understanding, and because of their compatability with such understanding, case studies can be expected to continue to have an epistemological advantage over other inquiry methods as a basis for naturalistic generalization" (p. 75). Van Maanen (1983) also endorses the use of a qualitative approach to research.

A renewed interest in and felt need for qualitative research has slowly been emerging...There has come of age the significant realization that the people we study (and often seek to assist) have a form of life, a culture that is their own and if we wish to understand the behavior of these people... we must first be able to both appreciate and describe their culture" (p.12).

In summary, case study methodology was selected because this approach to research seemed most appropriate for the study. Case study methodology allowed the researcher to consider a full variety of evidence while evaluating a customer training program. Observations, interviews, and examination of related documents took place within the natural business environment and 
required the active involvement of the researcher in the process. The research explored a customer training program from two viewpoints. First, sub-units of the program were examined. This characterized the research as an embedded case study. Second, a holistic view of the training program was also important. In order to evaluate training both globally and in its separate components, it was important to select a methodology that involved a variety of data gathering techniques and that took place in a natural, uncontrolled setting. Case study methodology was selected for all of these reasons. Iincoln and Guba (1985) supported the use of this methodology. "We shall propose that for naturalistic inquirers, the reporting mode of choice is the case study" (p. 358).

\section{Procedures}

Procedures for performing this study included the following:

1. Selection of two companies for whom naturalistic evaluation of customer training was to be performed. The first company served as a pilot for the research.

2. A pilot test of the research, which assisted in refining the procedures used during the customer evaluation. Modifications to these procedures were made and a report written describing the pilot. This report included a review of lessons learned during the process. 
3. Evaluation of one customer training program, including interviews with various stakeholders, observation of training classes, examination of related materials (e.g., documentation, training manuals, visual aids). The logistics of this evaluation process are documented in this chapter of the dissertation.

4. The research was designed to test the propositions of the study. This required the analysis of the information gathered during data collection. Qualitative data analysis was performed using data reduction, data display, conclusion drawing and verification as suggested by Miles and Huberman (1984).

5. Preparation of a final case study report. The study is an embedded case study, identifying various units of analysis, and drawing conclusions about these units of analysis as well as the training program as a whole. The final report addresses both the propositions of the study as well as the research questions.

6. Preparation of a practical guide to naturalistic evaluation of end-user training. This guide was compiled based on information collected during the research, the evaluation process itself, and specific needs expressed by participants in the study (e.g., trainers and company management). 


\section{Site Selection}

Two sites were selected for this study. The first site was used for the pilot test. The criteria for site selection were:

1. Each company must market computer systems consisting of both hardware and application software.

2. Each company must be a value added reseller (VAR) . A VAR is a company that buys state-of-theart hardware from a manufacturer at a deep discount, adds its own software, and assumes responsibility for training and support.

3. The company must market its computer systems to users throughout a large geographic distribution. 4. The company must have a current customer base of at least 100 users. 5. The company must have been selling these systems and training end-users for a period of at least one year.

6. The company must be responsible for all customer software support.

7. Each company must have an ongoing training program for the end-users of its product(s). 8. The company must employ its own product trainers and not use outside consultants in this role. 
9. The company must agree, in writing, to a thorough evaluation of its training program and permit observation of training, interviews with trainers, customers, and management. 10. The company must agree to make available samples of training related materials, including product documentation, instructional manuals and visual aids used in conjunction with end-user training.

\section{pilot study}

The pilot case study helps investigators to refine their data collection plans with respect to both the content of the data and the procedures to be followed...to develop relevant lines of questions - possibly even providing some conceptual clarification as well (Yin, 1984, p.74).

For this research, the pilot study was conducted with a company that met all of the site selection criteria outlined previously. The evaluation process included all of the procedures described in the methodology. As the evaluation was conducted, modifications to these procedures were made to reflect any problems encountered or to build on strategies which proved particularly successful. Interview guides, observation guides, and 
documentation evaluation forms for the pilot study are included in Appendix $A$ of this proposal.

Once the pilot study was completed, a report was compiled to describe the process and to discuss lessons learned and their implications for the actual case study research. Interview guides used during this research were finalized at that time. In addition, these guides and the pilot study report were reviewed by an expert in the field of instructional design. The recommendations and insights of this expert contributed to the quality and completeness of the customer training evaluation which followed.

The purpose of the pilot study was not to test the propositions outlined previously. It was designed to assist the researcher in developing procedures and instruments appropriate for performing naturalistic evaluation of a customer training program. It also assisted the researcher in generating a preliminary list of codes for use in data analysis. The report on the pilot study was, therefore, constructed differently from the final research report. Data was not analyzed to support or refute the study's propositions. Data was examined in order to refine the research procedures and to provide additional insight into the concepts underlying the overall study. The report was written in 
narrative form and completed the preparation required for the researcher to begin the case study. This report makes up Chapter Four of the dissertation.

\section{Case study}

once the pilot study was completed, interview guides revised, and final report prepared, the researcher began the actual case study. Once a site was selected, and it was determined that this company met all of the ten criteria for the study, the next step was to plan the research. The researcher met with the Director of Customer Support and the Manager of Training to review a schedule of classes. It was decided that course observations would take place over a two week period. Both of the week-long courses offered by the company to new customers were meeting at that time. Interviews would also be conducted during these two weeks, and during the following week.

The researcher arranged a separate meeting with the employee who is responsible for all training materials. He provided samples of manuals, workbooks, documentation, and overheads which were reviewed as part of the information gathering process.

\section{Company Background}

The company selected for the case study research is a value-added reseller of computer systems and is located in San Diego, California. It markets its systems 
primarily to home furnishing stores and has over 300 customers located throughout the United States. The company employs about 120 people, twenty of whom work in Customer support (training and telephone support). The company was recently acquired by one of the nation's largest corporations. Due to a steady increase in the growth of the company, and its ever expanding customer base, several regional sales and training offices were recently opened.

Case study Procedures

Interviews

Interviews were conducted with four different audiences: trainers, customers, company management, and company sales representatives. Interview guides used during these interviews are found in Appendix B of this document. Feedback from all of the people interviewed was considered critical to the study because of their different roles in the training process and because of the wealth of information they were able to provide. Bogdan and Biklen (1985) stated that "qualitative interviews offer the interviewer considerable latitude to pursue a range of topics and offer the subject a chance to shape the content of the interview" (p. 136). Lincoln and Guba (1985) identified a major advantage of the interview: "It permits the respondent to move back and forth in time - to reconstruct the past, interpret the present, and predict the future -- all without leaving a comfortable armchair" (p. 273). 
Two types of interviews were conducted -- focus group discussions and one-on-one interviews. Zemke (1987) explained the difference between the two types.

In focus group work, the presence of peers usually gives the group members a sense of power and protection. If the group members don't like or are bored with what you're doing, they'll tell you -- usually by moving the group away from your topic and toward theirs. In face-to-face interviewing, there's neither protection or autonomy (p. 104). Zemke stated that a focus group can be very valuable in building a trusting relationship with the interviewees prior to meeting face-to-face. In this study, a focus group discussion was held with several of the trainers during the first week of observation. This gave the researcher the opportunity to meet some of the people who would be conducting training classes as well as those who would not be observed but would be interviewed on a oneto-one basis. It also allowed the trainers to ask questions about the study and to be assured that the results of their interviews would remain confidential. No formal interview guide was used during this focus group discussion.

One-one-one, or face-to-face, interviews were conducted with the company's seven trainers. These 
interviews were informal and semistructured. Zemke (1987) endorsed the use of the informal interview which he characterizes as being spontaneous in nature and lacking structure. "We use the informal approach to add depth of understanding to things observed or learned in other ways. It serves to tap opinions of a broad range of performers and provides us with quotes and thoughts for enriching data gathered in other ways" (p.100). The semistructured interview "has the advantage of being reasonably objective while still permitting a more thorough understanding of the respondent's opinions and the reasons behind them" (Borg and Gall, p. 442). Semistructured interviews may be either open-ended or focused, depending upon the audience. Open-ended interviews were used with the trainers to allow the interviewer to ask for facts as well as opinions and attitudes.

An investigator can ask key respondents for the facts of a matter as well as for the respondents' opinions about events. In some situations, the investigator may even ask the respondent to propose his or her own insights into certain occurrences and may use such propositions as the basis for further inquiry" (Yin, 1984, p. 83). Trainers were interviewed in order to provide the investigator with insights about trainer preparation, 
education, technological competence, and morale. A semistructured interview guide was followed to assure completeness and consistency, but was not used to limit the scope of the discussion. The trainers were asked for feedback about instructional materials provided to them by the company and to suggest ways to improve these materials. They were also asked about the following: the quantity of information trainers must teach; the ability of typical trainees to digest this information; and the relevance of what they teach to actual use of the system by the trainees.

There was no set amount of time spent in each interview with a trainer. Interviews ranged from fortyfive minutes to two hours in length. In two cases, second interviews took place in order to gather all of the information desired. These interviews took approximately twenty to thirty minutes each.

A second group of stakeholders, the company's customers, was also interviewed. Customers interviewed were drawn from two groups of people: those who were currently involved in training as well as people who had completed training within the past year. Current trainees were asked specifically about the training classes they were participating in. They were asked about the materials they were using, the quantity of information they were asked to learn, their perception of 
the value of this information as it related to actual use of the system, and the effectiveness of the trainer. Due to time limitations resulting from training and travel schedules, these interviews were more focused than those conducted with trainers. They were scheduled on the last day of the customer training and took an average of thirty minutes each.

A sample of ten customers who had completed one or more phases of customer training approximately one year ago was selected after a discussion with the company's training manager and president. The sample was representative of the customer base (geographic distribution, company size, and software applications). Interviews with these people were designed to provide information about the overall effectiveness of the training classes and materials. There is, typically, a period of several months between the time training is completed and the time the system is actually put into use. In the case of this specific company, the time between training on a system and its actual installation and use can be as long as one year. Therefore, in order to give the users the opportunity to work with the system on the job, and to be in a position to reflect upon the effectiveness of their training, a period of at least a year between training and the interview was appropriate. 
Questions to these users focused on their recollections of training. Were the classes appropriately scheduled? Was too much/too little information covered? Were the materials easy to use? Was the information taught during the class relevant to what was actually needed upon returning to work and using the product? Might there be alternative methods for teaching some/all of this information in either a different manner or at a more appropriate time? The primary goal of these interviews was to determine how useful the training was to the users when it came time to actually use the system on which they were trained. In other words, the goal was to determine its worth. As was stated earlier in this proposal, "The number of information-system experts to users is usually less than 1 to 100. The only way to combat the obvious problem of this imbalance is to focus, right from the start, on making users proficient and independent..." (sokol and Bulyk, 1986, p.43). If the customer was not able to return to his own environment and use the system, training was not appropriate or adequate. If the customer was able to do this, training served two purposes. It trained the user to do the task at hand well, and it relieved the vendor of some of its support responsibilities. 
Interviews with these customers averaged about thirty to forty minutes in length and were conducted on the telephone. "Research has shown that telephone interviewing reaches nearly the same proportion of the target population, obtains nearly as high a percentage of returns, and produces comparable information at about one-half the cost of personal interviews" (Borg and Gall, p. 448).

The third group of stakeholders interviewed included four members of company management. They were: Manager of Training, Manager of Customer support, Vice-President of Marketing, and President. They were selected because of their role in designing, overseeing, and supporting customer training. The interviews were more focused than those conducted with trainers, especially in the case of the Vice-President of Marketing and the President. Questions addressed the history of the company's customer training department as well as how training is viewed by the company - what role it is perceived to play, how it is packaged in the overall marketing of the product, the company's short and long-term goals for customer training. These interviews were conducted in person at the company's corporate office. Several hours were spent in conversation with both the Manager of Training and Manager of Customer Support. About an hour was spent with both the Vice-President of Marketing and the President. 
The fourth group of stakeholders interviewed included two of the company's sales representatives. Although interviewing salespeople was not included as part of the initial design of the study, almost all of the trainers recommended that they be interviewed. Responses from trainers during the pilot study also indicated that sales reps would be valuable sources of insight and information. Their perceptions of training and the role of the trainer provided a great deal of insight into some of the problems faced during training classes.

Interviews with trainers, customers, company management, and sales representatives were designed to be focused and to use structured interview guides. Each interview began with the researcher following the appropriate guide quite closely. However, there were many instances when discussion got off track and answers to questions were arrived at in a much less formal manner. The researcher found this approach to be very effective, as some of the most valuable information and insights resulted from tangential conversations.

The first trainer interview was recorded on a tape recorder and reviewed by the instructional design expert assisting in this study. He verified that the interview guide was closely followed and that there was no evidence of researcher bias in the way the interview was 
conducted. It was decided not to tape record the other interviews, as many of the interviewees asked that this not be done. In all other cases, hand-written notes were taken by the researcher. These notes were later transcribed for analysis. Lincoln and Guba (1985) support the use of handwritten notes during interviews:

The advantages of handwritten notes are impressive: Taking them forces the interviewer to attend carefully to what is being said; the interviewer can interpolate questions or comments (including notations about nonverbal cues) onto the paper without the respondent's awareness, the notes can be easily flagged for important items to which the interviewer wishes to return later; the interviewer need not rely on his or her memory to compose the all-important summary that should be provided at the end of the interview (p. 272) .

In fact, Lincoln and Guba (1985) recommended that interviews not be tape-recorded unless there are legal or training reasons for doing so.

Interviews with all four groups of stakeholders provided valuable information and insights. These related to two areas: First, customer training at this particular site, including both its strengths and weaknesses; Second, the appropriateness of naturalistic inquiry as a technique for evaluating customer training. 
Interviews are an essential source of case study evidence because most case studies are about human affairs. These human affairs should be reported and interpreted through the eyes of specific interviewees, and well-informed respondents can provide important insights into a situation... However, the interviews should always be considered verbal reports only....a reasonable approach is to corrorobate interview data with information from other sources."(Yin, 1984 , p. 84-85)

\section{Observation}

In light of Yin's observation, direct observation of each company's training program was also critical to the study. Iincoln and Guba (1985) noted that a major advantage of observation is that it provides here-and-now experience in depth. They referred to observation as a "powerful tool indeed" (p. 274). The observations conducted during this study involved the researcher's attendance at three formal training classes. These weeklong training sessions are offered by the computer system vendor to each customer who buys a system. Participants in training are selected by the customer's management with the advice of the vendor's sales representative and the trainer assigned to the new account. In this case, the customer training focused on two areas. The first 
week-long course focused on merchandising, a topic that included inventory control and maintenance, purchasing and receiving, sales, delivery, and accounts receivable. This training class was attended by two participants. The second course topic was accounts payable and related subjects. Two week-long classes were being offered concurrently to different customers. These training sessions were attended by representatives from four different companies. A total of 11 people participated in these two classes. The researcher observed one class for three days, and another for two days.

An observation guide was used by the researcher during each training class in order to take notes about a variety of topics. These topics included the physical environment in which training occured (e.g. classroom size and arrangement), the quantity of material covered in the class, the teaching style of the trainer, amount of interaction between trainer and participant, frequency of use of training materials and documentation, and the level of comprehension experienced by the participants as perceived by the observer. The observation guide used during both training courses was designed based on the past experience of the researcher and was tested for completeness during the pilot study. Revisions were made to the guide prior to its use during the final study. In addition to this formal guide, extensive notes 
were taken during observation periods. Lincoln and Guba (1985) explained the use of these notes:

Field notes from observation can be treated similarly to field notes taken during interviews; they can be fleshed out and analyzed for preliminary units and categories of information. Those preliminary categories can be checked, expanded, and related during subsequent observations (p. 276).

These field notes were transcribed daily into typewritten form for later analysis. Observation also involved social interaction with trainers and/or customers. A variety of opportunities for observation of stakeholders were pursued whenever possible. The bulk of these opportunities arose during lunch and breaks. The modern methodology of participant observation is not a single standard technique to be applied in every case, that may be learned in the way that one learns to do a statistical test or to construct a questionnaire. It is a variable combination of techniques that will be used according to the necessities of the particular setting to be studied (Ball, p. 33). Notes were also taken about social interactions and later transcribed and coded for use during data analysis. 


\section{Documentation}

Yin (1984) stated that "...documentary information is likely to be relevant to every case study topic" (p. 79). In this study, documentary information included all available instructional materials and product documentation. Instructional materials included the following: trainer's manuals and accompanying trainee workbooks, overheads, a system implementation guide, and a trainer checklist. Documentation included all of the material provided to the customer as a reference accompanying the system they purchased. These materials were evaluated for their organization, content, readability, professional quality, and degree of use by the customer and/or trainer.

Separate evaluation forms were used to record the results of these reviews. The forms were designed to address the relevant research questions and propositions. Evaluation criteria were based on the past experience of the researcher in reviewing user documentation and training materials. Prior to the pilot study, the evaluation forms were reviewed by the instructional design expert and revised according to recommendations.

In summary, the researcher used multiple sources of evidence. Yin (1984) stated that

The use of multiple sources of evidence in case studies allows an investigator to address a 
broader range of historical, attitudinal, and observational issues...thus, any finding or conclusion in a case study is likely to be much more convincing and accurate if it is based on different sources of information..." (p.91). VanMaanen (1979) believed that "Ideally, the design of an evaluation brings together features of naturalistic social research (observation) and classical survey methods (asking people) within a historical and developing framework (records, documents and assorted program memorabilia" (p. 49). For this researcher, the ability to use multiple sources of evidence played a major role in selecting case study as the research method.

\section{Data Analysis}

Literature related to qualitative research shows that qualitative data analysis has never received the attention it deserves (Yin, 1981; Biklen and Bogdan, 1986; Miles and Huberman, 1985). When compared with quantitative data analysis, on which there have been many books and articles written, analysis of qualitative data has few fixed formulas or cookbook recipes to guide the novice (Yin, 1981). Miles (1979) believed that this is the most serious and central difficulty in using this type of data. Over the past few years, attempts have been made at alleviating this problem with the 
publication of guides to qualitative data analysis (Miles and Huberman, 1984; Bogdan and Biklen, 1982).

Bogdan and Biklen (1982) described data analysis as "the process of systematically searching and arranging the interview transcripts, fieldnotes, and other materials you accumulate to increase your own understanding of them and to enable you to present what you have discovered to others" (p. 145). They explain that the data in naturalistic evaluation have no meaning in themselves. Instead, data must be analyzed to give it meaning.

For naturalistic evaluators, the stages of the research project are not discrete. That is, design, data collection, and data analysis are not three stages of the research process. Rather, they are intermingled. Data analysis is the process of making sense out of the data" (Bogdan \& Biklen, 1986, p.98)

Data analysis is inductive, requiring the researcher to reconstruct inquirer-source interactions into meaningful wholes (Bogdan \& Biklen, 1986; Lincoln and Guba, 1985). In order to reconstruct the results of the research into a meaningful whole and to present these results in a concise and organized manner, the researcher analyzed the case by addressing the propositions set 
forth in the introduction of this proposal. Yin (1984) states that

the preferred strategy is to follow the theoretical propositions that led to the case study. The original objectives and design of the case study presumably were based on such propositions, which in turn reflected a set of research questions, reviews of the literature, and new insights (p.100).

As each proposition was addressed, subunits of the training program were discussed. The focus on these subunits caused the design of this study to be designated as an embedded case study. However, in order to avoid a potential pitfall of embedded case study mentioned by Yin (1984), the holistic aspects of the case -- the overall customer training program -- were not ignored. The final case study report addressed all aspects, including the subunits of the training program as well as the holistic view. Analysis of the data involved pattern-matching as described by Yin (1984). "Such a logic compares an empirically based pattern with a predicted one (or with several alternative predictions). If the patterns coincide, the results can help a case study to strengthen its internal validity" (p.103). In this study, a "nonequivalent, dependent variable design (Cook and Campbell, p.118) was used. This involved the 
possibility of a variety of outcomes. "If for each outcome, the initially predicted values have been found, and at the same time alternative patterns of predicted values have not been found, strong causal inferences can be made" (Yin, p.103).

Each of the study's propositions represented an outcome that was assessed using the various procedures followed during the research. These propositions are nonequivalent dependent variables. By virtue of the inclusion of the proposition in the study, it was considered a predicted outcome. Data analysis involved examining the information collected during the evaluation in order to determine which propositions were supported. It was important to keep in mind that "Proof is rarely obtainable in case-study research. Rather than setting proof as a primary goal, the case study worker should aim to increase understanding of the variables, parameters, and dynamics of the case under study" (MacDonald and Walker, p.7).

Analysis of the data was performed using methods outlined by Miles and Huberman (1984). They consider analysis to consist of three concurrent flows of activity: data reduction, data display, and conclusion drawing/verification. "Data reduction refers to the process of selecting, focusing, simplifying, abstracting, and transforming the "raw" data that appears in written-up 
field notes" (p. 21). Data reduction was accomplished by memos and coding. Memos are notes kept by the researcher to track his/her thinking and cover a variety of issues, including descriptions of activities, general discoveries, emerging themes, thoughts, or worries. Coding involved the design of a classification system used by the researcher to sort material into categories. Data display was defined by Miles and Huberman (1984) as an "organized assembly of information that permits conclusion drawing and action taking" (p. 21). These may be in the form of graphs, matrices, networks and charts. Conclusion drawing and verification involves deciding what everything reans and confirming that the conclusions are accurate. Lata analysis performed during the research involved all three steps.

The first step in the analysis was coding. Miles and Huberman (1984) suggested that a chronic problem of qualitative research is that it is done chiefly with words, not with numbers. They are more difficult to analyze because they frequently have multiple meanings and must be considered in context. Yet they stressed that they should not be converted into numbers. To accomplish this, a list of codes was created based on the propositions addressed in the research. (See Figure 1). 
SUB-UNITS CODE

EVOLUTION OF TRAINING

$\begin{array}{lll}\text { EV: } & \text { COMPANY GROWTH } & \text { EV-GRO } \\ \text { EV: } & \text { BEGINNINGS } & \text { EV-BEG } \\ \text { EV: TRAINING MGT. EXPER. } & \text { EV-MGTEXP } \\ \text { EV: TRAINER SCHEDULES } & \text { EV-T3 } \\ \text { EV: } & \text { MATERIAL DEVELOPMENT } & \text { EV-MAT }\end{array}$

\section{MERIT OF TRAINING}

$\begin{array}{lll}\text { M: } & \text { FACILITIES - GENERAL } & \text { M-FAC/GEN } \\ \text { M: } & \text { FACILITIES - BREAKS \& MEALS } & \text { M-FAC/BRKS } \\ \text { M: } & \text { FACILITIES - MISC. } & \text { M-FAC/MISC } \\ \text { M: } & \text { ROOM-TEMPERATURE } & \text { M-ROOM/TEMP } \\ \text { M: } & \text { ROOM-COMFORT } & \text { M-ROOM/COMF } \\ \text { M: } & \text { ROOM-LIGHTING } & \text { M-ROOM/LITE } \\ \text { M: } & \text { SETUP-AUDIOVISUAL } & \text { M-SET/AV } \\ \text { M: INSTRUCTOR'S GUIDE-LOOK } & \text { M-IG/LOOK } \\ \text { M: } & \text { INSTRUCTOR'S GUIDE-EASE } & \text { M-IG/USE } \\ & \text { OF USE } & \end{array}$

WORTH OF TRAINING

$\begin{array}{lll}\text { W: } & \text { TRAINER SUPPORT } & \text { W-TRNRSUPP } \\ \text { W: } & \text { CONSISTENCY OF PERSONNEL } & \text { W-TRNR/CONSIST } \\ \text { W: } & \text { FUTURE TRAINING } & \text { W-TRNG/FUT } \\ \text { W: } & \text { SUPPORT MATERIALS } & \text { W-MAT/SUPP } \\ \text { W: } & \text { ATTENTION TO PROBLEMS } & \text { W-PROBLEMS }\end{array}$

TRAINER AS TEACHER

$\begin{array}{ll}\text { TRN: SENSITIVITY TO LEARNER } & \text { TRN-SENS } \\ \text { TRN: RAPPORT } & \text { TRN-RAPP } \\ \text { TRN: ONE-ON-ONE SKILLS } & \text { TRN-ONE } \\ \text { TRN: GROUP SKILIS } & \text { TRN-GROUP } \\ \text { TRN: LISTENING SKILLS } & \text { TRN-LISTEN } \\ \text { TRN: QUESTIONING SKILIS } & \text { TRN-? }\end{array}$

LEARNER

$\begin{array}{ll}\text { IRN: INDUSTRY BACKGROUND } & \text { LRN-IND/EXP } \\ \text { LRN: COMPUTER BACKGROUND } & \text { LRN-COMP/EXP } \\ \text { LRN: COMPUTER SKILL IEVEL } & \text { LRN-COMP/SKILL } \\ \text { IRN: ATTITUDE TOWARD SYSTEM } & \text { IRN-ATT } \\ \text { LRN: ABILITY TO LEARN } & \text { LRN-SMARTS }\end{array}$

Figure 1, Sample of Codes Used for Sorting Data 
The preliminary list of codes was generated prior to beginning the observations and interviews (See Appendix B). As the notes were transcribed and analyzed, modifications to the list were made. In some cases new codes were added. In other cases existing codes were dropped. Changes to the list of codes were based on new ideas and insights. The final list of codes (See Appendix C) was used by the researcher to sort and identify those relevant comments or observations which related to units of analysis discussed in the propositions (See Figure 2). At the end of a day of observation, and following each interview, transcripts, notes and memos were reviewed and codes were assigned where appropriate (See Figure 3). This information was then transferred to context chart maps called matrices which allowed the researcher to track emerging patterns. Miles and Huberman (1985) explained that context charts map in graphic form the interrelationships among the roles and groups that go to make up the context of the behavior(s) being studies. Two types of charts were used for data analysis: the checklist matrix (See Figure 4) and the role-ordered matrix (See Figure 5). The checklist matrix was defined by Miles and Huberman (1986) as a format for analyzing field data that can be combined into a summative index or scale. Its basic principle is that it organizes several components of a single, coherent variable. Checklist matrices were 


\section{UNITS OF ANALYSIS}

PROPOSITION ONE:

Evolution of Training

Trainer Experience

Trainer Training

Material Development

PROPOSITION TWO:

Merit: Facilities

Merit: Instructor's Guide

Merit: Workbook

Merit: Course Content

Merit: Participants

Merit: Trainer

Merit: Training Database

Merit: Supplemental Materials

Worth: Post-class Support

Worth: Big Picture

Worth: Communication

Worth: Problem Solving

Worth: Train Others

Worth: Perspective from Past Trainees

PROPOSITION THREE:

Trainer: Rapport

Trainer: Communication skills

Trainer: Experience/Education

Trainer: Teaching Methods

Trainer: How Perceived by others

Learner: Background

Learner: Attitude/Motivation

Learner: Value to Job

Figure 2, Units of Analysis 


\section{DAY ONE OBSERVATION}

Day One - Course B Merchandising Class

Two participants: Husband/wife owners of small furniture store

The day began with coffee and donuts in the main conference room. This is the procedure every morning. The orientation is for all training participants in all classes offered that week. Introductions are made of trainers, trainees, and other members of the company. Carolyn, Manager of Customer support, did the introductions. Trainees who hadn't visited the facility before were given a brief tour.

This class is being taught by Cheryl. She's been with the company a brief amount of time. She used to be with Pacific Telephone. Two people are in the class. They are a husband and wife who own a furniture store in Arizona.

The classroom is very nice. There are six tables each seating $M F A C l$ two people. There is one terminal on each table. The instructor has a raised desk in the front with a white board and large screen. There is an overhead projector on the trainer's desk. There is a large window in the rear of the classroom and the lighting is good. No smoking is allowed anywhere in the building. There's a nice coffee and tea setup which is available all day to trainees. They also have hot chocolate and soda machines. Rest room facilities are clean and easily accessible. There is a telephone available for trainees in the lobby and a seat for use while making calls. No charge for making telephone calls.

The first 15 minutes was spent getting materials, distributing them, and answering questions about the trainees' activities since the last class. Both attended course $A$ several months ago and had been inputting data. They talked about their successes and asked some questions.

Trainer has already developed good rapport with the customers. She seems to know them well and understands their problems.

Course B began with a review of what would be learned this week and what would follow in the way of training after returning to the store. GERS provides a personal telephone support person to $W$ each customer for consistent service. The same trainer will do W/SUPP learning specific topics (scheduler, management report, month-end closing). These manuals are made available because it was decided that teaching the materials this week would be senseless. It would be a long time before it would be used and there was too much else to teach during the week that would be needed sooner. Also, the material lended itself to this type of learning.

Figure 3, Sample of Coded Observation Notes 
EXAMPLE OF A CHECKLIST MATRIX

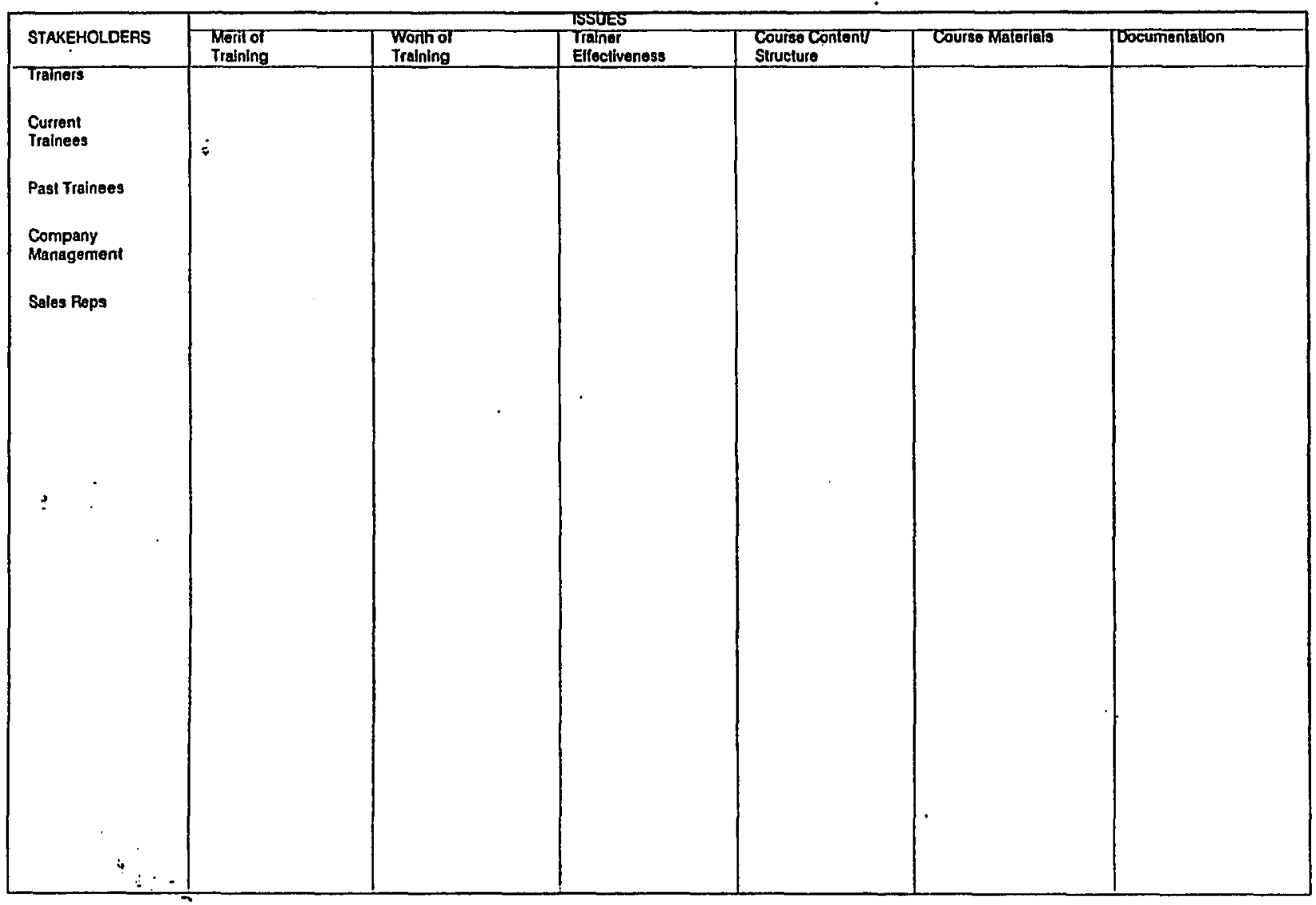

Figure 4, Example of Checklist Matrix 
EXAMPLE OF A ROLE-ORDERED MATRIX

Responses By Company Management

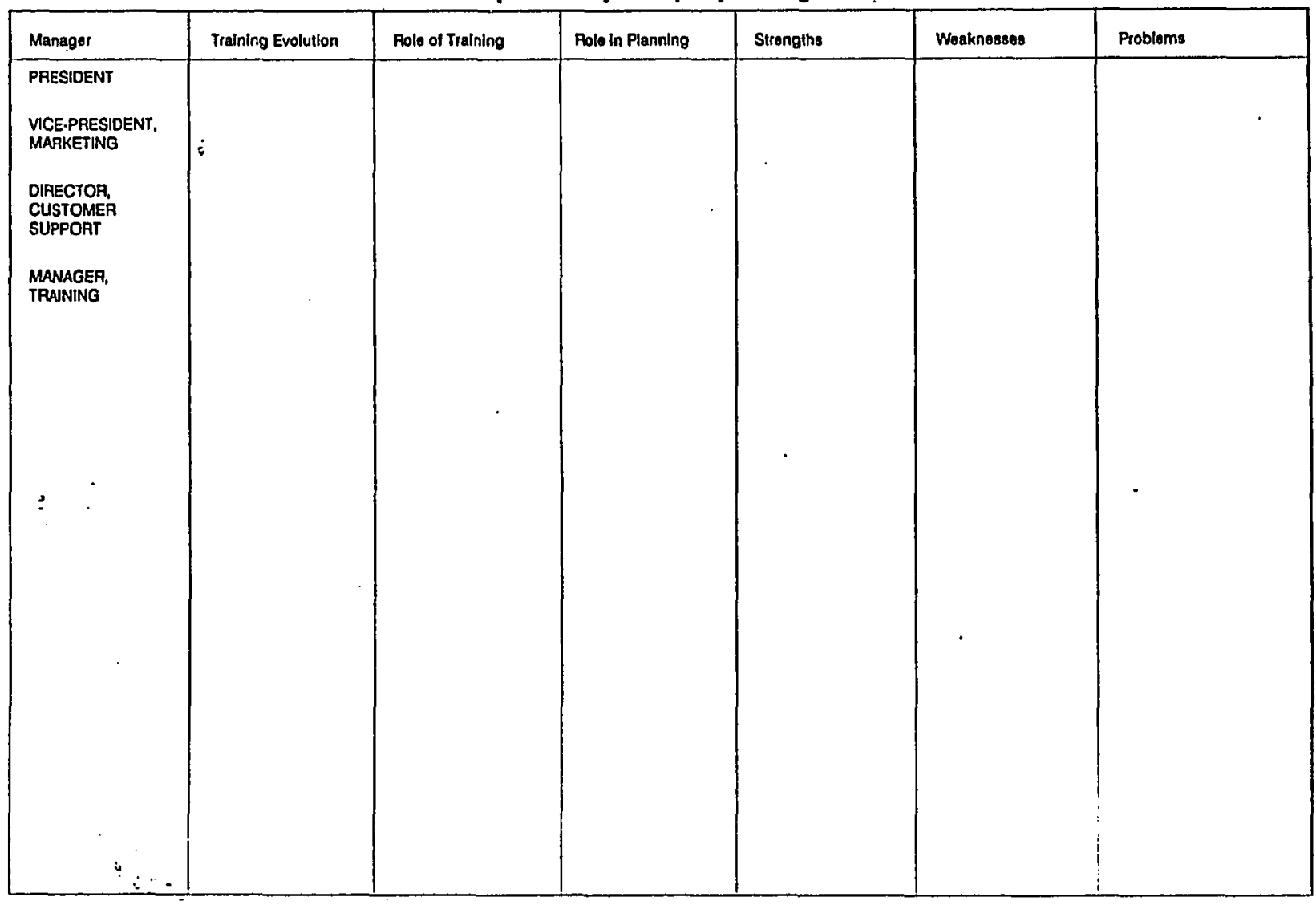

Figure 5, Example of Role-Ordered Matrix 
designed to include input from all four groups of stakeholders, as well as information gathered during observation of customer training and evaluation of documentation. Checklist matrices display information used to support Propositions one, Two and Three of the study •

In addition, a variety of role-ordered matrices were designed. Role-ordered matrices sort into rows data that has been collected from or about a certain set of participants, reflecting their views (Miles and Huberman, 1986). The first group of role-ordered matrices was used to sort data gathered from the seven company trainers interviewed during the research. Their responses to questions addressing Propositions Two and Three were summarized on these matrices. The second group of roleordered matrices was designed to sort data collected during interviews with participants (customers) involved in the training classes observed by the researcher. These matrices summarized responses to questions addressing Propositions Two and Three. A third group of role-ordered matrices was used to sort data gathered from the company's customers who had been trained one year previously. These also summarized answers to questions addressing Propositions Two and Three.

Once information was entered into the matrices, it was then analyzed. By using this form of data display, 
patterns and themes were identified. Yin (1984) stated that pattern-matching is one of the most desirable strategies for analyzing a case study. This technique "compares an empirically based pattern with a predicted one. If the patterns coincide, the results can help a case study to strengthen its internal validity" (p. 103). The researcher sought and identified patterns in the following manner.

First, all significant information collected during an interview was entered onto one or more of the matrices. After all of the matrices were complete, next-step matrices were constructed to present essentially the same information but in a condensed, summary fashion (Miles and Huberman, 1984). Next-step matrices were built by standardizing the cell entries and then taking the modal response(s). When there was more than one entry to a cell, the entries were arranged in order of frequency of response. For instance, if five trainers mentioned that indexing was needed in course materials, three trainers mentioned a need for additional scenarios, and two mentioned modular design of materials, the entries were listed in the following order: indexing, scenarios, modular design. In this way, it was easier for the researcher to analyze the information on these matrices and to recognize patterns based on the number of times an issue was raised or recommendation made. 
The final step of data analysis involved the researcher's drawing conclusions from these patterns and themes to support or refute the propositions of the study. These conclusions are discussed in Chapter Five of this dissertation.

To conclude the research and to relate the findings of the case study to the research questions identified in Chapter one, a final report was prepared which addressed four specific areas. First, each of the four research questions was answered. These questions all relate to the use of naturalistic evaluation as an appropriate method for assessing end-user training. Each question was answered based on the information collected during both the pilot study and the actual case study. Second, the implications of the research on customer training and evaluation theory were described. Third, recommendations were made for future research in both the training and evaluation fields. Finally, a summary of the research was presented.

A Guide to Naturalistic Evaluation of End-User Training

The study's final research question asks how information about performing naturalistic evaluation of customer training might best be presented to those interested in this process. After reviewing the literature and determining that there was no practical guide to this type of evaluation available to training 
professionals, the researcher decided that such a guide would be a valuable tool. Therefore, one was designed for use by companies interested in conducting their own naturalistic evaluations of customer training. This guide includes an introduction to naturalistic evaluation which describes the characteristics that make it appropriate for this process. It also includes the following:

1. Suggested interview formats to be used when talking with trainers, customers, and company management.

2. A guide to observing training classes, including ideas for assessing trainer effectiveness, quality of instructional materials, and course content. 3. A guide for evaluating user documentation and other written training materials.

4. An introduction to the qualitative data analysis techniques used in this study.

5. A sample coding sheet, sample coded field notes,

a sample checklist and role-ordered matrix.

It was the intent of the researcher to share the results of this study with professionals interested in conducting this type of customer training evaluation. The guide discussed here is found in chapter seven of this dissertation. 


\section{Researcher Training}

"Case study methods are rarely spelled out in advance, except in the most general of terms, and apprenticeship is the usual means of induction into its techniques" (MacDonald and Walker, p.3). Although this researcher had never performed a formal case study such as the one outlined in this proposal, her professional experience in the field of technical writing, public relations, and instructional design included all of the activities described here. Interviews, observations, and evaluation of materials were conducted with a variety of companies throughout the country.

Borg and Gall (1983) suggested that training for interviewing be conducted in two phases.

In the first phase, the trainees study the interview guide and learn about the interview conditions, logistics, necessary controls and safeguards, variables being studied, and similar information... In the second phase, research on interviewer training suggests that the trainees should conduct practice interviews..." (p. 444). Due to the researcher's interview experience consisting of over 100 interviews over the past 10 years, additional training in this area was not deemed necessary prior to conducting either the pilot study or research. The availability of an expert in the field of 
instructional design and this person's assistance in reviewing instruments, interview answers, and reports from both the pilot and research case studies were very valuable and supplemented the past experience of the researcher. 


\section{Chapter Four}

\section{Pilot Study}

A final preparation for data collection is the conduct of a pilot study....it is important to note that a pilot test is not a pre-test. The pilot case is used more formatively, assisting an investigator to develop relevant lines of questions - possibly even providing some conceptual clarification as well." (Yin, 1984, p. 74 )

Prior to embarking on the actual case study, a pilot study was conducted that included all of the evaluation procedures outlined in the methodology. These procedures included interviews, observation, and review of documentation. The intent of the pilot study was to carry out an evaluation of a training program using naturalistic inquiry and, in the process, identify problems which might exist in overall procedures or instruments. These procedures and/or instruments could then be modified prior to their use in the research.

The report on the pilot study will cover a variety of topics: site selection; step-by-step review of procedures; sample responses to interviews, observations, and reviews of documentation; review of procedures by an objective expert in the training and instructional design industry; lessons learned from the pilot study and 
modifications made to procedures and instruments; and finally, implications of the pilot study on the development of a guide for use by companies interested in conducting their own naturalistic evaluation of customer training.

\section{Site selection}

A computer system company, headquartered in Montreal, Canada, was selected for the pilot study. The company is a value-added reseller who purchases its computers from a major data processing vendor and packages these systems with its own application software. The company specializes in systems for large retail stores. The researcher selected this company for the pilot study for several reasons. First, the president of the company was familiar with a similar study conducted by the researcher at a site in San Diego. He was interested in having an evaluation of his company's customer training performed in the same manner and was willing to assume responsibility for all expenses incurred during the process. Second, other management personnel, including the Training Manager, expressed enthusiasm for the study and agreed to cooperate in whatever way necessary. Third, the company was eager to complete the study and was able to work out a schedule that met the timeline for this research. Fourth, the company met all of the ten criteria established for the research. 
1. It markets computer systems which consist both of hardware and application software.

2. It is a value-added reseller. The company purchases its hardware from an outside firm and packages it with its own software. They then assume responsibility for all customer training and support.

3. The company markets its systems to users in Canada and throughout the United states, with installations in locations such as New York City, San Francisco, Atlanta, Montreal, Cincinnati, and Dallas. 4. It has a current customer base of over 200 customers. 5. It has been selling its computer systems and training its end-users for over seven years. 6. The company is responsible for all of its own customer support. No external vendors or hardware company personnel are involved in this aspect of the company.

7. It has an ongoing training program designed to serve the training needs of its end-users. 8. The company employs its own product trainers and does not use outside consultants in this role. 9. Company management agreed, in writing, to a thorough evaluation of its training program and permitted observation of training, interviews with trainers, customers and management. 
10. They made available for review all of their

training related materials, including product documentation, existing instructional manuals and illustrations used during end-user training.

\section{Review of Procedures}

Conducting the pilot study involved all of the following: identifying the various components of customer training and establishing a "game plan" for the evaluation; observing training classes; interviewing stakeholders; reviewing documentation and related instructional materials; reporting the results of the study to the client.

\section{Identifying Training components}

The first step of the pilot study was to discuss with the company the components of their existing customer training and to decide on the steps required to complete the evaluation. Their training program is intended to assist users in the operation of a new computer system which has been purchased in order to automate a retail store's merchandising procedures. These procedures include entering purchase orders, receiving merchandise into the warehouse, transferring merchandise from one store to another, selling merchandise to customers, and carrying out the entire buying process as efficiently as possible. Retail merchandising is a very complex business and, because of 
the intense competition in today's market, a computerized system is extremely valuable. When setting up such a system, many variables must be identified to meet the specific needs of the retailer. Once these parameters are established, the system can be installed and users trained in its operation.

In order to do both -- establish system parameters and train users in the operation of the system -- the training consists of two major components. The first is called an Initial Review Meeting (IRM) and involves company owners and managers responsible for determining the way the system is to operate (e.g., what codes to use in order to track inventory and sales, what reports are required, what data these reports should contain and in what format, what customer and vendor information is to be maintained). The IRM is typically a three-day meeting that takes place at the corporate office in Montreal. End-user training takes place after the system is operational and involves the people who will actually be using the system, such as buyers, the warehouse manager, computer operators, and clerical staff. This training usually takes place at the customer site. Company management and the researcher decided that in order to evaluate customer training, it would be necessary to observe both training classes. Prior to observing the training, the researcher would become 
familiar with instructional materials used during these classes. An actual evaluation of the materials would not occur, however, until the observations had taken place. During both the IRM and the merchandising class, interviews would be conducted with trainees (customers) and trainers. Interviews with other stakeholders, including additional trainers, managers, and customers who participated in end-user training at an earlier time, would take place whenever they could be scheduled conveniently. Another aspect of the evaluation, review of documentation and related materials, would be conducted on an ongoing basis, depending upon the time available to the researcher.

\section{Observation}

An important part of the naturalistic evaluation process is the actual observation of a program - in this case, observation of both an IRM and a merchandising class. In order to complete this part of the process, the researcher traveled to Montreal and observed a threeday IRM in its entirety. This IRM was led by two trainers, one who served as a Project Leader for the client and one who acted solely as a product trainer. There were three representatives of the customer organization in attendance at the IRM. Shortly thereafter, a five-day merchandising class held at a customer site in New York City was also observed. This 
class was also conducted by a Project Leader and product trainer. Fifteen employees of the customer organization were trained this week, representing various departments (e.g. buying, warehouse, systems). During both classes, these procedures were followed:

1. Extensive notes were taken in order to document the content of the course, the perceived attention level of trainees, the knowledge base of the trainees, trainee/trainer rapport, and many other factors.

2. These notes were transferred to an observation guide immediately following the class. 3. Interviews were conducted with trainees at the conclusion of the class in order to determine their initial reaction to their experience.

4. Informal discussions were held with both trainees and trainers while class was not in session -e.g., during breaks and after class in a more social setting. Notes from these discussions were written in a notebook both during conversations and upon returning to the customer site or hotel. 5. Formal interviews were conducted with each of the four trainers involved in the two classes. These interviews related to training as a whole and were similar to the interviews conducted with other trainers at other times.

Note: Interview guides and observation forms used during the pilot may be found in Appendix $A$. 


\section{Interviews}

Interviews were conducted with three different audiences: trainers, customers, and company management. A breakdown of the people interviewed during the pilot study follows.

First, a total of 17 of the 20 product trainers involved in merchandising training were interviewed. These interviews were conducted while the researcher was in Montreal observing the IRM. The semi-structured interviews ranged in length from 20 minutes to over an hour, depending upon the trainers' schedules and their interest in elaborating on their experiences and insights. The researcher followed the interview guide designed for this specific audience. However, answers to the pre-designed questions frequently led to additional discussion on related topics. Insight gained during these discussions proved very valuable when it came time to revise the interview guides and to conduct the interviews during the actual case study. In two instances, telephone calls were made to trainers who had been previously interviewed in order to gather additional information.

Interviews with the two trainers involved in the merchandising class in New York extended beyond the scheduled conversations held with other trainers. Due to the length of time together and the opportunity to share 
many meals and other activities after class, the researcher benefited from more casual data collection which led to further insight into training procedures, materials, and trainers' morale.

Second, two members of company management were interviewed. The company president agreed to answer many of the questions contained in the interview guide. He chose not to answer some of these questions because he felt he did not have the knowledge required for accurate responses. The Training Manager was able to answer all of the questions asked of her. Her insights proved very valuable and led to discussions of topics not included in the interview guide. Conversations with the Training Manager were not limited to the formal interview, as discussion also took place in a more social setting on several occasions.

Third, interviews were conducted with customers from two groups. The first group included those people currently involved in training. They were the trainees involved in the IRM and merchandising classes held in Montreal and New York and observed by the researcher. A second group of customers were those who had completed merchandising training within the past year. These customers were identified by management as representative of the customer base and also were currently using the system on which they had been trained. People trained on 
the system within the past year may have been excluded from the sample for a variety of reasons: they no longer worked for the company; they were asked to participate in the evaluation but chose not to for their own reasons; the company chose not to ask them to participate in the evaluation because it was politically unwise at this time (e.g., bad working relationship, financial difficulties). The sample consisted of nine people from eight different user organizations. Each person interviewed had attended either an IRM, a merchandising class, or both. These people provided valuable insight into the training because they had had the opportunity to return to their site and actually use what they were taught. This is important because "If training carried out away from the job cannot be transferred effectively to the job, it will be abortive and a total waste of everybody's time" (Robinson, 1985, p.181). These interviews were conducted over the telephone due to the geographical location of those involved. Due to time limitations (the average interview took thirty minutes) and the company's desire to impose on these people as little as possible, the interviews were more focused than those conducted with other groups. Three of the interviews with product trainers were tape recorded. Although everyone interviewed was asked if tape recording the conversation was permitted, most chose 
not to record the session. Company management asked that taped interviews be reviewed only by the researcher and not by any outside party. This request is being honored.

\section{Documentation}

The documentation reviewed during the pilot study included the following: system documentation, an IRM training manual, a procedural checklist provided to trainees for use during the merchandising class, and a computer printout of customer support telephone calls over a one month period. The company uses no additional materials during customer training. The Guide for Evaluating System Documentation was used to report the researcher's impressions of the computer system documentation. The Guide for Evaluating A Training Manual was used for recording strengths and weaknesses of the IRM manual. The procedural checklist and computer printout were evaluated separately, and researcher notes on these two documents were recorded in the notebook kept during the evaluation.

\section{Final Report to client}

The final step in the pilot study was writing a report on the evaluation and presenting the report to the client. This involved returning to Montreal and meeting with four members of management -- the Training Manager, President, Vice-President of Marketing, and VicePresident of a second division of the company involved in marketing computer systems to the gas and petroleum industry. 


\section{Sample Responses}

Sample responses to questions asked during interviews with trainers and customers are included to provide an understanding of the type of answers volunteered during these conversations. There was no analysis of the responses to any of the interview questions in terms of the propositions set forth for the research. "Methodologically, the work at the pilot sites can provide information about relevant field questions and about the logistics of field inquiry" (Yin, 1984, p. 75) .

The purpose of this pilot study was twofold: to help the researcher in the design of the interview guides which would be used during the actual case study, and to provide insight into problems involving logistics and scheduling which might arise during the research. It was never intended that the pilot study be used to actually test the propositions set forth for the research. 
SAMPLE RESPONSES TO INTERVIEW GUIDE USED WITH CUSTOMERS ATTENDING PREVIOUS CLASSES

Pre-Class Preparation:

1. What information/skills would have been helpful to you prior to attending the training session.

"An overview of how the system works and how the general procedures relate to each other."

"None. I was involved in the decision to buy so I knew all I needed to know about the system. I had also attended the first three-day meeting."

2. How familiar were you with the company's product prior to attending the training session?

"Not at all familiar. I didn't even want the system. I liked the old one we had been using."

"As familiar as I could have been without using it. I talked to other customers and had visited a store where they were using it."

3. Did you have an understanding of the "big picture", especialiy in the following areas: What would the new system do for you?

"Yo idea at all."

How would each department be effected?

"I just knew it would change the way our department did things. we'd never used a computer before."

How would the new system impact your company as a whole?

"Never even thought about that."

4. What did you expect to learn during this training session? Were these expectations met?

"I expected to learn how to do my job better, like enter Pos and read reports. We did that in class, but it didn't really sink in until I had to do it at my desk. Then I realized how much I didn't learn." 
During Training:

5. Was the length of the course appropriate? If no, why not?

"It seemed long, but there was still too much to learn. And I feel we got dumped on. By Wednesday afternoon it all seemed like Greek."

"I was only there for the part of the class on warehouse stuff. It was only about $a$ day and a half, and it was $0 x$. $A$ nice break. But I forgot most of what I learned. Now I know it real good because I have to do it myself."

6. Was there too much/too little material covered in class? "Definitely too much for the time."

"About right. You can't remember it all anyway until you really use it for a while."

7. Was material covered in class that you did not use when you first began operating the new computer system?

"I can't remember. It was too long ago and I don't remember exactly what we learned then and what I learned on my own."

"Lots of the reports. You can't use the reports until you build up a sales history, so why bother doing them in class. A waste of time."

8. Which topics/activities did you enjoy the most? The least?

"I liked working on the terminal."

"When the trainer read from the manual it was really boring."

9. What training materials were used during the class?

"I can't remember."

"I think we used like a checklist. It was very hard to read and the xerox copies were terrible. I'm not sure why we used it."

10. Which of these materials were you able to use upon returning to your job? How did you use them?

"None." 
11. How would you suggest changing these materials to make them more useful?

"Improve the quality of the copies."

"I don't know. I never really paid much attention to them."

12. Were any training aids (e.g., overheads, slides) used during class? Were they helpful?

"None that I remember."

13. What supplemental materials would have made the training more effective?

"A better manual to follow along in and refer to later."

"Maybe a videotape or some way to see how everything worked as a system."

14. Was the trainer's teaching style effective?

If so, what did you like best? If no, what didn't you like?

"ghe was OR. I wasn't there the whole week so I can't really

say. She wouldn't let me smoke and I didn't like that."

"Yes. she was friendly and didn't make me feel stupid when I couldn't turn on the machine."

15. What types of activities (e.g., discussions, exercises) might have made the course content easier to understand and use?

"yore time using the computer. Maybe practice exercises that we could do after class."

"I wish we could have spent more time analyzing the buying reports. That was fun. It made me really look forward to getting up and running."

Post-class

16. Who did you train on the new system upon returning to your job after training?

"The assistant buyers."

"The second shift warehouse manager." 
17. What material did you cover during this training?

UHow to do purchase orders and price changes. And what to look for in the reports."

"Not much. He watched me and then we kind of learned together. Lots of mistakes."

18. What methods did you use to carry out this training?

"I had a saturday morning class for the assistant buyers."

"Trial and error."

19. What materials did you use as aids during this training?

"My notes. There really wasn't anything else, except samples of the reports."

20. If you didn't use any of the materials provided to you during your training, what was the reason?

"Mone available."

21. What would have made these materials more useful?

"What materials?"

22. What additional training materials would have made this process go more smoothly for both you and the people you trained?

"A better manual that told me step-by-step how to do POs."

23. How were you able to convey the "big picture" of the new system to your trainees?

"I don't know. I didn't. They don't need to know it. All they know is how to do their job." 
24. When questions about the system's operation or applications came up after training, and especially after you were actively using the system, what were these questions generally about?

"Bometimes the computer just stopped and I couldn't do anything. I was afraid I broke it."

"procedures I couldn't find in the documentation. I hate the documentation because I don't really understand it. It's easier to call."

25. Do you have any further ideas or suggestions about changing this training in order to make it a more useful and practical experience?

"Don't have it in the same room with the phones. It was really hard to concentrate and people kept walking in and out."

"Only try and teach what we really have to know and leave the rest for us to ask about later. There was too much stuff and not enough time. Besides, you really never learn it til you do it." 
SAMPLE RESPONSES TO INTERVIEW GUIDE USED WITH TRAINERS

Professional Experience:

1. How long have you been with this company?

Answers ranged from two months to seven years.

2. What is your professional background, both in training and in other fields?

Trainer background ranged from heavy retail sales background and a college degree to computer programing, systems analysis, and nothing related to either retail or computers.

3. What type of instruction did you receive in training methods prior to working in this field?

One person had been an education major at the university. Two had taken communications workshops. Noone had other experience.

4. What type of instruction did you receive in the course content which you now teach (e.g., system operation, applications)?

Trainers learned from each other by observation and studying documentation.

5. How would you change the way you were trained to do your job: Course content?

"Don't observe a class the first day you start. I knew nothing about the company and all of a sudden $I$ was sitting in a technical class. I couldn't even turn on a computer."

"Teach more about how it all applies and fits together. And learn more from the programmers."

How to be a trainer?

"Anything would be great. There was no help other than criticism about how I shouldn't be doing things."

"I'd love to learn about how to train. I wouldn't even know where to start. What is there that you can learn?" 
Training Materials:

6. What materials do you use when you teach?

"I go through the checklist step by step. Nothing else."

"I don't use the checklist. It's worthless. I just use the board and draw pictures and flowcharts. Then $I$ have them work on the terminals."

7. What do you like about these training materials?

"They're OK."

"I hate the materials."

8. What would you like to see improved?

"A better manual for the people in the class to follow would help."

"Everything."

9. What training aids do you use when you teach (e.g., overheads, slides)?

"None. There aren't any."

10. Are there additional training aids which would make you a more effective trainer?

"I don't know. I've never tried any. Kaybe overheads."

Course content (for each course taught):

11. Is the amount of material covered during the class appropriate?

"Too much."

If there is too much material, what topics might be eliminated and taught either at a later date or in another manner (e.g., self-study manual)?

"I'd teach some of the reports later."

"I don't know what we could take out. They need to know about everything because they bought it all and otherwise they'll think they aren't getting what we said they were." 
12. When is the material you cover during the course used by the trainees - immediately upon returning to the job, several months later, at year-end?

"Depends upon when they go live. sometimes it's pretty soon. sometimes it's over a year."

13. How well do you think the majority of the trainees understand the material you cover?

"gome learn most of it. some don't even begin to understand. Especially the warehouse guys. They are really scared of the whole thing."

14. What new teaching techniques (e.g., exercises) might help the trainees understand more of what you cover in class?

"Yore hands-on would help."

"I don't know if it would matter. They really have to use it to understand it."

15. How much time do you spend on "hands-on" training where the trainees are actually using the new system?

"As much as I can. It depends upon how much time the company gives us. sometimes they let people come for just a few hours and then it's hard to do much hands-on."

16. Do you use the system documentation during training? To what extent?

"No. It's too confusing."

"A little. If they don't learn to use it now, they never will."

Post-class Training:

17. When you receive telephone calls from customers who have returned to use their own system on the job, what types of questions do they typically ask?

"sometimes it's real simple stuff. They just don't remember what I told them. sometimes it's stuff that they have to call me for, like hardware problems." 
18. How might training on the system be modified to eliminate some of these telephone calls?

"Have the right people take the class."

"Give them a better manual and teach them to use it."

19. Do customers refer to their system documentation and attempt to answer their own questions before calling you?

"A few do. Others just call. It's easier and they figure they're paying for it."

20. What additional materials might be provided to customers in order to help them answer questions and thereby decrease their reliance on you?

"A better manual. Better procedures for them to hang by their desk so they can look for the simple answers."

Other Issues:

21. What do you like best about your job as a trainer?

"The customers and the variety."

"I get to see lots of new places."

22. What do you like least about your job as a trainer?

"Constant travel. At first it was fun, but it got old quickly." "sometimes I feel that I spend most of my time cleaning up the mess the salesman made. Then the customer is mad at me."

23. What type of training would you like to receive to help you become a more effective trainer?

"Maybe some help in how to get people more involved. I'm not very good at that."

"I don't know. I guess anything would help."

"I can't think of anything. I think I'm a really good trainer." 
24. How do you think management perceives the training function in your company?

"Varies. sometimes they help us. sometimes they don't." "It's pretty important to them. If we don't do a good job, everybody finds out about it." 


\section{Lessons Learned}

"One difference between the pilot reports and the actual case study reports is that the pilot reports should be explicit about the lessons learned for both research design and field procedures" (Yin, 1984, p.75).

The evaluation of the pilot study site's merchandising training program proved extremely valuable. It confirmed that the process of naturalistic evaluation as proposed by the researcher was not only practical but manageable, and that the results of such a study were of great interest to the company whose training program was studied. The pilot study also enabled the researcher to make modifications to the interview and evaluation guides which will maximize the quantity and quality of information gathered during these procedures. An additional benefit was assisting the researcher in designing data analysis procedures to be used during the research. This analysis involves coding and categorizing of information, followed by drawing conclusions and supporting or refuting the propositions of the study. The preliminary list of codes that was drawn up was based on information gathered during the pilot study.

Several important lessons were learned during the study.

1. It is important that the interviewer make every attempt to include all stakeholders in the research. 
This may not always be possible, but should be attempted -- especially if these stakeholders are aware the study is being conducted or will have access to the final report. During the pilot study, three of the product trainers were unavailable for personal interviews due to travel schedules, illness, and maternity leave. There were hurt feelings after the study was completed because at least one trainer felt excluded. This, of course, was not a problem in the case of management because those interested in participating did so. With customers, those contacted chose to be interviewed or decided of their own accord not to be involved. Those not contacted were unaware of the study. 2. The evaluator and client should have a clear and mutual understanding of the type of information which will be generated from the research. To clarify, the company involved in the pilot study believed that it would be receiving a report discussing the company's training courses, trainer effectiveness, customer perceptions of training, strengths and weaknesses of documentation and other materials. The final report also included insights about trainer morale and trainer/manager communication. These were considered important because morale and communication directly impact the effectiveness of a training 
program. However, they were not necessarily what the Training Manager thought she had asked for.

The evaluator should do one of two things: establish those specific components which are being evaluated and report only on those; or, inform the client prior to beginning the evaluation that additional concerns or issues may arise during the course of the evaluation process and ask their permission to include those findings in the final report. The researcher believes that the latter is the preferred approach. The purpose of naturalistic inquiry and the use of multiple sources of evidence is to allow the researcher to draw upon a great deal of information, within a natural setting, and to take a holistic look at what is being evaluated. These additional insights should be valued and not avoided. 3. It is not always necessary for the evaluator to observe every aspect of a training course. During the pilot study, both of the training classes were observed in their entirety. All three days of the IRM were definitely worth observing, primarily because their content changed each day and the activities which took place varied. However, the merchandising class involved teaching different procedures to different groups of people over a five- 
day period. The type of activity did not change significantly. It would have been sufficient to observe this class for three days instead of five. During the last two days the researcher learned very little other than confirming what had been learned during the first three days.

This decision regarding the amount of time to be spent observing a training class should be given considerable attention. Depending upon the type of activities, participants, and content of the class, it may be possible to save time and still collect all of the information necessary for an accurate and insightful evaluation.

4. The relationship between the training and marketing departments is very important to the success of customer training. Therefore, representatives of marketing should also be considered stakeholders and interviewed during the evaluation process. This will provide insight into the problems, attitudes, and responsibilities of both groups as well as how each group perceives the other. For this reason, an interview guide was developed and interviews with key sales people were included in the case study. (See Appendix E)

5. Interview questions should be phrased in an openended manner. Open-ended questions typically begin 
with one of the following words: why, how, when, where, who, or what. These questions cannot be answered by a "yes" or "no" response but cause the respondent to provide information. Closed-ended questions, which are answered by a "yes" or "no" should rarely be asked. They are useful only when eliciting specific information, such as "Did you attend the training meeting last Friday?" Prior to beginning the actual case study research and conducting interviews with a second company's employees and customers, interview guides were revised to eliminate closed-ended questions. 6. Some of the interview questions asked during the pilot study were unnecessary. They touched on areas already covered by previous questions and were therefore eliminated. other areas were not addressed in the interview guide. Questions about these topics were added to the proposed guides. 


\section{Interview Guide: For Use with Customers Who Attended Previous Classes}

Revision:

Question \#3: What was your understanding of the system's overall operation - the "big picture"? From where did you acquire this understanding?

Reason: Reworded to an open-ended question. Asked for further information about source of their understanding.

Revision:

Question \#4: What were your expectations for this training course? How were these expectations met? Reason: Reworded to an open-ended question.

Revision:

Question \#6: Was there too much/too little material covered in class? If so, how would you recommend modifying the course content/schedule? Reason: Reworded to an open-ended question and looked for suggestions on how to modify amount of material.

Revision:

Question \#12: What training aids (e.g. overheads, slides) were used during the class? How were they helpful? Distracting?

Reason: Reword second part of question to open-ended format. 
Revision:

Question \#14: What were the most effective aspects of the trainer's teaching style? What were the least effective?

Reason: Reword to open-ended question.

\section{Revision:}

Question \#25: What are your ideas or suggestions about changing this training in order to make it a more useful and practical experience?

Reason: Reword to open-ended question.

\section{Interview Guide: For Use With Trainers}

Revision:

Question \#10: What additional training aids would make you a more effective trainer? What benefits do you see them providing to both the trainer and the trainee?

Reason: Reword to open-ended question.

Revision:

Question \#15: How do you integrate "hands-on" training into the course? To what extent do you use this type of training?

Reason: Probe for more information besides amount of time spent on hands-on training. 
Revision:

Question \#16: How do you use system documentation during training? Why do you think this is an important part of training?

Reason: Reword to open-ended question. Check how important they feel the use of documentation is to training.

Revision:

Question \#19: If customers do refer to their system documentation and attempt to answer their own questions before calling you, why do you think they do so? Where did they learn to do this?

Reason: Reword to open-ended question.

Revision:

Question \#22: Add second part of question: What do you think might be done by either yourself or the company to make the situation better?

Reason: Learn more than just what they like least. Look for their suggestions on how to make improvements.

Addition:

Question \#25: How do training and marketing interact in your company?

Question \#26: How well do you think marketing understands the training function, and vice versa? 
Question \#27: What might be done to improve the overall relationship between training and marketing?

Reason: Add questions regarding marketing/training relationship. This relationship very important to the success of a training department. Trainers' perceptions and suggestions can be very revealing and valuable.

\section{Interview Guide: For Use with class Participants}

\section{Eliminate:}

Question \#5: Repetitive of information gathered in response to question \#4.

\section{Revision:}

Question \#12: a) Who will you be responsible for training when you return to the store? b) What information/materials were you given to help you train these people? c) How do you think they will help you do this training? d) What additional materials would be valuable for training purposes?

Reason: This information is critical, because so much of the worth of training is determined by how well the customer can return to the store and train others on the use of the system.

\section{Addition:}

Question \#17: When you return to the store and you have questions, what procedures will you follow in order to find an answer or to solve a problem? 
Reason: It is important to gauge whether or not the customer feels comfortable looking for answers independently or whether the training was not successful in instilling a feeling of confidence.

\section{Interview Guide: For Use With Company Management}

\section{Revision:}

Question \#5: How do you include include company growth projections in your budgeting for training (personnel, materials)?

Reason: Reword to open-ended questions.

\section{Eliminate:}

Question \#7: Questions on the location of training should be asked during the planning of the evaluation.

Replace:

Question \#7: If you do training both on-site and offsite, what are the advantages of both? The disadvantages?

Reason: Training might be more successful if its location were changed. Answers to this question may provide good insight into whether or not this is both feasible and/or desirable. 


\section{Implications of Pilot study on Development} of Guide

The researcher intends to share the results of the pilot and case-study with professionals interested in conducting their own naturalistic evaluation of customer training. The intent is to publish a guide to this type of evaluation that can be used by these companies independently. The guide was developed as part of this research and can be found in Chapter seven of this dissertation. Although the case-study will provide additional insight into the evaluation process, the pilot study also generated a great deal of helpful information.

First, the guide includes suggested interview questions to be used when talking with trainers, customers, and company management. The opportunity to develop these formats, use them in the pilot study, and then revise them for the final research was very valuable. Interview guides were tested twice with the opportunity to modify them as needed. The researcher believes that the interview questions were stronger, more focused, and better written as a result of the pilot study. Therefore, the questions which other training professionals may develop based on this study's questions will also be stronger and more focused.

Second, the observation guide designed for use while observing training classes was followed twice. The 
researcher found several factors which should have been evaluated but were not included in the guide designed for the pilot study. They were added to the guide for use in the research to follow.

The same was true for the guides to evaluating user documentation and training manuals. Once the actual training material was made available to the researcher during the pilot study, it was obvious that aspects of these documents not addressed in the guides needed to be added.

The pilot study was very important in another respect. The researcher designed all evaluation guides based on prior experience in evaluation of training programs, readings about interview techniques and instructional materials, and consultation with an expert in the field. However, the pilot study proved that nothing is carved in stone. Every company is different and no matter how diligently one tries to structure an interview or procedural guide, the evaluator must be flexible. The result of this realization is that the materials provided for use by other professionals within their own companies will be more generic than those used in either of these two studies. Those who use the guide will be apprised of its limitations and given appropriate warnings -- similar to those identified under the heading "Lessons Learned". 
It is important to note that the researcher had two opportunities to make things work in this study. If something was not as effective as it might have been during the pilot study, it was modified. Recommended procedures included in the practical guide will have benefited from a second chance -- the actual case-study. on the other hand, professionals who choose to use naturalistic inquiry for the evaluation of their own training program may only have one chance to make it work. It is up to the researcher to act responsibly in designing an instrument that is thorough, well-written, and based on sound experience within this particular industry. 
Chapter Five

Findings

The intent of this research was to illustrate the use of naturalistic inquiry as an appropriate method for evaluating customer training, specifically customer training carried out by companies who are categorized as value-added-resellers of computer systems. In order to show the appropriateness of this method and to describe its use and value in the business community, a case study was conducted by the researcher. This case study involved performing an evaluation of a customer training program using naturalistic techniques and analyzing the data gathered during the process. Analysis was performed using qualitative techniques as suggested by Miles and Huberman (1984).

The focus of the evaluation was established prior to beginning the research. Three propositions were identified in order to assist the researcher in designing the methodology for data collection, analysis, and reporting of findings. The propositions addressed issues and concerns of training professionals as evidenced by the literature and the past experience of the researcher. In order to report the findings of the case study in a logical manner, this chapter is organized by order of propositions. Summary matrices provide a review of the data collected through interviews, observations, and 
evaluations of materials. These matrices were designed to enhance the narrative description of the findings and to back-up the conclusions drawn by the researcher following data analysis.

Each of the following sections begins with a review of the proposition, a discussion of the findings, and initial recommendations made by the researcher in response to these findings. These recommendations are certainly not all inclusive. Further discussion with management and/or training staff would undoubtedly lead to the addition, deletion or revision of some of the suggestions. They do, however, reflect the concerns of the stakeholders and demonstrate the value of the naturalistic evaluation process in identifying methods for improving existing training. Proposition one Training programs designed for end-users of computer systems generally evolve as the company's customer base grows. These programs are rarely planned.

Related Findings

The research conducted during this case study supported the proposition that customer training evolves as the company grows and that this training is not wellplanned. Information regarding the evolution of training was collected during interviews with various members of company management. These included the President, Vice- 
President of Marketing, Director of Customer Support, and Manager of Training. Table 1 is a role-ordered matrix displaying a summary of their comments regarding various topics which relate to the evolution of XYZ's customer training and its current state.

At XYZ, the training function grew out of necessity. As the first systems were sold, end-users required training on how to use these systems. There were no employees dedicated to the training function. Instead, everyone did everything. XYZ was fortunate because one of its first executives, the vice-President of Marketing, was a previous user of the XYZ system. He, therefore, was aware of the importance of training and did a great deal to provide structure and professionalism to this function. The company's user base grew quickly, and as the number of customers increased it was necessary for XYZ to hire trainers. Management and salespeople could no longer be responsible for training.

The first trainers learned to do their job by trial and error. In the words of one of the company's most senior trainers, "I learned on the fly. By the seat of my pants. I read what little documentation there was and, by spending lots of time on the phone doubling as a customer support rep, found out how the system operated. There was no real training, since everybody there was in 
PROPOSITION \#1

Role-Ordered Matrix (Company Management)

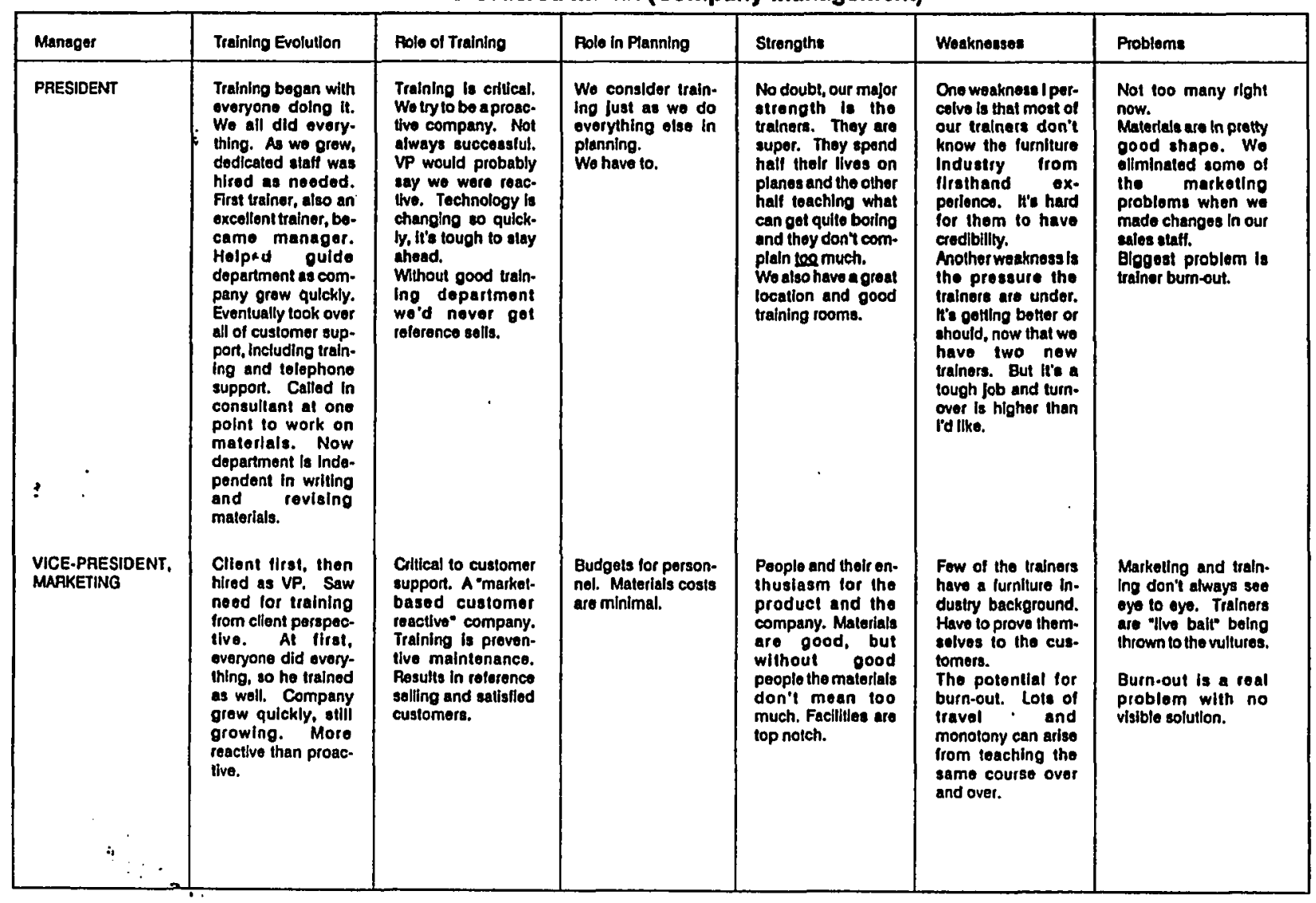

Table 1, Proposition \#1: Role-ordered Matrix

(Company Management) 
PROPOSITION \#1

Role-Ordered Matrlx (Company Management) Continued

\begin{tabular}{|c|c|c|c|c|c|c|}
\hline Manager & Training Evolution & Role of Training & Role In Planning & Sirengths & Weaknosset & Problems \\
\hline $\begin{array}{l}\text { OARECTOR, } \\
\text { CUSTOMER } \\
\text { SUPPORT }\end{array}$ & 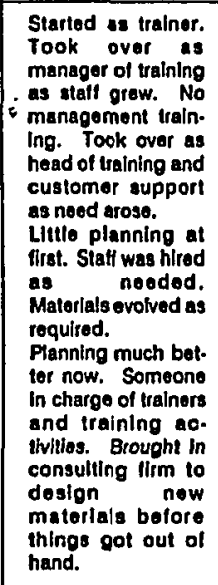 & $\begin{array}{l}\text { Customer support } \\
\text { vory important to } \\
\text { sales. Training is } \\
\text { major part of cus- } \\
\text { tomer support. }\end{array}$ & $\begin{array}{l}\text { Management very } \\
\text { supportive of train- } \\
\text { ing and its requltro- } \\
\text { ments. Considers } \\
\text { In budgeting. } \\
\text { involvod in rewrilting } \\
\text { salos agreements. }\end{array}$ & $\begin{array}{l}\text { Peoplo } \\
\text { Materlals } \\
\text { Communicallon } \\
\text { Managoment eup. } \\
\text { port }\end{array}$ & $\begin{array}{l}\text { Lack of Induatry } \\
\text { background lor } \\
\text { many of the tralners. } \\
\text { Hard to rolate to } \\
\text { customor'e spectllo } \\
\text { needs. } \\
\text { Lack of training in } \\
\text { how to teach. }\end{array}$ & $\begin{array}{l}\text { Bum-out. } \\
\text { Sometlmos Iralners } \\
\text { have to solve } \\
\text { problems croated by } \\
\text { sales reps, but not } \\
\text { very otten. }\end{array}$ \\
\hline$\dot{4}^{\cdot}$ & 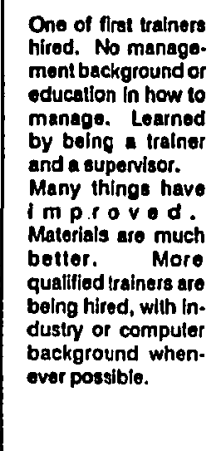 & $\begin{array}{l}\text { Citlcal to the com* } \\
\text { pany. II training } \\
\text { doesn' do a good } \\
\text { lob, customers are } \\
\text { very unhappy. }\end{array}$ & $\begin{array}{l}\text { Worka with Managor } \\
\text { of Customer Sup- } \\
\text { port lo plan, budget, } \\
\text { ote. Lols of thinking } \\
\text { ahead. }\end{array}$ & $\begin{array}{l}\text { Great people who } \\
\text { really care about the } \\
\text { customers. } \\
\text { Most of the } \\
\text { materials are very } \\
\text { good. Some are stlil } \\
\text { belng rewritten but } \\
\text { will soon be equally } \\
\text { as good. }\end{array}$ & $\begin{array}{l}\text { Exceptional Iralning } \\
\text { facilitios. } \\
\text { Management very } \\
\text { supportive. }\end{array}$ & 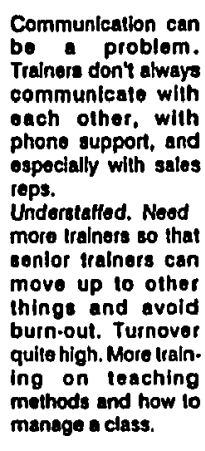 \\
\hline
\end{tabular}

Table 1, Proposition \#1: Role-ordered Matrix (Company Management), continued 
the same boat. The company was growing so quickly, we all just did whatever we could to make it happen. It's a good thing I knew something about computers or it would have been really tough. I certainly knew nothing about training!"

As time went on and $X Y Z$ continued to experience rapid growth, additional trainers were hired. Structure was given to the training program by dividing training into two separate sections, accounting and merchandising. Week-long training classes were designed and trainers were tasked with preparing course materials. These materials were based on documentation written by programmers. As necessary, based upon program revisions and software enhancements, portions of the materials were rewritten, added, or deleted.

By this time, the most senior trainer was promoted to manager and given the responsibility of operating the training program. She supervised the development of materials, scheduling of classes, and staffing of the department. The customer base continued to grow, increasing the pressure on this group to offer more and more classes and to continually enhance the computer system in order to keep up with the customers' needs. since trainers at XYZ also spend a week with each customer at the time of their "conversion" to the new system, the majority of their time was consumed either on 
the road or in the classroom. There was very little time to work on refining training materials or work on training methods.

It became evident to the training manager that the program, and especially the materials, lacked the professionalism desired by the company. Management had always been very supportive of training and had shown their support by providing excellent training facilities and a generous budget. However, the materials needed some work.

"I knew we needed help in developing better materials for our trainers and our customers. My staff just didn't have the time, or the skill, to to this. So I called on an outside consultant to look at what we were using and recommend changes. They rewrote several of our coursebooks and designed supplemental materials that made training much easier for the trainers and the customers. They were more professional and we were finally proud to put our name on them."

$\mathrm{XYZ}$ has been fortunate to have management who are so supportive of the training function and recognize its importance. The vice-President of Marketing emphasized its importance when he noted that "I view training as preventive maintenance. You can't provide good customer support unless your training is good. They expect it from us. We sell a very expensive product. We live in a 
beautiful building. I mean, we have a sushi bar and a swimming pool! If we didn't give them good training they wouldn't give us our money. And they wouldn't tell their friends to look at our system. This is a tight industry. Everyone knows everyone else, and competition is fierce. So we have to make and keep our friends. I know, I was there myself, and I knew when I took this job that one of my priorities would have to be training. We still have a long way to go, but we have a good program that we're proud of."

$\mathrm{XYZ}$ trainers and management realize that their continued growth means an increasing burden on the training department. Their staff is limited. Trainers have little time for anything but classroom training and on-site conversions. Opportunity for planning ahead is still hard to find. Management does its best to involve training in the planning process, but there are still areas to work on. When asked for the strengths of XYZ's training, everyone interviewed volunteered the same answers. The first response was always the people. They are a loyal, hard-working group who believe in the company and the product. "Our people are the greatest", said the president. And his views were echoed throughout the company. Everyone also acknowledged the excellent training facilities and the high level of support offered by management to the training department, both as a whole 
and to individual trainers. But they also recognized that there were weaknesses. The Manager of Training summed these up in the following way.

For one thing, we have a real problem with burnout. Trainers get sick and tired of being on the road several weeks in a row and then coming back to a classroom where they teach two weeks of the same class. Then they may have a week to catch up with customers and paperwork if they are lucky, but usually they hop back on a plane. It's not a glamorous job. And we don't always communicate real well with each other. But the one problem that I think is most evident to the customer is their lack of background in the furniture industry. It's hard to have credibility when you are a 25-year old woman who may be very sharp and know the system inside and out but who has never worked in a furniture store. Trainers have to earn the respect of Ma and $\mathrm{Pa}$ store owner, and it isn't always easy. If we could hire trainers who used to be clients, and we are doing that more and more all the time, it would make things easier for everyone. $\mathrm{XYZ}$ is making a concerted effort to restructure its training program in order to accommodate the terrific growth it is experiencing. They also want to provide 
opportunities for trainers so that burn-out is less of a problem. Two new trainers were very recently hired to handle some of the new customers. In addition, XYZ has begun to offer consulting services to its customers and senior trainers now have a new challenge to look forward to. This should help to reduce turnover and make the trainers' lives a little less hectic.

As with any computer company experiencing rapid growth, there may be increasing demands on the training staff to work harder and longer. When the training function evolves more as a reaction to this growth than as a planned evolution fueled by foresight and strategic thinking, it may be very difficult to keep up with these demands. Planning is critical to the operation of a successful training program. Evaluation of training is necessary if a company is to learn how it can better cope with growth and changes.

XYZ has taken some excellent steps toward improving the training it offers its customers. Management has supported the hiring of new staff; materials have been rewritten to reflect the professionalism of the company; facilities have been designed for the comfort of the company's employees as well as its clients. But there is still more that can be done, as noted by the President of XYZ • 
We have an excellent reputation in our industry. We have worked hard for that reputation, but we've gotten where we are more by 'reacting' than by 'proacting'. It's worked up to now, but technology is changing so fast, and our prospects are so much more sophisticated than they were two or three years ago. We can't just react anymore. If we don't put even more energy into planning, into getting a jump on things, we'll lose our number one spot. We just can't risk that. Training is no different. Now that we have a pretty adequate staff and our materials are in pretty good shape, we need to think ahead to what else we can do. Should we do CBT (computer based training)? Is that what the customer is going to expect? I don't know, but we need to spend more time thinking about these issues.

At XYZ, training did evolve out of necessity. There wasn't a great deal of planning involved. It's scope grew as its customer base grew. The company continues to enjoy rapid growth, and management recognizes the need to further evaluate the role of training and to consider what will be needed to meet the demands of its customers. 


\section{Recommendations}

1. Examine very closely XYZ's procedures for hiring and training new trainers. When hiring, explore all possibilities for finding capable people with a furniture background and/or computer experience. Develop a comprehensive "train the trainer" program which helps the new employee learn the required technical material as well as much needed training techniques.

2. Plan ahead by instituting an ongoing education program for the training staff. Include in this program development in the areas of adult education, communication skills, and classroom management. This type of training will help prepare trainers to be more successful in the classroom, thereby enhancing customer satisfaction and learning as well as developing management and leadership ability. 3. Continue to develop new programs for senior trainers so that boredom and burn-out become less of a problem. Turnover is very expensive. It not only costs a great deal of money to train a new person, but it results in decreased morale and customer dissatisfaction.

4. Develop a team-building program to strengthen the working relationship between the marketing and training departments. Lack of communication among 
these departments can result in additional work for trainers, resentment and low morale among both trainers and salespeople, and potentially serious customer complaints.

\section{Proposition Two}

Training can be evaluated for both merit and worth. Each play an important role in the overall success of the program.

Evaluating a training program can be a complex process. There are many factors to consider, and many activities which come into play. The methodology section of this document describes the procedures which were followed during the pilot study and case study research. The selection of these procedures and the identification of stakeholders was also discussed and justified as part of the methodology discussion.

Research procedures enabled the researcher to evaluate customer training from two points of view. First, the training was evaluated for its merit. Guba (1981) describes merit as the "intrinsic, context-free value" of the evaluand. In this case, merit referred to those aspects of the program which were unrelated to the lasting value or application of the learning experience. These included the environment (e.g. training room), the professional quality of the materials (e.g. appearance of 
the manual), the accuracy of the content, and the design of the training course. Merit was evaluated through interviews with trainers, trainees, personal observation of classes, and review of training materials.

Second, the training was evaluated for its worth. Guba (1981) describes worth as the extrinsic value of a program, or the value within some context of use or application. In this study, training was analyzed for long-term retention and application. Research explored the ability of the trainees to return to their jobs and actually use the material they had learned. Worth was evaluated on the basis of discussions with trainers, trainees currently attending classes, and trainees who attended classes up to one year ago.

\section{Related Findings: Merit}

The researcher found that the overall customer training program conducted by the XYZ Company had a good deal of merit. Feedback from trainers and trainees (past and present) indicated that the intrinsic value of the program was quite high. Table 2 summarizes responses to interview questions dealing with the training facilities, training materials, and course structure.

The researcher judged the $\mathrm{XYZ}$ training facilities to be superior. The corporate offices are part of a beautifully designed business park which includes a recreation center with exercise facilities and a swimming 
PROPOSITION \#2

Summary Matrix: Merlitworth of Training All Stakeholders

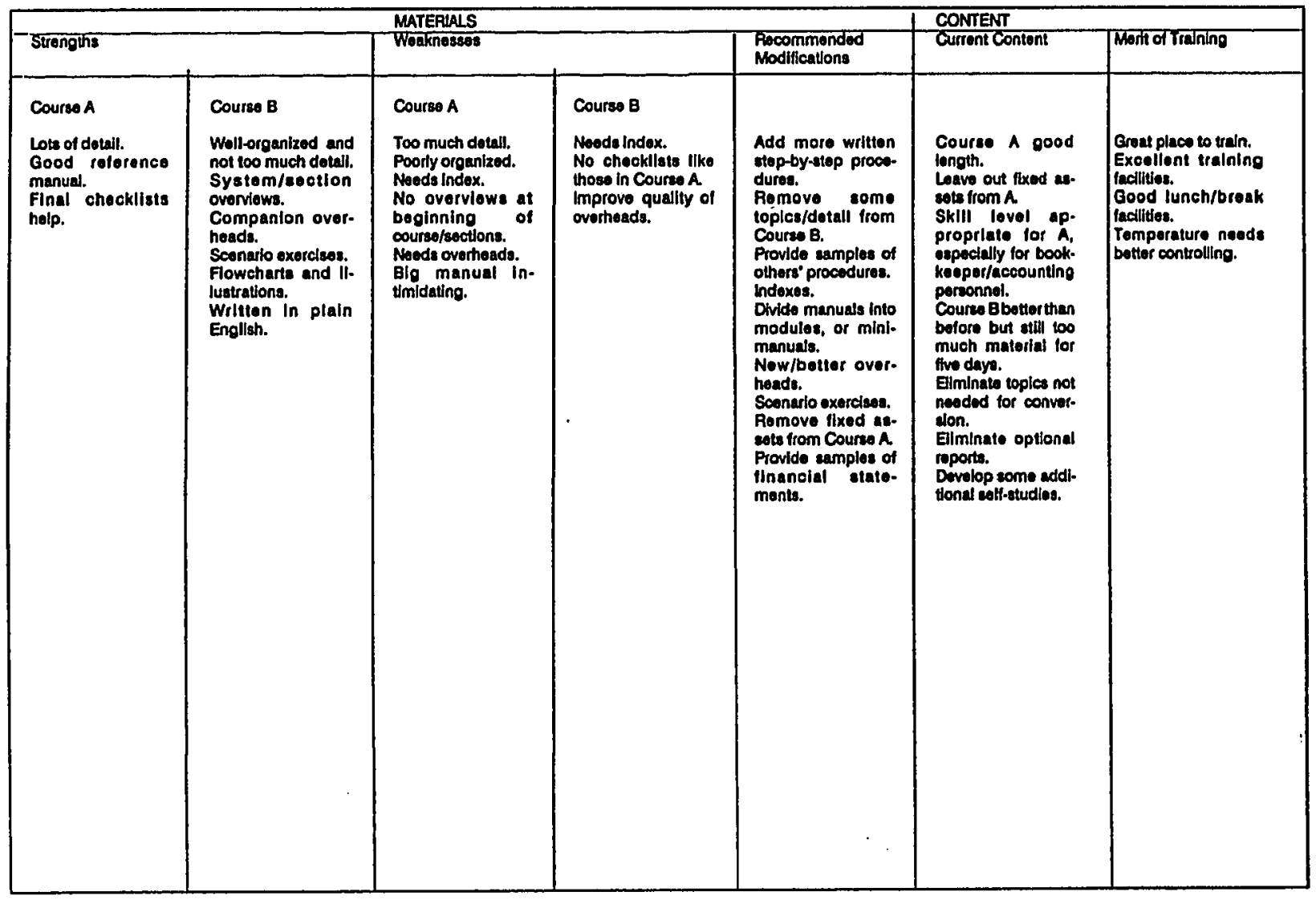

Table 2, Proposition \#2: Summary Matrix Merit/Worth of Training (All Stakeholders) 
PROPOSITION \#2

Summary Matrlx: Merit/Worth of Training All Stakeholders (Page Two)

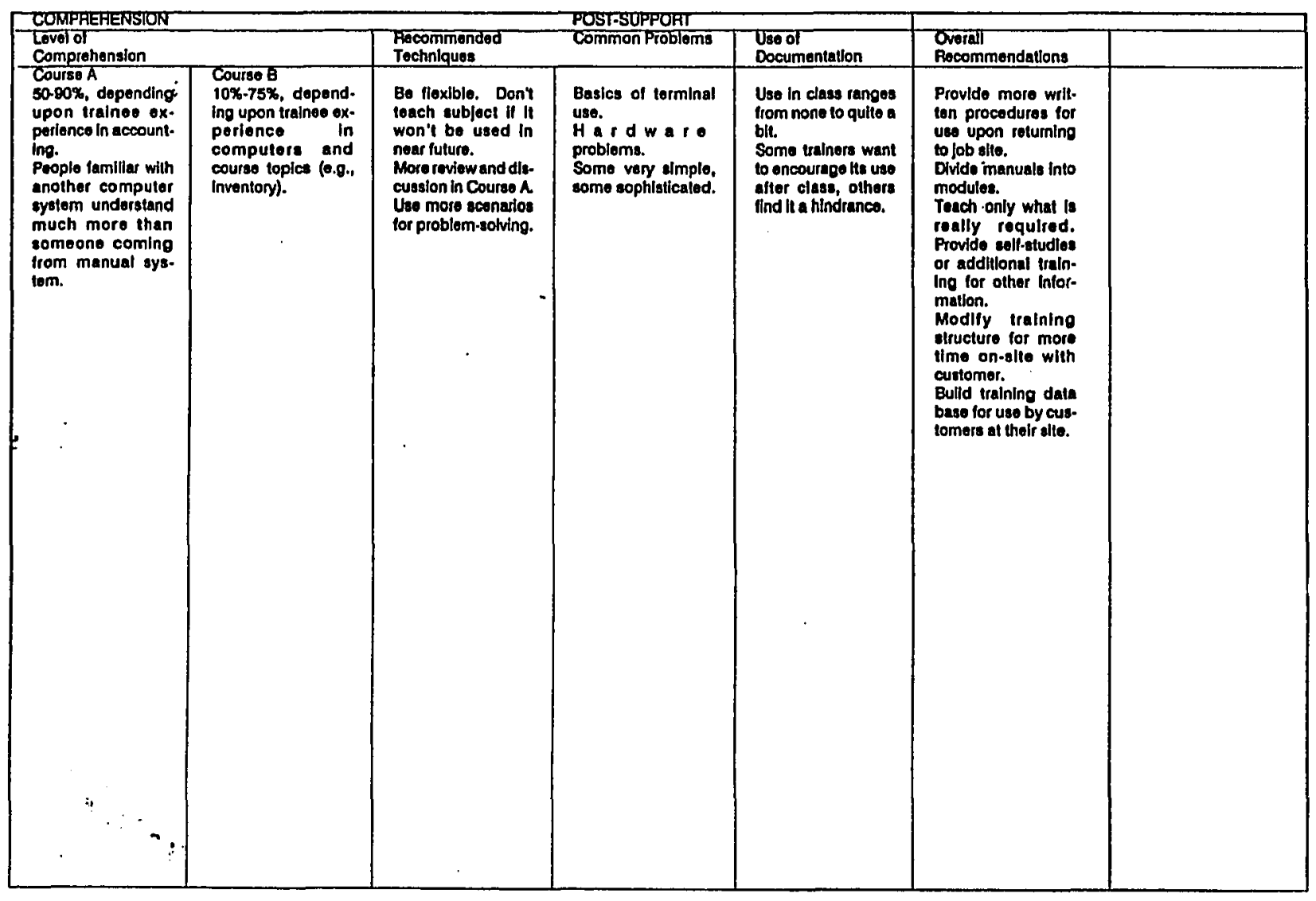

Table 2, Proposition \#2: Summary Matrix Merit/Worth of Training (All stakeholders), (continued) 
pool. There is a cafeteria and a sushi bar that is just a short, and very beautiful, walk away. Without exception, everyone interviewed expressed the same opinion of the facilities. They were described as "superior", "beautiful", and other similar adjectives. Training rooms are also well-designed, spacious, and comfortable. Trainees sit at tables for two, with up to twelve in a classroom at one time. There is one terminal at each table, allowing easy access for "hands-on" activities. The trainer has an elevated table in the front of the room at which he/she can sit or stand. There is a screen for projection of overheads and a white board in each classroom. XYZ appears to have a great deal of sensitivity to the needs of its employees and visiting guests. There are always hot and cold beverages available, clean rest rooms, and readily accessible telephones for use by the trainees at no cost.

One concern expressed by trainees was that the temperature in the training rooms fluctuated dramatically. It was either too hot or too cold, and although this is not a serious problem, it did cause some discomfort.

The merit of the training materials varied depending upon the course being offered. Course B materials were recently rewritten and were excellent instructional aids The trainer used an Instructor's Guide while trainees 
had their own Workbooks which served as reference manuals during class and will be used again when the trainees return to the job. The Workbooks were well organized and easy to follow. There were excellent illustrations, samples of computer screens and reports, learning objectives, step-by-step procedures, and exercises. The Workbooks were used extensively by the trainees for taking notes and for guiding the flow and discussion of the class. One area for improvement was the quality of the overheads. Some were very unclear and were more of a distraction than a visual aid.

Course B materials also included overheads of flowcharts, screens and reports which helped the trainees understand both the overall system operation and specific technical procedures.

Course A materials do not have the same "merit" or intrinsic value. Trainers and trainees confirmed the researcher's several concerns regarding these materials. First, they are not well-organized and it can be difficult to follow along with the instructor. second, there are no overheads accompanying the manuals. Third, there is too much detail in the Workbook with very little room for taking notes. Fourth, the appearance of the Workbook lacks the professionalism that the new Course B materials has. 
XYZ is currently in the process of rewriting course A materials and when they are finished these concerns should no longer exist. The new materials are similar to Course $B$ in design and organization, there are companion overheads, the amount of detail is reduced, and the quality of the print and the illustrations will be significantly improved.

Additional training materials used by XYZ with its customers include a system Implementation Guide and a series of four self-study Manuals. The system Implementation Guide is a well-organized, high quality manual, with a companion workbook, used by both the salesperson and the customer during the first official meeting after a sales contract is signed. This Guide walks the customer through the requirements of a new system. It describes the $\mathrm{XYZ}$ training program, important concepts and definitions, environmental requirements, and system initialization procedures. The Guide is the first example of training materials which the new customer sees, and it makes a strong impression.

Self-study manuals were designed to reduce the amount of material covered during the week-long merchandising training class. These manuals address four topics: code initialization, month-end closing, management reports, and the report scheduler. The manuals are well-written, nicely presented, and easy for the customer to use 
independently. Overall, training materials have a good deal of merit and make a strong, positive impression on the customers.

In regards to merit, the researcher evaluated one other aspect of XYZ's training program: course structure. Trainers and trainees were asked about the length of each class, the amount of material covered, and the timing of the class (as it related to the installation and use of the system).

The majority of the trainers and trainees interviewed believed that five days was an appropriate length of time for teaching course A. The timing of this course was also considered ideal, because the material covered during this week is generally used within a week or two of returning to the customer site. Most people agreed that the amount of material covered was also appropriate, although some trainees recognized their inability to remember everything. The people who were primarily responsible for this material (e.g. bookkeeper, owner) were confident in their ability to retain what was needed.

Course B, however, was judged by both trainers and trainees to be too short a class for the amount of material. The use of self-study manuals already reduced the number of topics covered during the five days, but there was still concern that no one could possibly 
remember everything they needed after this very full week of training.

In summary, the researcher judged the merit of the $\mathrm{XYZ}$ training program to be quite high. Facilities were excellent, providing a pleasant and comfortable environment for learning. In most cases, training materials were very professional written and presented. The company recognizes their importance and is making a concerted effort to improve those materials which lack the quality XYZ strives for. The structure and content of Course A was judged to be appropriate for the amount of time allowed; Course B, however, asked too much of the trainees. The potential for burn-out and intimidation was high.

\section{Recommendations}

1. Adjust the temperature in the training rooms so that it is more comfortable and there is less fluctuation from very cold to very hot. 2. Replace those overheads in course B that are difficult to read because of small print and poor print quality.

3. Continue to revise Course A materials in the same format of the new Course B materials. Develop companion overheads to enhance understanding. 4. Further reduce the content of course B by removing any material that is not required by the 
customer until long after converting to the new system. This will make for a more relaxing week and result in reduced stress and intimidation on the part of both the trainer and the trainees. (Note:

Further discussion of this recommendation is found in the section on "worth".)

\section{Related Findings: Worth}

The researcher drew conclusions regarding the worth of the XYZ training program by looking at three overall areas: In-class teaching techniques and activities; preparation for independent use of the system back at the customer site; reference materials available to the customer to promote customer independence. Table 3 summarizes the responses of trainers, trainees, and company management regarding these areas of inquiry.

Course A and Course B were very different in both content and presentation. Course A teaches the accounting side of the system, and there are few variations on these procedures from one user to another. For this reason, $\mathrm{XYZ}$ has recently begun co-teaching Course A. This approach allows XYZ to train employees of two companies at one time, which increases the efficiency and cost-effectiveness of this training. Both of the Course A classes observed by the researcher were made up of trainees from two companies. 
PROPOSITION \#3

Summary Matrix: Trainer Effectlveness/ All Stakeholders

\begin{tabular}{|c|c|c|c|c|c|c|}
\hline \multirow[b]{2}{*}{ STAKEHOLDERS } & \multicolumn{6}{|c|}{ ISSUES } \\
\hline & $\begin{array}{l}\text { Prior Education/ } \\
\text { Experionce }\end{array}$ & On the Job Training & People Skills & $\begin{array}{l}\text { Tochnical } \\
\text { Compotence }\end{array}$ & Training Strengths & Tralning Woaknesses \\
\hline $\begin{array}{l}\text { TRANEEESI } \\
\text { CURRENT }\end{array}$ & 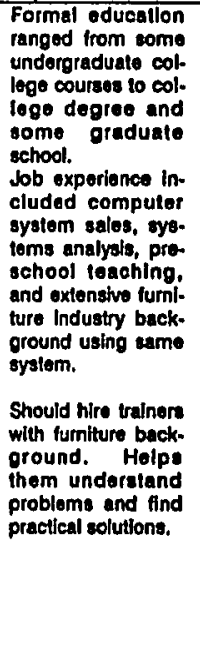 & $\begin{array}{l}\text { Majority folt too littio } \\
\text { atructure in trainling. } \\
\text { Too littlo foedbeck } \\
\text { too late. } \\
\text { artinciuded obser- } \\
\text { vation of classes, } \\
\text { mo morlzatlon of } \\
\text { systom operation } \\
\text { and procedures } \\
\text { fom manual, and } \\
\text { particlpating in con. } \\
\text { versions and co- } \\
\text { toaching. }\end{array}$ & 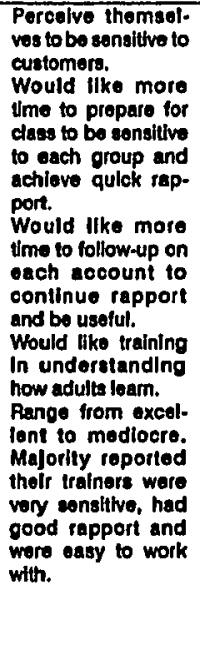 & 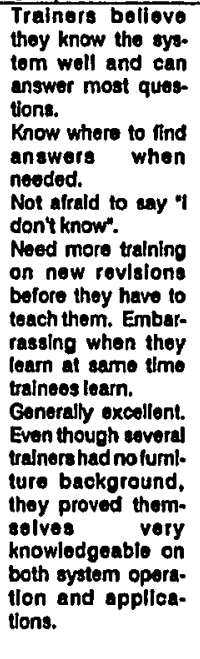 & $\begin{array}{l}\text { Ability to rolate to } \\
\text { customer slto and } \\
\text { procodures. } \\
\text { Minimal training In } \\
\text { Jlstoning and ques- } \\
\text { toning holped. } \\
\text { Excollent product } \\
\text { knowiodge and on- } \\
\text { thuslasm for sys- } \\
\text { tem. }\end{array}$ & 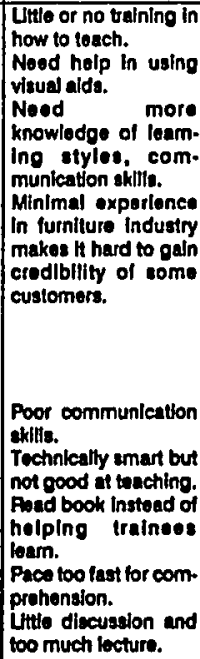 \\
\hline
\end{tabular}

Table 3, Summary Matrix: Trainer Effectiveness

All stakeholders 
PROPOSITION \#3

Summary Matrlx: Trainer Effectiveness/ All Stakeholders (Page Two)

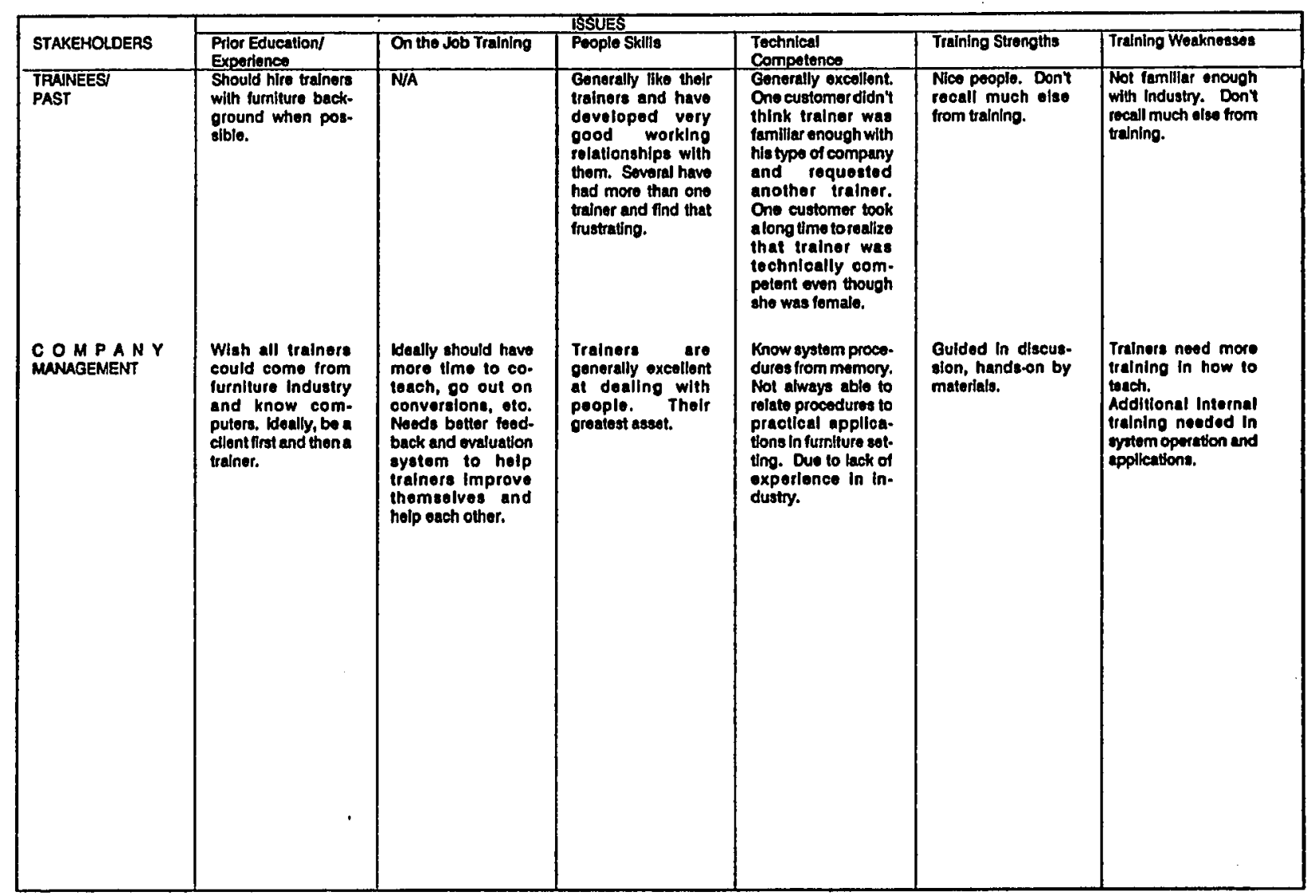

Table 3, Summary Matrix: Trainer Effectiveness All stakeholders (continued) 
Course B, however, teaches the merchandising side of the system. Here there are many variations to how customers carry out procedures. Every user has specific requirements that must be discussed, especially in the areas of inventory control and delivery. Therefore, it is not possible for XYZ to work with more than one customer at a time. Teaching employees from only one company is less efficient and more costly, but it is important for true learning and customer satisfaction. co-teaching Course B would result in decreased long-term value, or worth, of the training.

In-class teaching techniques and activities have a definite impact on the ultimate worth of the learning experience. Wlodkowski explains that adults need to be stimulated if they are to stay involved and fully comprehend what they are being taught.

What is stimulating to a person is a function of the person's developmental stage, mood, cultural background, experiential history, and expectancy for the situation. With twenty adult learners, there are twenty possibilities. That is why the instructor's empathy, creativity, flexibility, and constant attention to learner reaction are necessary ingredients to sustain a stimulating learning environment... To keep people stimulated means to keep them emotionally involved (p. 141). 
At $X Y Z$, both the trainer's style and training materials were key factors in determining the level of stimulation achieved by the trainer. Several of the trainers were skilled at involving trainees in discussion, encouraging questions and directing hands-on activities. other trainers were not as skilled in these areas. This was a problem in Course $A$, because the training materials do not incorporate instructions for how to present the material in an interesting, interactive manner. The Course A manual is strictly a guide to procedures (See Figure 6). In this class, the trainer is on his/her own to integrate questions, exercises, and discussions in the presentation. For some, this was not a problem. For others, it was, and the result was five days of primarily lecture.

Course B materials are designed differently in that there are built in questions, activities, and discussions which prompt the trainer to encourage interaction and involvement (See Figure 7). These frequently force the trainee to relate course content to his/her own experience or to try and use the material covered in class to solve real-life types of problems. "BY embedding the learning activity and what we say and do as instructors in current adult interests, we provide learners with a constant stream of relevant material" (Wlodkowski, 1985, p. 160). 
G. FIMANCINL STATEMENT PRINTOUT - STPR

The Financlal Statement Definition Print-out (STPR) program is run to review entrles entered into the Financlal Statment Definition (STMT) program. This report should be saved, in case the statement does not run when it is called up due to possible formatting errors in STMT.

INPUT:

The STPR progran is called fram the General Ledger System Selection Cirectory. The screen will display:

ENTER COPAYY MUE: WH

ENTER PASSMOPO: What

This question is only asked if you are a multi-company. Enter the name and assoclated password for the company that you want to work with. Single and multi-companies are set up in the Account File $|n| t|a|$ ization (INIT) in the General Ledger Monu.

FIMUNINL REPORT FOPAT EEJEATOR - FOCNAT PRINTINS

FROA REPORT COOE: HA:

\section{TO REPORT COOE: HA}

Enter the report code for the desired prilnt-out in both the FROM and TO flelds.

The report 111 start to print. After completion, the G/L Menu will display.

QUTEUI:

The STPR report is broken down into three sections. They are descrlbed on the following pages as they appear on the report.

\section{TIIRE}

Printed is the title record as 1 t 111 appear on the actual statement. Title IIne numbers are llsted on the left hand margin.

\section{2. cosurns}

col The col umn that is being detalled on the IIne.

Figure 6, Sample of Course A Training Manual 


\section{EXERCI8E}

1. Have the trainees run an unposted Purchase Journal (PJNL) with a date range of 01-JAN-87 through the last received date entered.

2. Review the PJNL with the trainees. $-$ PRESENTATION

3.11 POSTING TO THE GEKERAL LEDGER OBJECTIVE F: KNON HON TO POBT INVOICES TO THE GENERAL LEDGER.

A. After you have verified the report balances to the tape:

- Run the Purchase Journal (PJNL) for each batch of invoices to POST them to the General Ledger.

NOTE: When rerunning the report, answer $\mathbf{Y}$ to the question "Opdate General Ledger?".

- When running the posted version of the PJNL, it is very important to run the report for the proper date range.

- This is the same date range you entered when running the unposted version of PJNL.

This date range was printed in the heading of the un-posted PJNL you ran to balance with.

QOB8TIOK: What would happen if you ran the posted version for the wrong date range?

HOTs: The posting date to the $G / L$ will be the posting date entered when running the PJNL report.

Do not run the report for a recelved date range that crosses over two months (e.g., February 25 - March 10).

All G/L postings (including February's postings) will be posted to March 10 , resuiting in February and March postings being out of balance.

Figure 7, Sample of Course B Training Manual 
Perceptions of the worth of training at $\mathrm{XYZ}$ was definitely effected by the difference in trainer style and course materials. Trainees in Course A saw a need for more discussion and scenario type exercises which encouraged problem solving. Trainees in one particular class believed that there was too much lecture and not enough interaction and activity. Those who attended Course B felt otherwise. They enjoyed the scenario exercises, the discussions, the activities, and the opportunities to take the material they had covered and relate it to how they would be doing things back at their own site. Even though the participants believed that there was too much to learn in course $B$, they enjoyed the learning experience more than they did in Course $A$ where the amount of material was considered appropriate. These same reactions were expressed by trainees who attended class nine to twelve months ago. They remembered course $B$ as being more active and, in the words of one store owner, "less boring". He summed up many of the feelings of the people interviewed when he said, Course A dealt with material I find very dull. I'm not a numbers person so it wasn't easy to sit through this week. It was even tougher because it was almost all lecture. We worked at the terminal, but I was never really sure how I would use what we learned when I got home. Course B 
was different. The material was more varied, but so was the trainer's approach. He asked more questions and had us design procedures for our own system. We even played with blocks! One exercise had us go through the delivery process with toy trucks and blocks. I thought it was corny, but I remembered how to do it when I got back to the store.

This was an interesting comment because the same trainer taught both classes. The materials were, however, different in their approach. Therefore the trainer's style was different, and this particular trainee was more successful in learning the material.

It is important to note that $X Y Z$ recognizes the value of the Course B materials as an aid to more effective, long-term learning. They are currently in the process of revising Course A materials, as well as other training documents, in the same format. They are building in the types of activities which encourage trainer/trainee interaction because the feedback they have received from their customers has been so positive.

The research also looked at a second aspect of XYZ training, that of its effectiveness in preparing the trainees to actually use the system they had purchased. This was a critical factor in determining the program's worth, because if the material learned in class could not 
be transferred to the job site, then training was not successful. A primary reason for interviewing past trainees was to explore this aspect of the training program. These system users were best able to offer feedback on how valuable both Course A and course B were in preparing them to actually use their new system.

Everyone interviewed believed that the real education on the XYZ system didn't take place until it was in operation and they were forced to input data, carry out procedures, and print and read reports. However, they also realized that converting to the new system would have been extremely difficult without a strong foundation on system operation and specific job procedures.

There were two main things that led to a heightened degree of worth for both course A and B. The timing of the class was critical in course $A$. Customers were able to return home after the week of training, install the system, and immediately begin to use the information they had just learned. They began inputting customer and vendor files, setting up user-defined codes, and initializing a program security file. Timing was a disadvantage in the case of course B. Only a small portion of the information learned during this class was used right away. Some of the material, especially the sections on delivery procedures and inventory maintenance, was never used until after conversion. In 
one case this was nine months after course B. By then it was all forgotten, and during conversion the trainer had to reteach these procedures.

The structure of Course $B$, however, was more effective in training the users to actually operate the system. Many of the people interviewed remembered the discussions about how their specific system would operate and were grateful that the trainer had taken the time to work out procedures for their own employees. Course A involved much less of this type of discussion.

The third aspect of XYZ training which impacted its worth was the reference materials provided to the customers. For those attending course A, these materials included the manual and system documentation. For those attending Course B, there was the trainee workbook, four self-study manuals, and system documentation.

The course A manual contained a great deal of information, the majority of which was taken directly from the documentation. It was hard to follow in class, and equally difficult to reference back at the job site. There were many requests for a good index at the back of the manual so that information could be accessed quickly. In addition to the manual, many of the trainees returned home with lots of notes, most of which were written on yellow pads of paper. Many were lost or never used. The Course A manual contained so much information on each 
page that it was difficult to find a place to write in the book.

The Course $B$ manual was better organized and had plenty of room for notetaking. Therefore, users had more of a tendency to use the manual to find answers to questions instead of relying on the telephone. It was easier to use the manual as a reference tool.

The self-study manuals were quite successful in helping the users learn independently about things that weren't needed right away. For instance, month-end procedures aren't used until the system has been operational for at least a month, usually several months. Teaching these procedures during class would not be a good use of time. Before the new course B materials were designed, about a half-day was spent covering these procedures. Now, that time can be used more productively on discussion, activities, and review. The self-study manual allows the user to follow step-by-step instructions and work with the material when it is needed. The people interviewed found this approach to be extremely successful. In fact, several customers expressed an interest in cutting additional material out of the class and covering it in similar manuals. One customer expressed this idea in this way.

We spent at least four hours going over delivery procedures. But we couldn't even practice what 
we had learned until we had converted. I forgot just about everything and our trainer ended up re-teaching it to me and my warehouse staff. She should have just introduced the delivery process and then given us a self-study to work on a day or two before conversion. Then she could have reviewed it with us and walked us through the procedures the first time. That week (Course B) was so full that I had a hard time keeping up. We could have used the extra time. In summary, the researcher found the worth of XYZ training to be quite high. The timing of course A seemed to have the greatest impact on the ultimate value of the training. The worth of course $B$, or the ability of the trainees to transfer what they had learned to the workplace, was positively effected by the amount of time spent relating the course materials to the specific needs of the user. Discussion and activities regarding how the system would function within the customer's own environment made the training a useful, productive experience. The overwhelming opinion of the trainees who had been through both course $A$ and $B$ and had already returned to actually use the system was, however, that no matter how much you do in the classroom, you don't ever really understand it until you're up and running. one woman, a store manager, expressed her opinion this way. 
I thought I understood lots of what was covered in class. And I guess I did. But now that we've been on the system for a few months, I realize how much I didn't learn. The mistakes I made here at the store were the best teachers. Recommendations

1. Continue to revise all training materials in a format that encourages discussion, activities, and trainer/trainee interaction. This is especially important for course A materials. 2. Remove as much of the content from course $B$ as possible. Teach only what the trainees will need when they return to their site in order to prepare for conversion. Provide self-study manuals covering additional information (e.g., delivery procedures) so that users can work through it when it is needed. 3. Design manuals and documentation so that it is easy to find information. Provide an index and as many written procedures guides as possible. 4. Consider offering additional on-site time for trainers one or two months after conversion. By this time the trainees would have had time to discover what they hadn't learned and really needed. As one trainer put it, "let us go out there and rescue them before they drown". 


\section{Proposition Three}

The majority of trainers in end-user training programs come from an industry background with little or no training in educational methods. Training them to be good teachers is a critical step in the development of a successful training program.

\section{Related Findings}

The case study research did not entirely support this proposition. XYZ Company does attempt to hire trainers with experience in the home furnishings industry whenever possible. However, at this time only about one third of its trainers have this experience. It was found, however, that the trainers have little or no training in educational methods. In fact, very few trainers have had more than a one-day workshop in anything related to teaching. The pilot study, however, supported both the first annd second parts of the proposition, as all of the trainers came to the company (a VAR marketing its system to retail stores) with a retail background. These trainers also lacked any formal training in teaching methods.

The lack of education in how to be an effective trainer was identified as a major concern by company trainers and management. As evidenced in Figure 10, this was the first thing mentioned when asked about 
recommendations for improving training skills. Improving these skills involves a number of factors. Interviews with trainers, trainees, and management addressed these factors. Responses by these three groups, as well as observation on the part of the researcher, revealed the strengths and weaknesses of the trainers and led to recommendations about improving overall trainer effectiveness.

The researcher identified the following as important factors contributing to the success of a trainer: rapport and sensitivity; communication skills; presentation style; and teaching methods, including use of materials.

In the area of rapport and sensitivity, trainees involved in the observed classes were very pleased with the majority of the trainers and believed them to be friendly, concerned, sincere, and helpful. In only one case did they sense that the trainer was disinterested and lacked sensitivity to their needs. Past trainees remembered their trainers in the same positive way. Again, one person felt that the trainer was bored with the material and that this boredom resulted in a lack of rapport. It was interesting to note that in both instances where negative responses were given on this topic, customers were speaking about the same trainer. Overall, the personalities of the trainers and their attitude toward their customers was found to be a major 
strength of the XYZ program. Management echoed that same view when each person interviewed said that the best part of the training program was its people.

Communication skills of trainers, and especially listening and questioning, received mixed reviews. Trainers themselves recognized a need for more awareness on how to listen and how to ask good questions. A one-day workshop held about a year ago proved very popular, and there were many requests for a refresher course. One trainer noted his desire for further training, but also one factor that must be considered. Our whole job revolves around being able to hear our customers' problems, ask the right questions, and help them learn to solve these problems. One day of training in something so crucial to what we do is just a drop in the bucket. It only whetted our appetite. But it's hard to even think about another workshop when we can't even find time for a department meeting.

Trainees from both groups (current and past) agreed that further awareness of listening and questioning techniques would have improved the success of their training. In several cases, trainers were praised for their superior communication skills, but in most cases there was evidence of a lack of these skills. In those cases where listening and questioning were not seen as a 
problem, the materials being used by the trainer may have made a difference. All of these trainers used course B materials which were specifically designed to integrate questions and discussions in the training.

A third factor considered by the researcher was the presentation style of the trainers. Presentation style focuses on tone of voice, annoying or distracting habits, pace of presentation, ability to work with both groups and individuals, and control of the class.

overall, trainees reported a high degree of satisfaction with the presentation style of the trainers. No one noted any problems with tone of voice or distracting habits. Trainers, on the other hand, perceived themselves to be weaker in these areas than the trainees did. Several thought they had bad habits that might be annoying to people in the class. Several thought that they tended to drift into a monotone voice. They were pleased to hear that the trainees didn't share these perceptions.

Pace of presentation was more of a problem. This was especially true in Course B, where there is so much material to cover that trainees tended to feel overwhelmed and rushed. "When people are given too much knowledge in too short a time, panic sets in. Faced with new information, they need to practice new skills to see which areas fall into place and which don't" (Alessandra, 1987, p.3) . Panic was an emotion remembered by many of the 
past trainees and experienced by some of those in the observed classes.

In this case, trainers were also aware of the problem. They realized that they felt pressured to finish everything in the manual and that there just wasn't enough time. One trainer put it this way: It's a real dilemma for me. I know that if I cover everything, especially in course B, lots will go right over their heads. The second day is the worst, and when they get discouraged on Tuesday the rest of the week doesn't get much better. But if I leave things out then I feel that I'm cheating them. They won't know that the system can do these things, or print these reports, and they'll think we sold them a bill of goods. So I teach everything and hope most sinks in. If it doesn't, I teach it again at conversion. Although this trainer was speaking only for himself, others used the same approach. Trainees, however, wished that they had reduced the amount of material and taught only what was really necessary. They were not concerned that they would feel cheated. In fact, the opposite was true.

We gave up a week to come out and learn all we could, but we didn't expect to have to learn this much. Five days is too little time to really 
understand all of the material. I learned some of it, and I guess I'll figure out the rest when I needed it. I just wish that we hadn't bothered going over all those reports. We may never use them, especially not in the near future. When the same trainee was asked if she would have felt cheated by not knowing all the system was capable of, she contined, "Heavens no. In a way I feel more cheated because everything was so rushed. I know this is a powerful system, but I'd rather not know how powerful right now. It's a little overwhelming."

The final factor relating to trainer effectiveness was teaching methods. Teaching methods refer to how the trainer attempted to help the trainees learn the required material. Did he/she lecture? Was there enough time for discussion? Did the trainees have ample opportunity for hands-on activity using the terminals? Were the trainees given an overview of course material before beginning, and were there frequent reviews of what had been covered? As the review of the literature indicated, effective teaching requires an understanding of the people in the classroom. Teaching adults is not the same as teaching children. They have different backgrounds, different motivations, and their response to the learning process is shaped by many years of experience. The trainers in this study expressed little awareness of adult learning 
theory or, in fact, that there was anything unique about adult learners at all. In several cases they admitted that their teaching style was based upon the style of their high school or college teachers. Some were good, others not as good.

An important factor in teaching adults is the ability to relate what is being learned to the past and present experience of the trainees. It is important because it not only allows the trainees to better understand the new system, but it also validates their experience as being positive and valuable in preparing them to move to the new system. This ability to relate to the trainees' experiences is one area in which the XYZ trainers received mixed reviews. Some were praised by trainees for their ability to relate the new system to the way they were currently processing information. Others were given much lower marks because they tended to ignore this experience and concentrate only on the new, improved approach of the XYZ system. One trainee felt this way.

I realize that the way we've been doing things may be antiquated. Everyone else has computers and I've been doing the bookkeeping now for over fifteen years using a manual system. But it's worked for me and I am comfortable with it. I don't want a computer. I'm afraid of computers. And it bothered me because I felt I was being 
told that what I've been doing all these years was wrong.

Teaching methods of XYZ trainers was greatly effected by the training materials used in both Course $A$ and Course B. Differences in these materials were discussed earlier in the findings, and these differences contributed to the success of the trainers in the areas of lecture vs. discussion, hands-on activity, and presentation of both overviews and reviews of the course content. Course A lends itself to more lecture, while Course B guides the trainer through questions, discussions and exercises. Both classes encourage the use of hands-on activity, and this experience was much appreciated by the trainees. Overviews of material to be covered and periodic reviews were sorely missed in Course A. Again, they are built into course $B$, and if the materials are followed as designed, trainees receive a good understanding of how the system operates, how each part relates to the whole and to each other, and how their jobs effect the jobs of the other trainees. overviews are very important for understanding, as Alessandra (1987) illustrates with this example. New knowledge is easier to absorb when a clear picture of a goal is presented. Dr. John Lee, a leading management expert, demonstrates this principle in kis workshop by giving groups of 
participants a 70-piece puzzle to assemble. One group views a picture of the completed puzzle; the other groups put their pieces together without knowing what the finished product will look like. Consistently, the group with the picture finishes first. Why? They know their goal. They have the advantage of possessing a blueprint for success, which they tackle one bite-sized piece at a time (p. 3)

Frequent reviews are also important. Trainees felt that there was not enough time dedicated to reviewing material before they moved ahead to another topic. This led to confusion and frustration, especially during Course A. Even in Course B, where more time is spent on this type of activity, there was still a desire for more review. Trainees also felt that this review should include how the material directly related to their operation, e.g. how they would set up procedures or define user codes.

To summarize, the lack of education in how to be a good trainer was perceived to be a problem by trainers and trainees alike. Every trainer believed that he/she needed more awareness of teaching techniques and managing a class. They all felt that further education in communication skills was important and would add a great deal to their success. Many believed that the company 
had made a good start by offering a one-day workshop the previous year, but that it was only the beginning. As noted in the findings of Proposition One, lack of experience in the home furnishings industry was perceived by management to be a major weakness of the XYZ training program. Lack of formal education in how to be a good trainer was perceived to be a major weakness by the trainers themselves. No matter what their professional experience, these trainers need, and request, more training in educational methods.

\section{Recommendations}

1. The Director of Customer Support and the Manager of Training should meet with all of the trainers and brainstorm areas in which they would like further education. A long-range plan should then be developed to provide this education, either in the form of in-house workshops, videotapes or films, or attendance at off-site seminars or classes. 2. Make continuing education part of each trainer's annual goals and objectives. Talk about the training that will be pursued, either within the company or off-site, during personnel evaluations and salary reviews.

3. Whenever possible, recruit trainers who have, in addition to background in the home furnishings industry, experience as a trainer or as a student. 
It can be very beneficial to assume the role of the student in order to become more aware of the teaching process. This awareness can then result in improved teaching methods and sensitivity to the learner.

\section{Summary of Findings}

The three propositions identified at the beginning of the research were supported by the results of the evaluation process carried out in both the pilot study and the case study. The review of the findings demonstrated this support by summarizing the responses of the stakeholders interviewed, observations made by the researcher while attending several weeks of training classes, and a review of training materials.

It is important to remember that these findings are applicable only to the research discussed in this document. Kemmis (1983) expresses this note of caution in this manner:

Effective evaluation does not depend solely on research-based design and analysis methodology, nor must evaluation findings be widely generalisable to the whole universe of potential program settings which will differ from the settings studied in hundreds of dimensions. Similarly, interpretations and conclusions which are defensible when presented to one group may be quite differently received by another (p. 10). 
Chapter six

Summary, Conclusions, and Recommendations

Chapter Six is organized in four sections. The first section presents the findings of the study as they relate to the four research questions. The second section addresses the implications of the research on the customer training process and evaluation theory. Section three outlines recommendations for future research in both the training and evaluation fields. The final section summarizes the case study research.

The ideas presented in this chapter were based on the researcher's experience throughout the entire study and were formed with both the pilot study and the actual case study research in mind. Both processes were instrumental in providing information and insights into the use of naturalistic inquiry as a method for evaluating customer training.

\section{Research Questions}

At the beginning of this study, four research questions were identified. These questions addressed the appropriateness of naturalistic inquiry as an approach to evaluating customer training for computer system valueadded-resellers. In order to illustrate the use of this method and to demonstrate its effectiveness in this setting, thereby allowing the researcher to answer the four research questions, a case study evaluation was 
conducted using naturalistic techniques. The results of the case study were presented in the previous chapter. These findings specifically related to the study's three propositions, focusing on what the evaluator could learn about a customer training program using a naturalistic approach.

The primary purpose of this study was to show that a great deal of valuable information could be collected and analyzed through this approach, and that specific characteristics of naturalistic evaluation made the process an effective one. Each of the four research questions focus on this type of inquiry and its practical use within the business environment.

Research Question \#1

1. What characteristics of naturalistic evaluation make it an appropriate method for assessing end-user system training?

Wolf and Tymitz (1976-1977) define naturalistic inquiry by explaining some of the characteristics of this qualitative approach to understanding.

It is a process geared to the uncovering of many... important stories told by real people, about real events, in real and natural ways. The more general the provocation, the more these stories will reflect what respondents view as salient issues, the meaningful evidence, and the 
appropriate inferences... Naturalistic inquiry attempts to present 'slice of life' episodes documented through natural language and representing as closely as possible how people feel, what they know, and what their concerns, beliefs, perceptions, and understandings are (p.6). In order to evaluate a customer training program and to determine its effectiveness, it is important that the researcher uncover a variety of information about real events, taking place in natural settings, and representing how different people (e.g. trainers, customers) feel about the training process. The characteristics of naturalistic evaluation make it an ideal technique for this type of research. Guba and Lincoln (1981) outline these characteristics, which include the following:

1. The preferred research techniques are qualitative.

2. The criterion for quality is relevance.

3. The purpose of the research is discovery.

4. The primary instrument used for data collection is the inquirer.

5. Data collection and analysis takes place throughout the research.

6. The design is emergent.

7. The setting is the natural environment for what is being studied.

8. Analytic units are patterns. 
It was evident throughout the research that these eight characteristics facilitated the process and were, in fact, necessary for the successful completion of the case study. Qualitative techniques, such as interviewing and observation were critical to data collection. An important aspect of any training evaluation is to show the relevance of the training to the stakeholders. This relevance is demonstrated through a discovery process that unfolds throughout the evaluation. The inquirer is the main instrument for gathering information, and as this information is collected, the design of the research emerges. The entire process takes place in a natural setting, whether that be training classrooms, offices, or customer sites. And finally, conclusions are drawn by looking for patterns which are identified during data analysis.

In view of this, the researcher believes strongly that these characteristics of naturalistic inquiry make it a very appropriate technique for evaluating customer training.

There are several notes of caution, however, which should be considered by anyone attempting this type of evaluation. First, the evaluation process is always a political one.

Evaluation findings inevitably attach themselves to the reputations of the people who work on the 
program. They live with the consequences of the evaluation. The evaluator must take great care to control the production and distribution of information. An evaluation plan should specify the procedures to be adopted for information control. These will refer to such matters as the evaluator's role, access to the program setting, the negotiation of boundaries for the evaluation and the conduct of the study, negotiations about release of information and ownership of the evaluation data, and the like (Kemmis, 1983, p. 6) .

During the pilot study, it became evident that the company's trainers did not perceive their manager, the Manager of Training, to be as competent and communicative as she perceived herself to be. This was confirmed by her reaction to the evaluation report, in which trainer morale issues were addressed. Trainers felt they were treated unfairly at times, that they didn't receive the quantity or quality of feedback they needed, and that certain policies established by the Manager of Training were inappropriate. Although it was important that the evaluation report address these issues, they were not received well at first. In fact, management believed that the evaluation had gone beyond the agreed upon scope. Once the evaluator explained that morale issues 
were critical to the success of any training program and should be addressed during an evaluation, there was increased acceptance of this feedback. However, politically it would have been wise to confirm a mutual understanding of the boundaries of the evaluation before beginning the process.

A second note of caution concerns logistical problems which the evaluator may encounter. Ball (1983) addresses this concern:

It is possible that any participant observation may be carried off without problems or mishaps of any kind...but it is more likely that the researcher will encounter some difficulties and setbacks. The nature of participant observation is such that it is impossible to legislate in advance for every circumstance and occurrence, and that on many occasions the field worker will be left to improvise in order to maintain the continuity of his study or continue to follow up particular lines of enquiry that may otherwise be closed off to him (p. 59). The ability to improvise is a necessary quality of someone intent on doing a naturalisitic evaluation. The sheer logistics of scheduling interviews with trainers, especially if these trainers travel a great deal or spend long days in the classroom, can be frustrating. In both 
the pilot study and the case study research it was difficult to find times to talk with all of the trainers. In one instance, an interview was rescheduled four times. Each time the trainer thought he would be available, an emergency came up. On one occasion another trainer became ill and he had to take over the class. On a second occasion a customer called in with a crisis situation and the trainer spent three hours on the phone talking him through his problems. Rescheduling of interviews happened more often than would have been desired, and it was frustrating.

Trainers were not the only people with whom it was difficult to arrange meetings. Management, especially the presidents of both companies, were extremely busy. They were totally in favor of the evaluation and cooperated in every way possible, but their schedules made it hard to find time to sit and talk for more than a few minutes. These interviews finally occurred and were very important to the evaluation process, but they were also a source of frustration.

As Ball (1983) noted, the ability to improvise is critical. The characteristics of naturalistic evaluation that make it such an effective and valuable approach also make it a source of frustration and logistical mishaps. 
Research questions \#2 and \#3

2. How can this method be used to evaluate the major components of an end-user training program?

3. Which naturalistic techniques are most appropriate for gathering information about each component.

Research questions \#2 and \#3 are very closely related. In order to explain how the naturalistic approach to evaluation can be used, it is necessary to do two things. First, identify the major components of this type of training program. second, describe which data gathering techniques are most appropriate for learning about each of these major components.

Keep in mind that training programs are developed, staffed, and affected by a number of people -trainers, customers, salespeople, company management. These people may not be directly involved with the program, but they are stakeholders. One of the steps suggested by stake (1975) is to "talk with clients, program staff, and audiences -- everyone in and around the program -- to gain a sense of their posture with respect to the evaluand and the purposes of the evaluation." In fact, Van Maanen notes that "it is usually from the client's perspective that the most important general evaluation issues may be pinpointed" (1983, p.49) . Schuerman (1983) outlines three objectives of a qualitative evaluation, all of which involve interaction 
with and feedback from a variety of sources. The first is "the production of as complete a description as possible of the components of the program, particularly the interactions among program participants, both staff and clients." The second calls for "a thorough description of the context of the program. What forces external to the program affect its development and course? What do participants bring to the program in the way of beliefs, skills and knowledge? What social and political factors influence the program?" The third objective is "an understanding of how staff and clients experience the program. The researcher attempts to capture how it feels to be a worker or client in the program and to describe what kinds of changes they go through during its course."

There are sources other than people with which the evaluator must also be concerned. Guba and Lincoln (1985) explain that

While it is the case that the major and sometimes only data collection instrument utilized in naturalistic inquiry is the inquirer him- or herself, the sources that instrument utilizes may be both human and nonhuman. Human sources are tapped by interviews and observations... Nonhuman sources include documents and records" (p.267). 
The evaluator must, therefore, consider multiple sources of evidence in order to complete a thorough evaluation of customer training. The use of multiple sources of evidence was supported by the wealth and variety of information gathered during the research (See Table 4).

It is important to note that there are a great many customer training programs in operation today. Each computer system VAR may approach customer training very differently. Therefore, no one list of program components or sources of evidence can be drawn up to accurately describe each and every one. The components of the training programs evaluated during this research can, however, be identified. It is up to the reader to determine how closely this program matches his/her own. As Walker (1983) noted, "The problem of generalizing ceases to become a problem for the author. It is the reader who has to ask what is there in this study that I can apply to my own site, and what clearly does not apply" (p.49)

The first component of both the pilot and case studies was the training staff. Each trainer played an important part in the success of the customer training program. Feedback from as many trainers as possible was important in order to understand the strengths and weaknesses of the overall program as well as determining specific steps which could be taken to improve the program. 
MULTIPLE SOURCES OF EVIDENCE

Variety of Information Gathered from Sources

\begin{tabular}{|c|c|c|c|c|c|c|}
\hline Trainers & Trainees & Past Trainees & $\begin{array}{l}\text { Company } \\
\text { Management }\end{array}$ & Sales Paps & Observatlon & Aovlow of Matorlals \\
\hline $\begin{array}{l}\text { Course contont } \\
\text { Training materials } \\
\text { Training mothods } \\
\text { Mosit } \\
\text { Worth } \\
\text { Sirongths/weak- } \\
\text { nesses } \\
\text { Training/marketing } \\
\text { Inlorketion } \\
\text { Pocommendations }\end{array}$ & $\begin{array}{l}\text { Course content } \\
\text { Trainlng materials } \\
\text { Training moihods } \\
\text { Trainer offective. } \\
\text { noss } \\
\text { Morit } \\
\text { Worth } \\
\text { Strengthe/weak- } \\
\text { nosses } \\
\text { Pocommendations }\end{array}$ & $\begin{array}{l}\text { Couree content } \\
\text { Training materials } \\
\text { Training mothods } \\
\text { Trainer elfectlve- } \\
\text { nesa } \\
\text { Morit } \\
\text { Worth } \\
\text { Strengthe/weak- } \\
\text { nesses } \\
\text { Pocommendations }\end{array}$ & $\begin{array}{l}\text { Evolution of training } \\
\text { Company growth } \\
\text { Foio of training } \\
\text { Strongths/woak. } \\
\text { nosses } \\
\text { Training/marketing } \\
\text { interaction } \\
\text { System Implemen- } \\
\text { tation guldo }\end{array}$ & $\begin{array}{l}\text { Training/marketing } \\
\text { Interaction } \\
\text { System Implemen- } \\
\text { tation guldo }\end{array}$ & $\begin{array}{l}\text { Tralning materials } \\
\text { Training methods } \\
\text { Trainer offoctive. } \\
\text { noss } \\
\text { Morit } \\
\text { Traines Involvement } \\
\text { Trainer/fralnee inter- } \\
\text { action } \\
\text { Strengths/weak- } \\
\text { nesses }\end{array}$ & $\begin{array}{l}\text { Morth } \\
\text { Worth } \\
\text { Traineo involvement } \\
\text { Pros on t a t I o n } \\
\text { methods }\end{array}$ \\
\hline
\end{tabular}

Table 4, Multiple Sources of Evidence 
The researcher used open-ended interviewing as the method for gathering information from trainers. Although an interview guide was loosely followed, the most valuable information was frequently unsolicited, flowing freely from the conversation or as a result of probing on the part of the interviewer.

Listening by itself, of course, does not always lead to depth of understanding. Probing is necessary to get behind the expected response or test the significance of what you are being told. Taking up cues from the interviewee, asking them to elaborate or explain why they adopted a particular view or introducing a theme for comment are all means of extending the initial response (Simons, 1983, p.119). In addition to trainer feedback through interviews, the evaluator was able to learn a great deal about the effectiveness of training techniques through observation. Ball (1983) describes observation in this manner: One common element of all participant studies is the attempt and effort by the researcher or researchers involved to know about the actors world from the inside, as they know it themselves, to understand the social phenomena by sharing in the interpretation and handling of them in everyday life (p. 37). 
Observing trainers in action was one very effective means of gaining insight into the training process. As discussed in the study's findings, specifically in regards to propositions \#2 and \#3, the researcher collected information about trainer style, teaching methods, listening and questioning techniques, rapport, and sensitivity to the learners. It would have been very difficult to do this without personal observation of trainers at work in the classroom. The researcher got to know the "actors" as they performed on their own stage.

A second component of the study's training program was the various training classes. Information about these classes was gathered through participant observation. In this case, two different types of training classes were offered. One course focused on accounting, while a second course focused on the merchandising aspects of the computer system. Three actual classes were observed, each with their own trainer and group of participants; one merchandising class, and two accounting classes.

By observing the classes it was possible to learn a great deal about both the merit and the worth of the training. For instance, the researcher noted the degree of involvement of class participants, as well as the type of trainer/trainee interaction which took place. As discussed in the findings about trainer effectiveness, 
the researcher observed several important things: varying degrees of trainee involvement in the learning process; listening and questioning ability ranging from excellent to poor; presentation styles ranging from strict pedagogy to a far more androgogical approach to teaching. All of these observations contributed to the conclusions and recommendations of the researcher.

Interviews also played an important part in evaluating the training classes. Assessing the worth of training is a critical part of the evaluation process, and the best source of information on this topic were the people who were previously trained on the system. Customers who had attended classes nine to twelve months ago and later returned to their store to actually use the system provided valuable insight to the relevance of the training. As noted by Robinson (1985), "If training carred out away from the job cannot be transferred effectively to the job, it will be abortive and a total waste of everybody's time" (p.181). This same group of stakeholders also contributed information about the merit of the training as well as the effectiveness of the training staff.

Another group of interviewees also provided feedback on the effectiveness of the training classes. This group included those people who participated in the courses observed by the researcher. Conversations revealed 
their perceptions of how much worth the training would prove to have once they returned to use the system at their store. They also revealed a great deal of information about the characteristics of an effective trainer and offered recommendations about how to improve activities, trainer/trainee interaction, and classroom management.

In addition to the staff and the courses which comprised this particular customer training program, there were two other groups of people who provided valuable input to the evaluation. The first group consisted of several members of company management. They contributed their knowledge of how the training program evolved and its role in the company's development. They also offered insights on the programs' strengths and weaknesses as well as the future of training in the company. The technique used to gather this information was also the open-ended interview. This naturalistic technique was extremely effective in allowing the researcher to dig for answers to questions as they arose. It would not be wise to evaluate a customer training program without considering the perceptions of these key people, and a very effective way to uncover these perceptions is by interviewing. The final component considered in the evaluation of this particular training program was the materials used. 
In both cases, training materials included similar types of materials, including course workbooks, self-study manuals, a system implementation guide used prior to formal training classes, a trainer checklist, and system documentation. Review of these materials was important to assessing both the merit and worth of the training. The professional appearance of these materials -- or lack of professional appearance in some cases -- was evaluated, as was the usefulness of the materials to the trainees both during class and upon returning to their store. Interviews with trainers, current trainees, and previous course participants included questions about the workbooks, self-study manuals, and system documentation. Interviews with the manager of training and the sales representatives provided information about the system implementation guide. Merit and worth of these materials were discussed in the findings relating to proposition \#2.

Before concluding this discussion, consider one important note of caution. When planning an evaluation of this type, keep in mind that there are many different components which should be considered. Each company will be different. In one company there may be important people who contribute to the success, or lack of success, of customer training yet who work behind the scenes. For instance, during the pilot study it became evident that 
the relationship between the marketing and training departments had a detrimental effect on the trainers' morale. It was only through interviewing these trainers that this was made clear. The researcher had no plans to interview anyone in marketing, but after discussing the situation with trainers, plans were revised. When planning the case study research, interviews with this group of stakeholders were also scheduled.

The point to remember is to be flexible throughout the process. First, be flexible in the initial stages when the evaluation is being designed. Don't assume that what was important to this study will also be important to another study. And be open to adding new components to the evaluation design. Second, be flexible during the process. If new materials are uncovered or a new group of stakeholders is identified, be ready to revise plans as needed.

To summarize a response to research questions \#2 and \#3, naturalistic inquiry proved very effective as a method for evaluating this particular customer training program. The major components of the training, which included the training staff, company management, training classes, and related materials, were explored through a variety of naturalistic techniques. These techniques included interviewing, observation, and review of materials. For each component, the researcher found 
various evaluation techniques to be appropriate. From each component, the researcher learned new and different things and, most important, learned to be flexible. Again, it is the responsibility of the reader to determine which training program components to include in a comprehensive evaluation, to inake adjustments as needed, and to determine which data gathering techniques will be most effective.

The flexibility of the method and its openness, the use of a combination of supplementary techniques and the possibility of making participant observation work in the context of other types of field study, all add up to make it difficult to define there being one single type or variety, there will be as many variations of the participant observation as there are studies done in new research settings (Ball, 1983, p. 91).

\section{Research Question \#4}

4. How can this information best be presented to companies interested in performing naturalistic evaluation of their training program(s)?

A review of the literature revealed a lack of practical information on conducting evaluations of customer training. In fact, there appears to be very little information on any aspect of customer training as 
it relates to teaching end-users to use a new computer system. The literature that does deal with evaluating training focuses primarily on quantitative techniques. A qualitative approach to this process is much needed.

The researcher believes that a guide to naturalistic evaluation for use by a training manager or other professional would be very valuable. This guide would benefit the person interested in looking closely at his/her company's ongoing training program. It would describe the naturalistic method and explain why it is appropriate in this type of setting. It would also take the reader, step-by-step, through the evaluation process and illustrate the process as clearly as possible. Samples of interview and observation guides would provide additional guidance, as would recommendations on analysis of the data collected during the evaluation process.

In response to this research question, and as a means of addressing this perceived need, Chapter seven of this study is entitled "A Guide To Evaluating Customer Training: A Naturalistic Approach". This guide was designed on the basis of the pilot study, the actual case study research, and the researcher's previous experience in the field of customer training and evaluation. Implications of the Research

A review of the literature showed a wealth of information on training, primarily in the areas of 
employee and management development. Very little emphasis was placed on customer training, although an increasing number of companies are responsible for teaching their customers how to use their products or services. It would behoove professionals in the training field to look more closely at customer training techniques. Teaching hard, technical skills, such as those required for the operation of a computer system, is very different from teaching the soft, human relations skills associated with human resource development. There is also a need for further examination of the evaluation process, especially as it relates to customer training. So much depends upon the satisfaction of the customer, and training that customer is a critical step toward achieving a high level of satisfaction. Yet for a company to operate a successful training program, it must be willing to evaluate what it is doing and then take steps to make necessary improvement. Evaluation is extremely important, but frequently neglected. There is a special need for more attention to qualitative approaches to evaluation. Quite a bit of literature exists on how to conduct quantitative studies, but this type of study may not provide the type of information needed. Guba and Lincoln (1981) explain why qualitative evaluation is appropriate, especially for the type of evaluation discussed in this study. 
Merit might conceivably be determined through a scientific inquiry; since merit is context free, it is possible that statements of merit might take some generalized form. But it is certain that worth cannot be determined in that way. In order to determine values and motivational factors...the inquirer has to deal with persons in each context. Field studies are called for, and field studies cannot be carried out experimentally but only naturalistically (p. 82). Therefore, the researcher believes that there are three primary areas which deserve further emphasis and study on the part of both theorists and practicitioners. These areas are customer training, evaluation of training, and naturalistic evaluation of training.

\section{Recommendations for Future Research}

1. Future research should further examine the use of naturalistic evaluation in customer training programs, either for other computer system valueadded-resellers, or for companies training their customers to use other types of products or services. 2. Future research should explore the use of naturalistic inquiry as an appropriate method for evaluating alternate types of training, such as employee and management development, supervisory training, and sales training. 
3. Future research should study the quantitative methods currently being used to evaluate customer training programs and to identify the advantages and disadvantages of these methods.

4. Future research should examine the education and professional experience of successful trainers employed by companies who conduct customer training. This research should attempt to identify characteristics of successful trainers working in this type of setting. 5. Future research should explore the relationships between marketing and training departments in computer system vendors. The perceptions which each holds of the other might lead to some very interesting conclusions about why problems arise in both the training and sales deparments after the sale of a computer system has been closed. 6. Future research should examine the practice of both pedagogical and andragogical approaches to teaching in the customer training classroom. The effects of each approach on the trainees' understanding and skill mastery, as well as attitude and motivation, should be studied. 


\section{Summary}

This case study demonstrated that naturalistic inquiry was not only an appropriate, but highly effective, technique for evaluating a computer system VAR's customer training program. The findings suggest that, when approached with organization and flexibility, a great deal of valuable information can be collected about various components of the training program through the use of naturalistic research techniques. This information can be analyzed using qualitative data analysis methods in order to identify patterns and trends. These can then lead the evaluator to conclusions and recommendations that will ultimately improve the effectiveness of the training. 
Chapter Seven

\section{A Guide To Evaluating Customer Training:}

\section{A Naturalistic Approach}

\section{Foreward}

There are several potential audiences for a guide to customer training evaluation. First, training professionals may be curious about a qualitative approach toward this task. These professionals need not be employed by computer system VARs, but instead have an interest in exploring the use of naturalistic inquiry within any business environment. Second, managers within the computer industry, and specifically those working for value-added-resellers, might find this approach to customer training evaluation useful. They have an obvious stake in the effectiveness of their training and should consider its evaluation an important part of their company's operation. Third, educators or researchers with an interest in the practical use of qualitative methods may also find this particular application of naturalistic inquiry informative.

In order to reach each of the above groups most effectively, it would be necessary to write the guide at various levels of sophistication. Training professionals familiar with training terminology would understand concepts that VAR managers might find foreign to them or confusing. Researchers might find the more simplistic 
approach too elementary. For this reason, the guide that follows was designed for one type of audience only. It was written for training professionals working within the computer system VAR industry and would require revisjon in order to be suited to other audiences. Introduction

The word evaluation frequently strikes a note of fear in those who are tasked both with evaluating something or someone and those who are going to be evaluated. Yet we all spend a good part of our life involved in this process. We evaluate the results of our most recent tennis or golf game. We evaluate the meal we just enjoyed at our favorite restaurant. We evaluate the success of our child's first semester at college or the competence of a new auto mechanic. Evaluation is a part of Iife to all of us, yet it is also the cause of many anxious moments.

Evaluation very simply enables us to look at what has taken place in a specific situation or environment and to determine how it compares with what we had hoped would happen. It is then possible to draw a number of conclusions: Was it worth the money? Are there ways to make improvements next time? Should the activity be eliminated in the future, or should more time be dedicated to it? 
As training professionals, it is important that we recognize the importance of evaluation. Training is an important factor in a company's growth and profitability and it should not be taken lightly. Management should be enthusiastic -- not fearful -- about stepping back and taking an objective look at how it trains both its employees and, where applicable, it customers. Yet there are many companies who do not do a very good job of training evaluation.

There are reasons, of course, for neglecting this important task. First, there may be insufficient time and/or personnel to carry out an evaluation. The process requires training staff time and the cooperation of other employees. Management may have other priorities. There are sales to be made, capital goods to be purchased, employees to be hired, and transactions to be negotiated. Second, training is frequently neglected or given a lower status within the company than other departments such as marketing or engineering -- departments viewed as potential money makers. Third, evaluating a training program is something that must be done by skilled personnel. It requires an understanding of many aspects of the business, including organizational goals, related technology, end-user needs, and trainer effectiveness. Even more important, evaluating training requires the ability to look into the future. It is not only 
important to look at what is needed now, but what will be needed one, two, five years from now.

Why Evaluate Customer Training?

A review of the literature shows that the vast majority of material related to evaluation of training programs focus on human resource development, specifically management and employee training. The area of customer training has received little attention. Yet more and more companies are faced with this responsibility. This is especially true in the computer industry. Its tremendous growth has resulted in an increase in demand for training users of both computer hardware and software. Many companies which sell computer systems have assumed this responsibility, frequently without the benefit of advance planning. Customer training is, in many cases, far more reactive than proactive. Yet excellent customer training is critical to the success of a computer company. In his most recent book, Thriving on Chaos, Peters notes that "training your customer's employees becomes yet one more opportunity to redefine responsiveness and make it an offensive marketing strategy" (1987, p.117).

Customer training is important from several perspectives. First, it can have a significant impact on the company's bottom-line. When a new customer is welltrained on a new system, word spreads to other potential 
customers and a reputation for quality develops. This often leads to increased sales. Second, good customer training prepares the end-user to become independent. When a customer is not well-trained on a system, he must rely on help from the people who sold it to him. This can be very expensive. Customer support, either via telephone or personal contact, costs money. Third, creative, confident users look for new ways to use a system. They seek other applications which will help them do their job more efficiently. This desire for new applications often results in the need for additional hardware or enhanced software.

It follows, then, that customer training can be a critical factor in a company's growth and success. Therefore, it should also follow that every company involved in customer training wants to look objectively at its training program. This is especially true for companies who have experienced a period of rapid growth. What used to be adequate training for new customers may now be inadequate.

A Naturalistic Approach to Evaluation

How, then, should this evaluation take place? Much has been written about assessing a company's management development and employee training. There are guides for doing quantitative studies involving pre-tests and posttests, attitude surveys, needs assessments, and other 
types of research. Yet customer training requires a special approach because it involves a whole different group of people - customers. So much hinges on their satisfaction and independence. Therefore, it is important that the evaluator examine the various components of the training program. This involves looking objectively at the training facilities, training materials, documentation, and audio-visual aids. It requires observation of training classes and workshops. It also involves feedback from all concerned parties -trainers, trainees, users and non-training personnel (e.g., company management and sales reps). These people can be considered part of the "stakeholding audience". Guba (1981) defines this audience as "a group of persons having some common characteristics that has some stake in the performance (or outcome or impact) of the evaluation, that is, is somehow involved in or affected by the entity being evaluated". The evaluation process should focus on each aspect of the training program as well as look holistically at the overall program.

one approach to evaluating customer training which can be very successful is that of naturalistic inquiry. What is naturalistic inquiry? The best way to explain it is by describing some of its characteristics.

1. Data collection is performed with a person or people as the prime data collection instrument(s) . Techniques include interview, observation, and the analysis of documentation and records. 
2. Intuitions, apprehensions, and gut feelings are admitted and built upon. They are not denied or avoided. The evaluator's experience is valued and interaction is encouraged.

3. Natural settings are preferred over laboratory settings. These natural settings may include the training classroom or, in the case of customer training, the site where the product is actually being used. There is no attempt at creating a controlled environment.

4. The research and the final report are designed ahead of time only in the broadest sense. The design, and the method for reporting results, will evolve as the inquiry takes place. Naturalistic evaluation is a dynamic, holistic approach that allows the evaluator to become involved in the training process and to interact with everyone who plays a part in this process. It encourages feedback through personal interviews, observations within a natural setting, examination of related materials, and use of both experience and intuition on the part of the evaluator. It is a qualitative approach to evaluation that can provide the evaluator with answers to a wide variety of questions.

Performing an evaluation using a naturalistic approach can also be far less intimidating than performing a quantitative study. There are many of us in 
the training field who cringe when we remember our college statistics class, or find ourselves confused when we read journal articles that report the results of quantitative studies. We are more likely to become motivated at the prospect of doing what we do naturally -watching, listening, questioning, and drawing conclusions. Yet there is much more to the process.

Naturalistic evaluation requires planning activities, setting realistic schedules, and identifying the members of the stakeholding audience. These will differ for every company, depending upon the structure and make-up of the training program. This approach also involves gathering information from valuable resources, using various data collection techniques (personal interviews, observation and review of materials). The evaluator must then sort through this information and analyze it in order to draw valid conclusions. This guide should help you do just that. It is designed to take you through an evaluation process from beginning to end.

In order to better illustrate the use of this approach, let's look at one company, TBM Computer systems, who recently completed a comprehensive evaluation of its customer training. Keep in mind that this is just one example of how a company used a naturalistic approach to evaluation. Every company who decides to use this approach will need to identify its own strategies, resources, and specific procedures. 
TBM Computer Systems: An Evaluation of Customer Training

\section{Background}

TBM is a VAR (value-added-reseller) who markets computer hardware and applications software to home improvement stores. They currently have over 300 users who have installed their systems over the past five years. The company has been experiencing a period of tremendous growth, and it has been enjoying a nice increase in profits. Yet there is a downside to this success story. As TBM's user base has grown, so have the demands on its limited training staff. Every company who purchases a system receives training for its employees. These employees attend two one-week courses prior to system installation. They learn to use the system for all of the accounting functions as well as for the merchandising side of the business. Training takes place both at TBM's corporate offices and at the customer's sites.

TBM's training director was concerned that customers were not receiving adequate instruction in how to use their systems. Customer support costs were skyrocketing, and it seemed as if many of the telephone calls related to concepts and basic skills which should have been covered in class. Trainers were also concerned because they were spending so much time on airplanes. Burn-out was a frequent complaint. In order to determine the success of customer training, and to identify steps that could be taken to improve this aspect of customer service, TBM embarked on a comprehensive evaluation of customer training. 


\section{Five steps of Evaluation}

Five steps were identified as important to the evaluation process.

1. The first step was to plan the overall evaluation. This involved identifying the components of customer training as well as the most effective techniques for evaluating each component. It was decided that portions of the company's two week-long training classes would be observed. Personal interviews would be conducted with as many members of the stakeholding audience as possible. This included ten trainers, three of the company's ten sales representatives, the vice-presidents of marketing and human resource development, and the president of the company. In addition, two groups of customers would be interviewed. Those who were currently attending the training classes would be interviewed at the conclusion of the course. A sample of customers who had trained on the system about a year earlier would also be interviewed by telephone.

2. The second step was to design data collection instruments where needed and to actually gather the information from a variety of sources. Five separate interview guides were generated for use with trainers, current class participants, customers who had undergone training the previous year, sales reps, and company management. 
3. The third step was to sort all of this information and to arrange it in an order that facilitated data analysis. This involved compiling a list of codes which could be used to categorize the data.

4. The fourth step was to actually analyze the data and to draw conclusions about the various components of the customer training program. Analysis involved visually displaying the categorized data in order to identify patterns or trends.

5. Once the analysis was complete, the evaluator reported his findings and made recommendations for modifications to the training program based on these conclusions.

Let's take a closer look at this five-step process.

\section{Planning}

TBM decided to look at the following components of its customer training: a) training class structure; b) trainer effectiveness and morale; c) customer satisfaction; d) training materials and system documentation; e) training facilities. The training director recognized the importance of feedback from a variety of sources and decided that observation of classes and personal interviews with trainers and customers would provide the best information. He also recognized that a very valuable source of feedback would 
be those system users who had attended training classes some time ago. They would be in a good position to judge how effective the training had actually been. After all, they had experienced the formal training and had returned to their jobs where they actually used the system. The final group of people included in the interviews were sales representatives. Marketing and training departments are often at odds. Marketing sells the product that the trainers must teach the customer to use. If promises are made that can't be kept, or if capabilities are discussed that are unrealistic, the trainer frequently is put in the position of dealing with an unhappy user. On the other hand, trainers may make demands on salespeople that they feel are unrealistic or unnecessary, leading to resentment and frustration for both groups. Interviews with sales reps led to valuable insights into this very important departmental interaction.

The following ten-week plan was generated based on the components identified and the TBM training staff schedule.

Week One: Design and test interview guides for use with trainers and users.

Week Two: Begin interviews with trainers. Revise interview guides as needed. Review training materials and documentation. 
Week Three: Observe Course 1 (Accounting)

Interview trainees attending course 1 .

Revise interview guides as needed.

Week Four: Complete interviews with trainers.

Begin interviews with users trained on

the system one year ago.

Week Five: Observe Course 2 (Merchandising)

Interview trainees attending course 2.

Week Six: Complete interviews with users trained

on the system one year ago.

Interview company management and other

sales reps.

Week Seven: Complete transcription of all observation

and interview notes.

Begin sorting and arranging data using

coding and categorizing techniques.

Week Eight: Analyze data by identifying patterns and

trends.

Week Nine: Complete data analysis.

Draw conclusions and formulate

recommendations.

Week Ten: Prepare final evaluation report and

present to company management for

discussion. 


\section{Data Collection}

Before beginning the interviews or observations, it was important to design guides which would assist in recording the information gathered. The training director designed several interview guides. These guides are included here for reference only. Keep in mind that every company is different, and every evaluator will have different concerns and interests. The questions included in these guides may be relevant to some evaluations and not to others.

The first interview guide was designed for use with trainers (See Figure 8). It focused on trainer preparation, teaching methods and materials, education and experience, technical expertise, and morale. The second guide was for use with class participants (See Figure 9). It included questions about course materials, trainer effectiveness, relevance of training to their jobs, and motivation and attitude. A third guide was designed to learn more about how customers, trained on the system a year ago, perceived the value of that training (See Figure 10). They were asked to reflect upon its effectiveness. Was the amount of information taught appropriate? Were the materials valuable both during class and as a reference/training tool back on the job? Would alternative approaches be more effective in conveying this information more 
INTERVIEW GUIDE FOR USE WITH TRAINERS

Professional Experience:

1. How long have you been with this company?

2. What is your professional background, both in training and in other fields?

3. What type of instruction did you receive in training methods prior to working in this field?

Where did you receive this instruction?

4. What type of instruction did you receive in the course content which you now teach (e.g., system operation, applications)?

How did this instruction take place (e.g., attending classes taught by other trainers, reading documentation)?

5. How would you change the way you were trained to do your job: course content?

How to be a trainer?

Training Materials:

6. What materials do you use when you teach?

7. What do you like about these training materials?

8. What would you like to see improved?

9. What training aids do you use when you teach (e.g., overheads, slides)?

10. What additional training aids would make you a more effective trainer? What benefits do you see them providing to both the trainer and the trainees?

Figure 8, Interview Guide For Trainers 
Course content (for each course taught):

11. Is the amount of material covered during the class appropriate?

If there is too much material, what topics might be eliminated and taught either at a later date or in another manner (e.g., self-study manual)?

12. When is the material you cover during the course used by the trainees - immediately upon returning to the job, several months later, at year-end?

13. How well do you think the majority of the trainees understand the material you cover?

14. What new teaching techniques (e.g., exercises) might help the trainees understand more of what you cover in class?

15. How do you integrate "hands-on" training into the course? To what extent do you use this type of training?

16. How do you use the system documentation during training? To what extent? Why do you think this is or isn't an important part of training?

Post-class Training:

17. When you receive telephone calls from customers who have returned to use their own system on the job, what types of questions do they typically ask?

18. How might training on the system be modified to eliminate some of these telephone calls?

19. If customers do refer to their system documentation and attempt to answer their own questions before calling you, why do you think they do so? Where did they learn to do this?

20. What additional materials might be provided to customers in order to help them answer questions and thereby decrease their reliance on you? 
Other Issues:

21. What do you like best about your job as a trainer?

22. What do you like least about your job as a trainer?

What do you think might be done by either yourself or the company to make the situation better?

23. What type of training would you like to receive to help you become a more effective trainer?

24. How do you think management perceives the training function in your company?

25. How do training and marketing interact in your company?

26. How well do you think marketing understands the training function, and vice versa?

27. What might be done to improve the overall relationship between training and marketing? 


\section{INTERVIEW GUIDE FOR USE WITH CLASS PARTICIPANTS}

1. Why did you attend this class?

2. Did you listen attentively to the information presented? If you responded No, explain:

3. Did you arrive on time and return from breaks as requested by the trainer?

If you responded No, explain:

4. Did you participate willingly in the workshop activities? If you responded No, explain:

5. What is your experience working with computers?

6. Do you believe that the course was taught at a skill level appropriate for you?

If No, why not?

7. Do you think the course was the proper length (number of days, hours per day, etc.)?

If No, why not?

8. How would you describe the training facilities (building, room, break/lunch areas)?

9. Prior to attending the class, how much of an understanding did you have of the overall workings of the system?

From where did you get this understanding?

Figure 9, Interview Guide For Class Participants 
10. Please describe your reaction to the following course materials:
a. Overheads
b. Use of board or flipchart
c. Workbook
d. Other materials

11. Who will you be responsible for training when you return to the store? What information/materials were you given to help you train these people? How do you think they will help you do this training? What additional materials would be valuable for training purposes?

12. Please evaluate the course trainer in the following areas:
a. Sensitivity/rapport
b. Presentation/teaching style
c. Language (appropriate to skill level)
d. Iistening and questioning skills
e. Ability to relate system functions to your specific situation

13. How would you rate the amount of material presented during the course?

14. How will the information presented during the class be used by you at your job?

15. When do you anticipate using the skills and information you acquired during the course?

Would you want to change the timing of the course in any way (earlier, later)?

16. When you return to the store and you have questions, what procedures will you follow in order to find an answer or solve a problem? 
INTERVIEW GUIDE:

FOR USE WITH CUSTOMERS WHO ATTENDED PREVIOUS CLASSES

Pre-class Preparation:

1. What information/skills would have been helpful to you prior to attending the training session.

2. How familiar were you with the company's product prior to attending the training session?

3. What was your understanding of the system's overall operation - the "big picture?" From where did you acquire this understanding?

4. What were your expectations for this training session? How were these expectations met?

During Training:

5. Was the length of the course appropriate? If no, why not?

6. Was there too much/too little material covered in class? If so, how would you recommend modifying the course content/schedule?

7. Was material covered in class that you did not use when you first began operating the new computer system?

8. Which topics/activities did you enjoy the most? The least?

9. What training materials were used during the class?

10. Which of these materials were you able to use upon returning to your job? How did you use them?

11. How would you suggest changing these materials to make them more useful?

Figure 10, Interview Guide For Customers Attending Previous Classes 
12. What training aids (e.g., overheads, slides) were used during class? How were they helpful? Distracting?

13. What supplemental materials would have made the training more effective?

14. What were the most effective aspects of the trainer's teaching style? What were the least effective?

15. What types of activities (e.g., discussions, exercises) might have made the course content easier to understand and use?

Post-Class

16. Who did you train on the new system upon returning to your job after training?

17. What material did you cover during this training?

18. What methods did you use to carry out this training?

19. What materials did you use as aids during this training?

20. If you didn't use any of the materials provided to you during your training, what was the reason?

21. What would have made these materials more useful?

22. What additional training materials would have made this process go more smoothly for both you and the people you trained?

23. How were you able to convey the "big picture" of the new system to your trainees?

24. When questions about the system's operation or applications came up after training, and especially after you were actively using the system, what were these questions generally about?

25. What are your ideas or suggestions about changing this training in order to make it a more useful and practical experience? 
efficiently or cost-effectively? A fourth guide was developed for use with the company president and two vice-presidents (See Figure 11). This guide focuses on questions about the company's growth and the development of the training department. It also explores perceptions about training, its importance to the company, and its reputation among users. A fifth guide was designed to be used with sales reps (See Figure 12) who were asked about their perceptions of what trainers do, how the marketing and training should relate to each other, responsibilities of both departments, and problems they encounter due to training activities.

Prior to its use, each interview guide was pilot tested by the training director. He conducted one interview using each of the guides in order to identify topics which had been neglected, questions which needed rewording, or areas which required more or less consideration than planned. Interviews were then conducted with all participants over a five-week period. Interview guides were semistructured and openended, which allowed the interviewer to ask for facts as well as opinions and attitudes. This format encouraged the respondents to elaborate on their answers as needed. During each interview, extensive notes were taken. At the end of each day, or immediately following an interview whenever possible, these notes were transcribed into typewritten form. 


\section{INTERVIEW GUIDE FOR COMPANY MANAGEMENT}

1. Briefly describe the evolution of your company. (To be asked of only one person or researched through available materials.)

2. What is your relationship to the training function? What responsibilities do you have that relate to training?

3. How is training marketed in your company? (Included in purchase price, sold separately, etc.?)

4. When engaging in strategic and long-range planning, how much consideration do you give to customer training?

5. How do you include company growth projections in your budgeting for training (personnel, materials, etc.)?

6. What do you consider to be the strengths of your customer training?

The weaknesses?

7. If you do training both on-site and off-site, what are the advantages of both? The disadvantages?

8. What do you perceive to be the relationship between training, customer support, and sales in your company?

9. What characteristics/experience do you think are important for a successful trainer in your company?

10. What are some of the problems which your company/trainers encounter that interfere with successful training?

Figure 11, Interview Guide For Company Management 
INTERVIEW GUIDE FOR SALES REPRESENTATIVES

1. Briefly describe the typical sales cycle for a sales rep in your company?

2. At what points in the sales cycle does marketing interface with the training department?

3. What do you perceive the relationship to be between marketing and training?

4. What types of problems do the trainers create for you once a system has been sold?

5. What problems do you think trainers might believe you create for them?

6. Do you have any suggestions for how the training/marketing relationship might be improved?

Figure 12, Interview Guide For Sales Representatives 
An observation guide was also prepared for use during the two training classes (See Figure 13). This guide was quite general, but it served as a good tool for summarizing the notes recorded during observation (See Figure 14). A guide for evaluating training materials was also helpful for recording impressions about the various instructor's manuals, participant workbooks, and system documentation used during training (See Figure 15). Sorting and Charting Data

Once all of the interviews, observation, and evaluation of materials were completed, the next step was to sort all of the data and arrange it in a logical order so that it could be analyzed. As you can imagine, the evaluator was faced with many pages of notes. They contained facts, impressions, and insights gathered from very valuable sources. In order to sort the data logically and efficiently, he devised a coding system. coding involves the design of a classification system used by the evaluator to sort material into categories. In this case, the training director generated a list of codes that represented aspects of training which he considered important to the evaluation (See Figure 16). A preliminary list of codes was drawn up before beginning the interview and observation processes. This list was refined as time went on. 


\section{TRAINING OBSERVATION GUIDE}

TRAINING SITE:

Overall Appearance

Parking

Telephone

TRAINING ROOM:

Comfort

Table/chair arrangement

Distractors (e.g. noise, smoke)

\section{TRAINER:}

Appearance

Presentation style

Pace

Listening ability

Questioning ability

Control of class

Rapport

Sensitivity to learners

Figure 13, Training Observation Guide 
TRAINING OBSERVATION GUIDE

TRAINING SITE:

Overall Appearance Excellent site. Professional, clean, no smoking allowed. spacious, part of a beautiful business park.

Parking No problem at all. Lots of space and short walk.

Telephone several available to customers. Free calls.

TRAINING ROOM:

Comfort Tables for 2. Comfortable chairs. spacious desks. Temperature varies from too hot to too cold. Tough to regulate with computers. No smoking allowed.

Table/chair arrangement Two chairs to a table, six tables. Each table has one terminal. Lots of space for writing notes and reading. Good visibility of instructor/screen.

Distractors (e.g. noise, smoke) No smoke. pretty quiet, except for printer. Fan a little noisy but not a distraction.

\section{TRAINER:}

Appearance Very professional. Always wears a suit. Not too formal but not at all casual.

Presentation style Mellow, friendly. Good rapport with trainees. Works from front of room but walks around and spends lots of time helping individuals. Good sense of humor.

Pace Excellent for learner. Not rushed, not boring.

Listening ability Excellent listener. Customer commented on how good a listener she is, both on-site and in the classroom.

Questioning ability Also excellent. Uses lots of open-ended questions. Knows how to find out if the trainees really understand the material.

Control of class No problem, but only 2 in class.

Rapport Excellent - she's worked with them before and they seem to get along very well.

Sensitivity to learners Rnows what to cover based on what they'il be using at the store. Reviews briefly when detail not necessary. Understands their operation well.

Figure 14, Sample Page of Observation Guide 
GUIDE FOR EVALUATING TRAINING MATERIALS

Needs

Excellent Improvement Poor Comments

ORGANIZATION

Easy to Reference

Table of Contents

Index

APPEARANCE

Type style

Type size

Illustrations

Page layout

Binder (s)

IANGUAGE

Written for Layperson

Grammar and spelling

CONTENT

Aids for Understanding

(e.g., flowcharts)

Up to Date

Technically Accurate

COMMENTS:

Figure 15, Guide For Evaluating Training Materials 
EVOLUTION OF TRAINING

$\begin{array}{lll}\text { EV: COMPANY GROWTH } & \text { EV-GRO } \\ \text { EV: } & \text { TRAINING MGT.EXPER. } & \text { EV-MGTEXP } \\ \text { EV: } & \text { TRAINER SCHEDULES } & \text { EV-T3 } \\ \text { EV: } & \text { MATERIAL DEVELOPMENT } & \text { EV-MAT } \\ \text { EV: } & \text { TRAINER TRAINING } & \text { EV-T3 }\end{array}$

EV: TRAINER TRAINING EV-T3

MERIT OF TRAINING

$\begin{array}{lll}\text { M: } & \text { FACILITIES } & \text { M-FAC } \\ \text { M: } & \text { ROOM-TEMPERATURE } & \text { M-ROOM/TEMP } \\ \text { M: } & \text { ROOM-COMFORT } & \text { M-ROOM/COMF } \\ \text { M: } & \text { ROOM-LIGHTING } & \text { M-ROOM/LITE } \\ \text { M: } & \text { SETUP-AUDIOVISUAL } & \text { M-SET/AV } \\ \text { M: } & \text { INSTRUCTOR'S GUIDE-LOOK } & \text { M-IG/LOOK } \\ \text { M: } & \text { INSTRUCTOR'S GUIDE-EASE } & \text { M-IG/USE } \\ & \text { OF USE } & \\ \text { M: } & \text { INSTRUCTOR'S GUIDE-ORG } & \text { M-IG/ORG } \\ \text { M: } & \text { WORKBOOK-LOOK } & \text { M-WRK/LOOK } \\ \text { M: } & \text { WORKBOOK-ILLUSTRATIONS } & \text { M-WRK/ILLUS } \\ \text { M: } & \text { WORKBOOK-EASE OF USE } & \text { M-WRK/USE } \\ \text { M: } & \text { WORKBOOK-VALUE TO TRAINEE } & \text { M-WRK/VALUE } \\ \text { M: } & \text { CONTENT-QUANTITY } & \text { M-CONT/QUAN } \\ \text { M: } & \text { CONTENT-DEGREE OF DIFF } & \text { M-CONT/DIFF } \\ \text { M: } & \text { CONTENT-ORGANIZATION } & \text { M-CONT/ORG } \\ \text { M: } & \text { CONTENT-BIG PICTURE } & \text { M-CONT/BIG } \\ \text { M: } & \text { CONTENT-TOPIC FLOW } & \text { M-CONT/FLO } \\ \text { M: } & \text { PARTICIPANTS-MAKEUP } & \text { M-PART/MAKEUP } \\ \text { M: } & \text { PARTICIPANTS-COOPERATION } & \text { M-PART/COOP } \\ \text { M: } & \text { PARTICIPANTS-COMPETENCE } & \text { M-PART/SMARTS } \\ \text { M: } & \text { TRAINING DATABASE } & \text { M-DBASE } \\ \text { M: } & \text { SUPPLEMENTAL MATERIALS } & \text { M-SUPPMAT } \\ & & \end{array}$

Figure 16, List of Codes for Analysis 
WORTH OF TRAINING

$\begin{array}{lll}\text { W: } & \text { TRAINER SUPPORT } & \text { W-TRNRSUPP } \\ \text { W: } & \text { SUPPORT MATERIALS } & \text { W-MAT/SUPP } \\ \text { W: } & \text { RELATE TO CUSTOMER SITE } & \text { W-CUSTSITE } \\ \text { W: } & \text { UNDERSTAND BIG PICTURE } & \text { W-BIG } \\ \text { W: } & \text { DATA PROCESSING BASICS } & \text { W-DPBASICS } \\ \text { W: } & \text { UNDERSTAND BENEFITS } & \text { W-BENEFITS } \\ \text { W: } & \text { GOOD QUESTIONING } & \text { W-? } \\ \text { W: } & \text { USE OF TESTS/REVIEWS } & \text { W-TEST } \\ \text { W: } & \text { BASIC COMPUTER SKILIS } & \text { W-COMPUSE } \\ \text { W: } & \text { HANDS-ON PRACTICE } & \text { W-HANDSON } \\ \text { W: } & \text { REPORTS } & \text { W-REPORTS } \\ \text { W: } & \text { USE OF DOCUMENTATION } & \text { W-USEDOC } \\ \text { W: } & \text { PROBLEM SOLVING } & \text { W-SOLVE } \\ \text { W: } & \text { PRACTICAL TIPS } & \text { W-TIPS } \\ \text { W: } & \text { TRAIN OTHERS } & \text { W-OTHERS } \\ \text { W: } & \text { RETROSPECTIVE/LACKING } & \text { W-RETRO/IACK } \\ \text { W: } & \text { RETROSPECTIVE/STRENGTHS } & \text { W-RETRO/STRENGTH } \\ \text { BUB-ULITE } & \end{array}$

TRAINER AS TEACHER

$\begin{array}{ll}\text { TRN: RAPPORT } & \text { TRN-RAPP } \\ \text { TRN: ONE-ON-ONE SKILLS } & \text { TRN-ONE } \\ \text { TRN: GROUP SKILLS } & \text { TRN-GROUP } \\ \text { TRN: IISTENING SKILLS } & \text { TRN-LISTEN } \\ \text { TRN: QUESTIONING SKILLS } & \text { TRN-? } \\ \text { TRN: RELATE TO REAL-WORLD } & \text { TRN-REALWORLD } \\ \text { TRN: INDUSTRY EXPERIENCE } & \text { TRN-IND/EXP } \\ \text { TRN: COMPUTER BACKGROUND } & \text { TRN-COMP/EXP } \\ \text { TRN: FORMAL EDUCATION } & \text { TRN-EDUC } \\ \text { TRN: JOB TRAINING } & \text { TRN-OJT } \\ \text { TRN: TEACHING METHODS } & \text { TRN-METHODS } \\ \text { TRN: TRAINING AIDS } & \text { TRN-AIDS } \\ \text { TRN: STRENGTHS } & \text { TRN-PLUS } \\ \text { TRN: WEAKNESSES } & \text { TRN-MINUS } \\ \text { TRN: HOW MANAGEMENT PERCEIVES } & \text { TRN-MGT } \\ \text { TRN: HOW SALES REPS PERCEIVE } & \text { TRN-SALES }\end{array}$

LEARNER

$\begin{array}{ll}\text { LRN: COMPUTER BACKGROUND } & \text { IRN-COMP/EXP } \\ \text { LRN: ATTITUDE TOWARD SYSTEM } & \text { LRN-ATT } \\ \text { LRN: JOB AT CUSTOMER SITE } & \text { LRN-JOB } \\ \text { LRN: MOTIVATION } & \text { IRN-MOT } \\ \text { LRN: HANDS-ON ACTIVITY } & \text { LRN-HANDSON } \\ \text { LRN: RELATE TO EXPERIENCE } & \text { LRN-EXPER }\end{array}$


Once the list of codes was generated, the next step was to code the data. Coding actually began during the data collection process, usually as soon as interview/observation notes were transcribed. After all interviews and observations took place, coding was completed and the data was ready to be displayed in a format for analysis.

Data display involved the use of two types of charts: checklist matrices and role-ordered matrices. These matrices allowed the evaluator to visually record data in order to track emerging patterns and draw conclusions about the various components of the training program. A checklist matrix (See Figure 17) was used to display input from the people interviewed -- trainers, customers (current and past trainees), and company management. It was also used to display information collected during observation of training and evaluation of materials. Role-ordered matrices (See Figure 18) were used to sort data from two groups: trainers, and class participants. Analysis and Conclusion-Drawing

once information was entered into the matrices, it could then be analyzed. Patterns and themes were identified in order to draw conclusions about the various aspects of TBM's customer training. By using visual displays -- in this case, charts which organized coded data into categories -- analysis of the many pages of 
EXAMPLE OF A CHECKLIST MATRIX

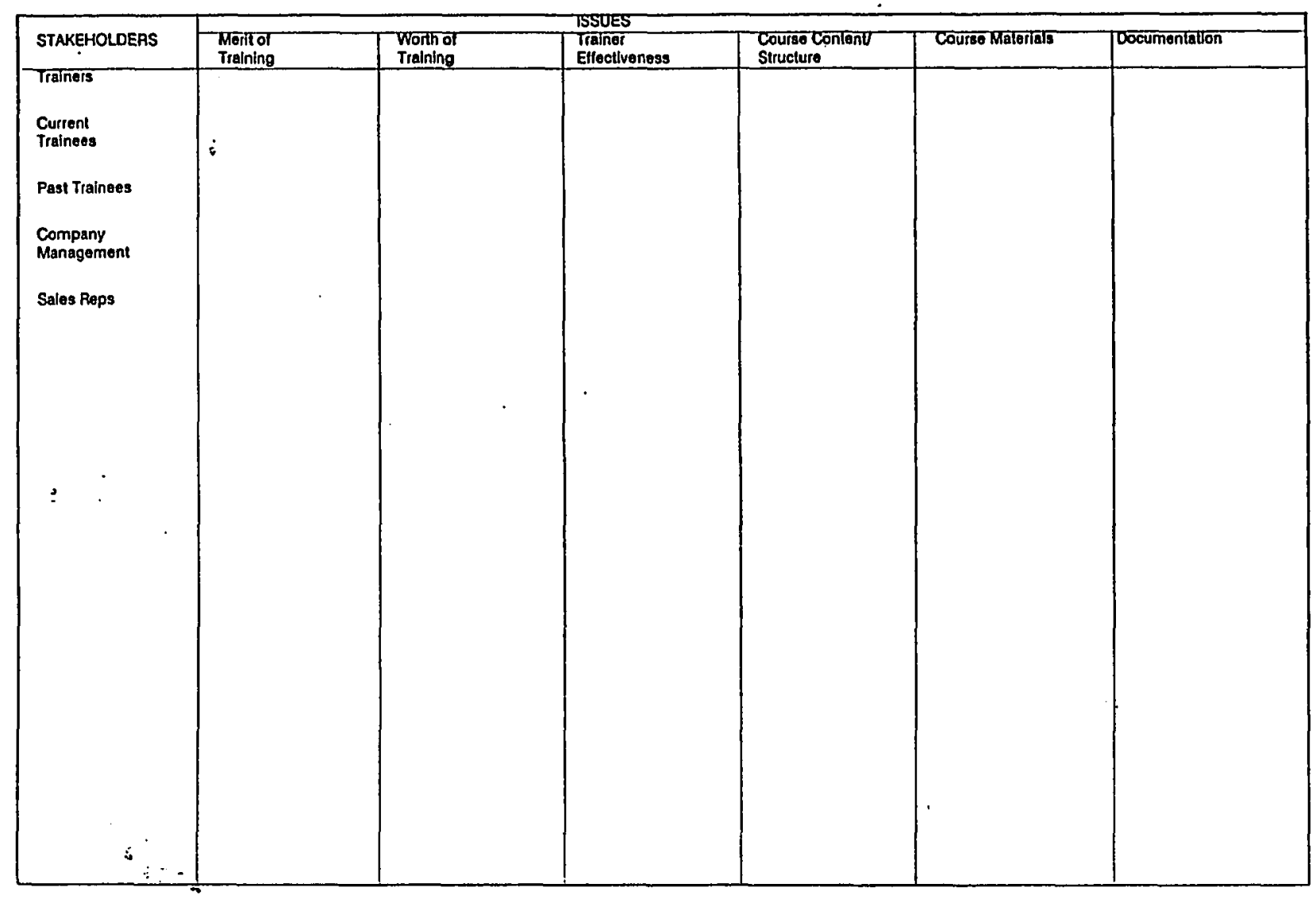

Figure 21, Example of a Checklist Matrix 
EXAMPLE OF A ROLE-ORDERED MATRIX

Responses By Company Management

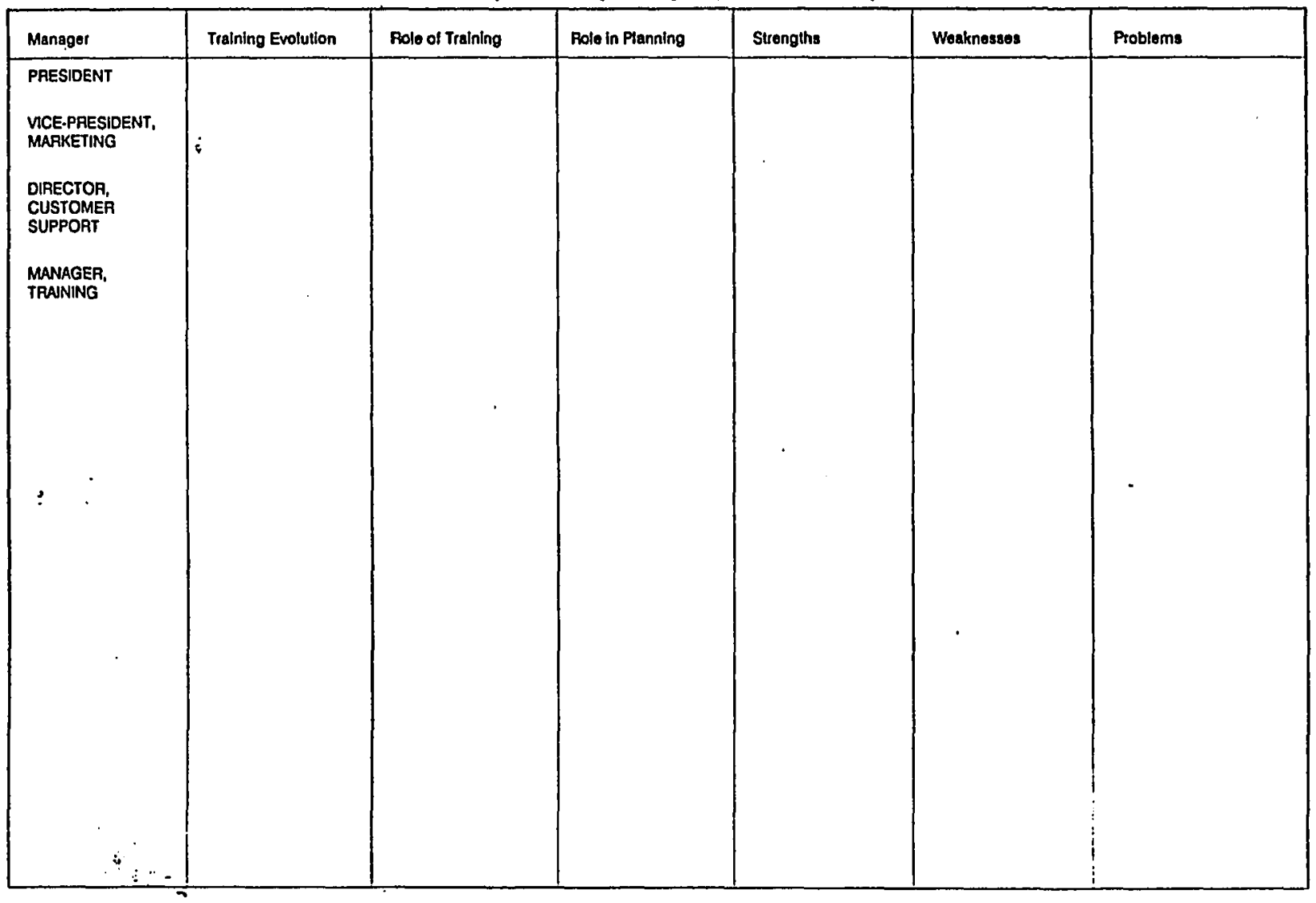

Figure 22, Example of a Role-Ordered Matrix

Reproduced with permission of the copyright owner. Further reproduction prohibited without permission. 
transcripts and notes was simplified. This type of data analysis is designed specifically for the type of qualitative data which is generated during a naturalistic evaluation.

The final step in the evaluation was to generate recommendations for improving customer training at TBM. The training director reviewed all of the findings and, after considering budget and personnel restraints, identified specific guidelines for enhancing existing materials, courses, and personnel. These findings and recommendations were presented to company management and the training staff and an action plan was generated. Practical Tips For Success

Naturalistic evaluation involves the activities which training professionals normally engage in -- observation, listening and questioning, review of materials, program planning and analysis of information -- but it is not a simple process. It involves a great deal of planning as well as a significant investment of time and energy. The results, however, can mean tremendous improvement in your training program. If you recognize the importance of evaluation and decide to engage in the process, consider using the naturalistic approach outlined here. For your further edification, and to make your job a little easier, consider these words to the wise. 
1. Include as many people as you can in the evaluation. It is important that you interview every trainer, not just those who have the most experience or those who you believe will have the best ideas. If you limit your study, you risk missing some very important feedback, and you also risk hurting feelings. Both should be avoided. 2. Give the people you interview every opportunity to provide the valuable information you are looking for. Ask only open-ended questions, those which cannot be answered with a simple "Yes" or "no". True, it's more work for you, but the objective of this type of evaluation is to promote communication, not close it down prematurely. Be flexible during interviews, and dig...dig...dig.

3. Don't neglect sources of information just because they don't fall into one of the categories mentioned here. If you know of someone whose ideas and insights might be of value to you -- a particularly satisfied, or dissatisfied, customer; your predecessor in the training department; the training director of a similar company -- talk with them. Be open to new ideas and new sources of information. 4. Take your time! This is a time-consuming process and shouldn't be rushed. Give yourself time to enjoy the task. Allow yourself time for reflection. You 
have the opportunity to learn a great deal about something very important to your company and its customers. Make the most of it.

\section{References}

For additional information on the evaluating training programs, the naturalistic evaluation process, or qualitative data analysis, refer to the following:

Ball, S. (1983). Participant observation as a method of research. The conduct of fieldwork. Victoria: Deakin University Press.

Biklen, S. K. and R. Bogdan (1986). On your own with naturalistic evaluation. In New directions for program evaluation, $\underline{30}$, San Francisco: Jossey-Bass.

Bogdan, R. C. and S. K. Biklen (1982) d Qualitative research for education: An introduction to theory and methods. Boston, MA: Allyn and Bacon.

Guba, E. G. (1987) . Naturalistic evaluation. In Cordray, D. S., H. S. Bloom, and R. J. Light (Eds.). Evaluation practice in review. San Francisco, CA: Jossey-Bass, 23-43.

Guba, E. G. and Y. S. Lincoln (1981) . Effective Evaluation. San Francisco, CA: Jossey-Bass.

Hamblin, A.C. (1974) . Evaluation and control of training. London: McGraw-Hill.

Kemmis, s. (1983) A guide to evaluation design. In Case study methods: The conduct of fieldwork. Victoria: Deakin University, p. 1-32.

Lincoln, Y. S. and E. G. Guba (1986). But is it rigorous? Trustworthiness and authenticity in naturalistic evaluation. In D. D. Williams (Ed.). New directions in program evaluation. San Francisco, CA: Jossey-Bass, 73-83.

MacDonald, B. and R. Walker (1983). Case study and the social philosophy of educational research. In Perspectives on case study: Naturalistic observation. victoria: Deakin University Press. 
Margolis, F. H. and C. R. Bell (1986). Instructing for results. San Diego, CA: University Associates.

Mayo, G. D. and P. H. DuBois (1987). The complete book of training: Theory, principles, and techniques. San Diego, CA: University Associates.

Miles, M. B. and A. M. Huberman (1984). Qualitative data analysis: A sourcebook of new methods. Beverly Hills, CA: Sage Publications.

Patton, M. (1980) . Qualitative evaluation methods. Beverly Hills, CA: Sage Publications.

Smith, J. K. (1983). Quantitative versus qualitative research: An attempt to clarify the issue. Educational Researcher, $12(3), 6-13$.

stake, R.E. (1983). The case study method in social inquiry. Case study: An overview. Victoria: Deakin University Press.

Stake, R.E. (1983). Program evaluation, particularly responsive evaluation. In G. F. Madaus, M. Scriven, and D. L. Stufflebeam (Eds.). Evaluation models: viewpoints on educational

and human services evaluation. Boston, MA: Kluwer-Nijhoff.

Van Maanen, J., Ed. (1979) . Qualitative methodology. Beverly Hills, CA: Sage Publications.

Van Maanen, J., J. M. Dabbs, Jr., and R. R. Faulkner (1982). Varieties of qualitative research. Beverly Hills, CA: Sage Publications.

Williams, D. D. (1986). When is naturalistic evaluation appropriate? In D. D. Williams (Ed.), Naturalistic evaluation. San Francisco, CA: Alfred A. Knopf, 85-92.

Zemke, R. and T. Kramlinger (1987). Figuring things out: A trainer's guide to needs and task analysis. Reading, MA: Addison-Wesley. 
APPENDIX A

Interview/Observation Guides Used During Pilot study 


\section{INTERVIEW GUIDE:}

FOR USE WITH CUSTOMERS WHO ATTENDED PREVIOUS CLASSES

\section{Pre-Class Preparation:}

1. What information/skills would have been helpful to you prior to attending the training session.

2. How familiar were you with the company's product prior to attending the training session?

3. Did you have an understanding of the "big picture", especially in the following areas: What would the new system do for you?

How would each department be effected?

How would the new system impact your company as a whole?

4. What did you expect to learn during this training session? Were these expectations met?

During Training:

5. Was the length of the course appropriate? If no, why not?

6. Was there too much/too little material covered in class?

7. Was material covered in class that you did not use when you first began operating the new computer system?

8. Which topics/activities did you enjoy the most? The least?

9. What training materials were used during the class?

10. Which of these materials were you able to use upon returning to your job? How did you use them?

11. How would you suggest changing these materials to make them more useful? 
12. Were any training aids (e.g., overheads, slides) used during class? Were they helpful?

13. What supplemental materials would have made the training more effective?

14. Was the trainer's teaching style effective? If so, what did you like best? If no, what didn't you like?

15. What types of activities (e.g., discussions, exercises) might have made the course content easier to understand and use?

Post-Class

16. Who did you train on the new system upon returning to your job after training?

17. What material did you cover during this training?

18. What methods did you use to carry out this training?

19. What materials did you use as aids during this training?

20. If you didn't use any of the materials provided to you during your training, what was the reason?

21. What would have made these materials more useful?

22. What additional training materials would have made this process go more smoothly for both you and the people you trained?

23. How were you able to convey the "big picture" of the new system to your trainees?

24. When questions about the system's operation or applications came up after training, and especially after you were actively using the system, what were these questions generally about?

25. Do you have any further ideas or suggestions about changing this training in order to make it a more useful and practical experience? 
INTERVIEW GUIDE FOR USE WITH TRAINERS

Professional Experience:

1. How long have you been with this company?

2. What is your professional background, both in training and in other fields?

3. What type of instruction did you receive in training methods prior to working in this field?

Where did you receive this instruction?

4. What type of instruction did you receive in the course content which you now teach (e.g., system operation, applications)?

How did this instruction take place (e.g., attending classes taught by other trainers, reading documentation)?

5. How would you change the way you were trained to do your job:

Course content?

How to be a trainer?

Training Materials:

6. What materials do you use when you teach?

7. What do you like about these training materials?

8. What would you like to see improved?

9. What training aids do you use when you teach (e.g., overheads, slides)?

10. Are there additional training aids which would make you a more effective trainer? 
Course Content (for each course taught):

11. Is the amount of material covered during the class appropriate?

If there is too much material, what topics might be eliminated and taught either at a later date or in another manner (e.g., self-study manual)?

12. When is the material you cover during the course used by the trainees - immediately upon returning to the job, several months later, at year-end?

13. How well do you think the majority of the trainees understand the material you cover?

14. What new teaching techniques (e.g., exercises) might help the trainees understand more of what you cover in class?

15. How much time do you spend on "hands-on" training where the trainees are actually using the new system?

16. Do you use the system documentation during training? To what extent?

Post-class Training:

17. When you receive telephone calls from customers who have returned to use their own system on the job, what types of questions do they typically ask?

18. How might training on the system be modified to eliminate some of these telephone calls?

19. Do customers refer to their system documentation and attempt to answer their own questions before calling you?

20. What additional materials might be provided to customers in order to help them answer questions and thereby decrease their reliance on you? 


\section{Other Issues:}

21. What do you like best about your job as a trainer?

22. What do you like least about your job as a trainer?

23. What type of training would you like to receive to help you become a more effective trainer?

24. How do you think management perceives the training function in your company? 
INTERVIEW GUIDE FOR USE WITH CLASS PARTICIPANTS

1. Why did you attend this class?

2. Did you listen attentively to the information presented? If you responded No, explain:

3. Did you arrive on time and return from breaks as requested by the trainer?

If you responded No, explain:

4. Did you participate willingly in the workshop activities? If you responded No, explain:

5. Did you have an acceptable attitude that facilitated learning?

If No, explain:

6. What is your experience working with computers?

7. Do you believe that the course was taught at a skill level appropriate for you?

If No, why not?

8. Do you think the course was the proper length (number of days, hours per day, etc.)?

If No, why not?

9. How would you describe the training facilities (building, room, break/lunch areas)?

10. Prior to attending the class, how much of an understanding did you have of the overall workings of the system?

From where did you get this understanding? 
11. Please describe your reaction to the following course materials:
a. Overheads
b. Use of board or flipchart
c. Workbook
a. Other materials

12. What information/materials were you given to help you train other employees upon returning to your store?

Are these materials adequate?

13. Please evaluate the course trainer in the following areas:
a. Sensitivity/rapport
b. Presentation/teaching style
c. Language (appropriate to skill level)
d. Iistening and questioning skills
e. Ability to relate system functions to your specific situation

14. How would you rate the amount of material presented during the course?

15. How will the information presented during the class be used by you at your job?

16. When do you anticipate using the skills and information you acquired during the course?

Would you want to change the timing of the course in any way (earlier, later)? 


\section{INTERVIEW GUIDE FOR COMPANY MANAGEMENT}

1. Briefly describe the evolution of your company. (To be asked of only one person or researched through available materials.)

2. What is your relationship to the training function?

What responsibilities do you have that relate to training?

3. How is training marketed in your company? (Included in purchase price, sold separately, etc.?)

4. When engaging in strategic and long-range planning, how much consideration do you give to customer training?

5. Do you anticipate company growth when budgeting for training (personnel, materials, etc.)?

6. What do you consider to be the strengths of your customer training?

The weaknesses?

7. Do you do your training on-site or off-site?

How would you rate your training facilities?

8. What do you perceive to be the relationship between

training, customer support, and sales in your company?

9. What characteristics/experience do you think are important for a successful trainer in your company?

10. What are some of the problems which your company/trainers encounter that interfere with successful training? 
GUIDE FOR EVALUATING SYSTEM DOCUMENTATION

Excellent Improvement Poor Comments

ORGANIZATION
Easy to Reference
Table of Contents
Index

APPEARANCE

Type style

Type size

Illustrations

Page layout

Binder (s)

I.ANGUAGE

Written for Layperson

Grammar and spelling

CONTENT

Aids for Understanding

(e.g., flowcharts)

Up to Date

Technically Accuraṫe

COMMENTS : 


\section{TRAINING OBSERVATION GUIDE}

\section{TRAINING SITE:}

Overall Appearance

Parking

Telephone

\section{TRAINING ROOM:}

Comfort

Table/chair arrangement

Distractors (e.g. noise, smoke)

\section{TRAINER:}

Appearance

Presentation style

Pace

Listening ability

Questioning ability

Control of class

Rapport

Sensitivity to learners 
PARTICIPANTS:

\# of people

Who attended? Responsibilities?

Characteristics (e.g., computer experience, age)

Level of involvement

Skill mastery

\section{MATERIALS:}

Instructor's guide

Trainee workbook

Supplemental materials

Visual aids

FINDINGS :

OVERALL RECOMMENDATIONS: 


\section{APPENDIX B}

Interview/Observation Guides Used During Case Study Research 


\section{INTERVIEW GUIDE:}

FOR USE WITH CUSTOMERS WHO ATTENDED PREVIOUS CLASSES

\section{Pre-Class Preparation:}

1. What information/skills would have been helpful to you prior to attending the training session.

2. How familiar were you with the company's product prior to attending the training session?

3. What was your understanding of the system's overall operation - the "big picture?" From where did you acquire this understanding?

4. What were your expectations for this training session? How were these expectations met?

During Training:

5. Was the length of the course appropriate? If no, why not?

6. Was there too much/too little material covered in class? If so, how would you recommend modifying the course content/schedule?

7. Was material covered in class that you did not use when you first began operating the new computer system?

8. Which topics/activities did you enjoy the most? The least?

9. What training materials were used during the class?

10. Which of these materials were you able to use upon returning to your job? How did you use them?

11. How would you suggest changing these materials to make them more useful? 
12. What training aids (e.g., overheads, slides) were used during class? How were they helpful? Distracting?

13. What supplemental materials would have made the training more effective?

14. What were the most effective aspects of the trainer's teaching style? What were the least effective?

15. What types of activities (e.g., discussions, exercises) might have made the course content easier to understand and use?

Post-class

16. Who did you train on the new system upon returning to your job after training?

17. What material did you cover during this training?

18. What methods did you use to carry out this training?

19. What materials did you use as aids during this training?

20. If you didn't use any of the materials provided to you during your training, what was the reason?

21. What would have made these materials more useful?

22. What additional training materials would have made this process go more smoothly for both you and the people you trained?

23. How were you able to convey the "big picture" of the new system to your trainees?

24. When questions about the system's operation or applications came up after training, and especially after you were actively using the system, what were these questions generaliy about?

25. What are your ideas or suggestions about changing this training in order to make it a more useful and practical experience? 


\section{INTERVIEW GUIDE FOR USE WITH TRAINERS}

Professional Experience:

1. How long have you been with this company?

2. What is your professional background, both in training and in other fields?

3. What type of instruction did you receive in training methods prior to working in this field?

Where did you receive this instruction?

4. What type of instruction did you receive in the course content which you now teach (e.g., system operation, applications)?

How did this instruction take place (e.g., attending classes taught by other trainers, reading documentation)?

5. How would you change the way you were trained to do your job: course content?

How to be a trainer?

\section{Training Materials:}

6. What materials do you use when you teach?

7. What do you like about these training materials?

8. What would you like to see improved?

9. What training aids do you use when you teach (e.g., overheads, slides)?

10. What additional training aids would make you a more effective trainer? What benefits do you see them providing to both the trainer and the trainees? 
Course content (for each course taught):

11. Is the amount of material covered during the class appropriate?

If there is too much material, what topics might be eliminated and taught either at a later date or in another manner (e.g., self-study manual)?

12. When is the material you cover during the course used by the trainees - immediately upon returning to the job, several months later, at year-end?

13. How well do you think the majority of the trainees understand the material you cover?

14. What new teaching techniques (e.g., exercises) might help the trainees understand more of what you cover in class?

15. How do you integrate "hands-on" training into the course? To what extent do you use this type of training?

16. How do you use the system documentation during training? To what extent? Why do you think this is or isn't an important part of training?

Post-class Training:

17. When you receive telephone calls from customers who have returned to use their own system on the job, what types of questions do they typically ask?

18. How might training on the system be modified to eliminate some of these telephone calls?

19. If customers do refer to their system documentation and attempt to answer their own questions before calling you, why do you think they do so? Where did they learn to do this?

20. What additional materials might be provided to customers in order to help them answer questions and thereby decrease their reliance on you? 
Other Issues:

21. What do you like best about your job as a trainer?

22. What do you like least about your job as a trainer? What do you think might be done by either yourself or the company to make the situation better?

23. What type of training would you like to receive to help you become a more effective trainer?

24. How do you think management perceives the training function in your company?

25. How do training and marketing interact in your company?

26. How well do you think marketing understands the training function, and vice versa?

27. What might be done to improve the overall relationship between training and marketing? 


\section{INTERVIEW GUIDE FOR USE WITH CLASS PARTICIPANTS}

1. Why did you attend this class?

2. Did you listen attentively to the information presented? If you responded No, explain:

3. Did you arrive on time and return from breaks as requested by the trainer?

If you responded No, explain:

4. Did you participate willingly in the workshop activities? If you responded No, explain:

5. What is your experience working with computers?

6. Do you believe that the course was taught at a skill level appropriate for you?

If No, why not?

7. Do you think the course was the proper length (number of days, hours per day, etc.)?

If No, why not?

8. How would you describe the training facilities (building, room, break/lunch areas)?

9. Prior to attending the class, how much of an understanding did you have of the overall workings of the system?

From where did you get this understanding? 
10. Please describe your reaction to the following course materials:
a. Overheads
b. Use of board or flipchart
c. Workbook
d. Other materials

11. Who will you be responsible for training when you return to the store? What information/materials were you given to help you train these people? How do you think they will help you do this training? What additional materials would be valuable for training purposes?

12. Please evaluate the course trainer in the following areas:
a. Sensitivity/rapport
b. Presentation/teaching style
c. Language (appropriate to skill level)
d. Listening and questioning skills
e. Ability to relate system functions to your specific situation

13. How would you rate the amount of material presented during the course?

14. How will the information presented during the class be used by you at your job?

15. When do you anticipate using the skills and information you acquired during the course?

Would you want to change the timing of the course in any way (earlier, later)?

16. When you return to the store and you have questions, what prccedures will you follow in order to find an answer or solve a problem? 


\section{INTERVIEW GUIDE FOR COMPANY MANAGEMENT}

1. Briefly describe the evolution of your company. (To be asked of only one person or researched through available materials.)

2. What is your relationship to the training function? What responsibilities do you have that relate to training?

3. How is training marketed in your company? (Included in purchase price, sold separately, etc.?)

4. When engaging in strategic and long-range planning, how much consideration do you give to customer training?

5. How do you include company growth projections in your budgeting for training (personnel, materials, etc.)?

6. What do you consider to be the strengths of your customer training?

The weaknesses?

7. If you do training both on-site and off-site, what are the advantages of both? The disadvantages?

8. What do you perceive to be the relationship between training, customer support, and sales in your company?

9. What characteristics/experience do you think are important for a successful trainer in your company?

10. What are some of the problems which your company/trainers encounter that interfere with successful training? 
GUIDE FOR EVALUATING TRAINING MATERIALS

Needs

Excellent Improvement Poor comments

ORGANIZATION

Easy to Reference

Table of Contents

Index

APPEARANCE

Type style

Type size

Illustrations

Page layout

Binder(s)

IANGUAGE

Written for Layperson

Grammar and spelling

CONTENT

Aids for Understanding

(e.g., flowcharts)

Up to Date

Technically Accurate

COMMENTS: 
TRAINING OBSERVATION GUIDE

TRAINING SITE:

Overall Appearance

Parking

Telephone

TRAINING ROOM:

Comfort

Table/chair arrangement

Distractors (e.g. noise, smoke)

\section{TRAINER:}

Appearance

Presentation style

Pace

Listening ability

Questioning ability

Control of class

Rapport

Sensitivity to learners 


\section{PARTICIPANTS :}

\# of people

Who attended? Responsibilities?

Characteristics (e.g., computer experience, age)

Level of involvement

skill mastery

\section{MATERIALS :}

Instructor's guide

Trainee workbook

Supplemental materials

Visuai aids

\section{FINDINGS :}

OVERALL RECOMMENDATIONS: 
APPENDIX C

Preliminary set of Codes For Data Analysis 
SUB-UYITS

EVOLUTION OF TRAINING

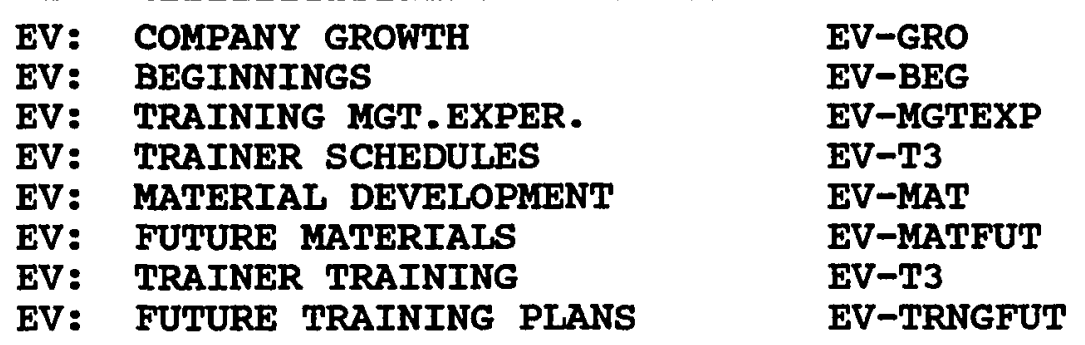

\section{MERIT OF TRAINING}

$\begin{array}{lll}\text { M: } & \text { FACILITIES - GENERAL } & \text { M-FAC/GEN } \\ \text { M: } & \text { FACILITIES - BREAKS \& MEALS } & \text { M-FAC/BRKS } \\ \text { M: } & \text { FACILITIES - MISC. } & \text { M-FAC/MISC } \\ \text { M: } & \text { ROOM-TEMPERATURE } & \text { M-ROOM/TEMP } \\ \text { M: } & \text { ROOM-COMFORT } & \text { M-ROOM/COMF } \\ \text { M: } & \text { ROOM-LIGHTING } & \text { M-ROOM/LITE } \\ \text { M: } & \text { SETUP-AUDIOVISUAL } & \text { M-SET/AV } \\ \text { M: } & \text { INSTRUCTOR'S GUIDE-LOOK } & \text { M-IG/LOOK } \\ \text { M: } & \text { INSTRUCTOR'S GUIDE-EASE } & \text { M-IG/USE } \\ & \text { OF USE } & \\ \text { M: } & \text { INSTRUCTOR'S GUIDE-ORG } & \text { M-IG/ORG } \\ \text { M: } & \text { WORKBOOK-LOOK } & \text { M-WRK/LOOK } \\ \text { M: } & \text { WORKBOOK-ILLUSTRATIONS } & \text { M-WRK/ILLUS } \\ \text { M: } & \text { WORKBOOK-EASE OF USE } & \text { M-WRK/USE } \\ \text { M: } & \text { WORKBOOK-VALUE TO TRAINEE } & \text { M-WRK/VALUE } \\ \text { M: } & \text { CONTENT-QUANTITY } & \text { M-CONT/QUAN } \\ \text { M: } & \text { CONTENT-SCHEDULE } & \text { M-CONT/SCHED } \\ \text { M: } & \text { CONTENT-DEGREE OF DIFF. } & \text { M-CONT/DIFF } \\ \text { M: } & \text { CONTENT-LANGUAGE } & \text { M-CONT/LANG } \\ \text { M: } & \text { CONTENT-ORGANIZATION } & \text { M-CONT/ORG } \\ \text { M: } & \text { CONTENT-BIG PICTURE } & \text { M-CONT/BIG } \\ \text { M: } & \text { CONTENT-TOPIC FIOW } & \text { M-CONT/FLO } \\ \text { M: } & \text { PARTICIPANTS-MAKEUP } & \text { M-PART/MAKEUP } \\ \text { M: } & \text { PARTICIPANTS-ATTITUDE } & \text { M-PART/ATT } \\ \text { M: } & \text { PARTICIPANTS-COOPERATION } & \text { M-PART/COOP } \\ \text { M: } & \text { PARTICIPANTS-COMPETENCE } & \text { M-PART/SMARTS } \\ \text { M: } & \text { TRAINER-DRESS } & \text { M-TRNR/DRESS } \\ \text { M: } & \text { TRAINER-DELIVERY } & \text { M-TRNR/DEL } \\ \text { M: } & \text { TRAINER-CONTROL } & \text { M-TRNR/CONT } \\ \text { M: } & \text { TRAINING DATABASE } & \text { M-DBASE } \\ \text { M: } & \text { SUPPLEMENTAL MATERIALS } & \text { M-SUPPMAT } \\ & & \\ & & \end{array}$


WORTH OF TRAINING

$\begin{array}{lll}\text { W: } & \text { TRAINER SUPPORT } & \text { W-TRNRSUPP } \\ \text { W: } & \text { CONSISTENCY OF PERSONNEL } & \text { W-TRNR/CONSIST } \\ \text { W: } & \text { FUTURE TRAINING } & \text { W-TRNG/FUT } \\ \text { W: } & \text { SUPPORT MATERIALS } & \text { W-MAT/SUPP } \\ \text { W: } & \text { ATTENTION TO PROBLEMS } & \text { W-PROBLEMS } \\ \text { W: } & \text { RELATE TO CUSTOMER SITE } & \text { W-CUSTSITE } \\ \text { W: } & \text { TEACH WHY TO DO THINGS } & \text { W-WHY } \\ \text { W: } & \text { UNDERSTAND BIG PICTURE } & \text { W-BIG } \\ \text { W: } & \text { DATA PROCESSING BASICS } & \text { W-DPBASICS } \\ \text { W: } & \text { UNDERSTAND BENEFITS } & \text { W-BENETITS } \\ \text { W: } & \text { GOOD QUESTIONING } & \text { W-? } \\ \text { W: } & \text { USE OF TESTS/REVIEWS } & \text { W-TEST } \\ \text { W: } & \text { BASIC COMPUTER SKILLS } & \text { W-COMPUSE } \\ \text { W: } & \text { SIMPLEX } & \text { W-SIMPIEX } \\ \text { W: } & \text { HANDS-ON PRACTICE } & \text { W-HANDSON } \\ \text { W: } & \text { REPORT PRINTING } & \text { W-REP/PRINT } \\ \text { W: } & \text { REPORT READING } & \text { W-REP/READ } \\ \text { W: } & \text { USE OF DOCUMENTATION } & \text { W-USEDOC } \\ \text { W: } & \text { PROBLEM SOLVING } & \text { W-SOLVE } \\ \text { W: } & \text { PRACTICAL TIPS } & \text { W-TIPS } \\ \text { W: } & \text { USE SKILLS WHEN? } & \text { W-WHEN? } \\ \text { W: } & \text { TRAIN OTHERS/MATERIALS } & \text { W-OTHERS/MAT } \\ \text { W: } & \text { TRAIN OTHERS/EXERCISES } & \text { W-OTHERS/EXER } \\ \text { W: } & \text { TRAIN OTHERS/HINTS } & \text { W-OTHERS/HINTS } \\ \text { W: } & \text { RETROSPECTIVE/LACKING } & \text { W-RETRO/IACK } \\ \text { W: } & \text { RETROSPECTIVE/STRENGTHS } & \text { W-RETRO/STRENGTH } \\ \text { W: } & \text { RETROSPECTIVE/PHONE CALLS } & \text { W-RETRO/PHONE } \\ \text { W: } & \text { RETROSPECTIVE/MATERIALS } & \text { W-RETRO/MAT } \\ & & \end{array}$


BUB-UNITS

TRAINER AS TEACHER

TRN: SENSITIVITY TO LEARNER

TRN: RAPPORT

TRN: ONE-ON-ONE SKILLS

TRN: GROUP SKILLS

TRN: IISTENING SRILIS

TRN: QUESTIONING SKILIS

TRN: RELATE TO REAL-WORLD

TRN: CLASSROOM SET-UP

TRN: MONITOR SCHEDULE

TRN: AV USE

TRN: CONTROL OF PARTICIPANTS

TRN: INDUSTRY EXPERIENCE

TRN: COMPUTER BACKGROUND

TRN: FORMAL EDUCATION

TRN: SUPPLEMENTAL EDUCATION

TRN: JOB TRAINING

TRN: TEACHING METHODS

TRN: TRAINING AIDS

TRN: STRENGTHS

TRN: WEAKNESSES

TRN: HOW MANAGEMENT PERCEIVES

TRN: HOW SALES REPS PERCEIVE
CODE

TRN-SENS

TRN-RAPP

TRN-ONE

TRN-GROUP

TRN-IISTEN

TRN-?

TRN-REALWORLD

TRN-ROOM

TRN-SCHED

TRN-AV

TRN-CONTROI

TRN-IND/EXP

TRN-COMP/EXP

TRN-EDUC

TRN-EDUC/SUPP

TRN-OJT

TRN-METHODS

TRN-AIDS

TRN-PLUS

TRN-MINUS

TRN-MGT

TRN-SALES

\section{LEARNER}

$\begin{array}{ll}\text { LRN: INDUSTRY BACKGROUND } & \text { LRN-IND/EXP } \\ \text { LRN: COMPUTER BACKGROUND } & \text { LRN-COMP/EXP } \\ \text { LRN: COMPUTER SKILL LEVEL } & \text { LRN-COMP/SKILI } \\ \text { LRN: ATTITUDE TOWARD SYSTEM } & \text { LRN-ATT } \\ \text { LRN: ABILITY TO LEARN } & \text { LRN-SMARTS } \\ \text { LRN: JOB AT CUSTOMER SITE } & \text { LRN-JOB } \\ \text { LRN: INVOLVEMENT IN SALE } & \text { LRN-SALE } \\ \text { LRN: MOTIVATION } & \text { LRN-MOT } \\ \text { LRN: PARTICIPATE IN DECISIONS } & \text { LRN-DECISION } \\ \text { LRN: HANDS-ON ACTIVITY } & \text { LRN-HANDSON } \\ \text { LRN: RELATE TO OWN JOB } & \text { LRN-RELATE } \\ \text { LRN: RELATE TO EXPERIENCE } & \text { LRN-EXPER }\end{array}$


APPENDIX D

Final set of Codes For Data Analysis 
EVOLUTION OF TRAINING

$\begin{array}{lll}\text { EV: COMPANY GROWTH } & \text { EV-GRO } \\ \text { EV: TRAINING MGT.EXPER. } & \text { EV-MGTEXP } \\ \text { EV: TRAINER SCHEDULES } & \text { EV-T3 } \\ \text { EV: } & \text { MATERIAL DEVELOPMENT } & \text { EV-MAT } \\ \text { EV: TRAINER TRAINING } & \text { EV-T3 }\end{array}$

EV: TRAINER TRAINING EV-T3

\begin{tabular}{|c|c|c|}
\hline M: & FACILITIES & \\
\hline M: & ROOM-TEMPERATURE & M-ROOM/TEMP \\
\hline M: & ROOM-COMFORT & M-ROOM/COMF \\
\hline M: & ROOM-LIGHTING & M-ROOM/LITE \\
\hline M: & SETUP-AUDIOVISUAL & M-SET/AV \\
\hline M: & INSTRUCTOR'S GUIDE-LOOK & M-IG/LOOK \\
\hline M: & $\begin{array}{l}\text { INSTRUCTOR'S GUIDE-EASE } \\
\text { OF USE }\end{array}$ & M-IG/USE \\
\hline M: & INSTRUCTOR'S GUIDE-ORG & M-IG/ORG \\
\hline M: & WORKBOOK-LOOK & M-WRK/LOOK \\
\hline M: & WORKBOOK-ILLUSTRATIONS & M-WRK/ILLUS \\
\hline M: & WORKBOOK-EASE OF USE & M-WRK/USE \\
\hline M: & WORKBOOK-VALUE TO TRAINEE & M-WRK/VALUE \\
\hline M: & CONTENT-QUANTITY & M-CONT/QUAN \\
\hline M: & CONTENT-DEGREE OF DIFF. & M-CONT/DIFF \\
\hline M: & CONTENT-ORGANIZATION & M-CONT/ORG \\
\hline M: & CONTENT-BIG PICTURE & M-CONT/BIG \\
\hline M: & CONTENT-TOPIC FLOW & M-CONT/FLO \\
\hline M: & PARTICIPANTS-MAKEUP & M-PART/MAKEUP \\
\hline M: & PARTICIPANTS-COOPERATION & M-PART/COOP \\
\hline M: & PARTICIPANTS-COMPETENCE & M-PART/SMARTS \\
\hline M: & TRAINER-PRES & M-IRNR/ PRES \\
\hline M: & TRAINING DATABASE & M-DBASE \\
\hline M: & SUPPLEMENTAL MATERIALS & M-SUPPMAT \\
\hline
\end{tabular}


WORTH OF TRAINING

\begin{tabular}{lll} 
W: & TRAINER SUPPORT & W-TRNRSUPP \\
W: & SUPPORT MATERIALS & W-MAT/SUPP \\
W: & RELATE TO CUSTOMER SITE & W-CUSTSITE \\
W: & UNDERSTAND BIG PICTURE & W-BIG \\
W: & DATA PROCESSING BASICS & W-DPBASICS \\
W: & UNDERSTAND BENEFITS & W-BENEFITS \\
W: & WOOD QUESTIONING & W-? \\
W: USE OF TESTS/REVIEWS & W-TEST \\
W: & BASIC COMPUTER SKILLS & W-HAMPUSE \\
W: HANDS-ON PRACTICE & W-REPORTS \\
W: REPORTS & W-USEDOC \\
W: USE OF DOCUMENTATION & W-SOLVE \\
W: PROBLEM SOLVING & W-TIPS \\
W: & PRACTICAL TIPS & W-OTHERS \\
W: TRAIN OTHERS & W-RETRO/IACK \\
W: RETROSPECTIVE/LACKING & W-RETRO/STRENGTH \\
W: & RETROSPECTIVE/STRENGTHS \\
BUB-UNITB & \\
\hline
\end{tabular}

TRAINER AS TEACHER

$\begin{array}{ll}\text { TRN: RAPPORT } & \text { TRN-RAPP } \\ \text { TRN: ONE-ON-ONE SKILLS } & \text { TRN-ONE } \\ \text { TRN: GROUP SKILLS } & \text { TRN-GROUP } \\ \text { TRN: LISTENING SKILLS } & \text { TRN-ISTTEN } \\ \text { TRN: QUESTIONING SKILLS } & \text { TRN-? } \\ \text { TRN: RELATE TO REAL-WORLD } & \text { TRN-REALWORLD } \\ \text { TRN: INDUSTRY EXPERIENCE } & \text { TRN-IND/EXP } \\ \text { TRN: COMPUTER BACKGROUND } & \text { TRN-COMP/EXP } \\ \text { TRN: FORMAL EDUCATION } & \text { TRN-EDUC } \\ \text { TRN: JOB TRAINING } & \text { TRN-OJT } \\ \text { TRN: TEACHING METHODS } & \text { TRN-METHODS } \\ \text { TRN: TRAINING AIDS } & \text { TRN-AIDS } \\ \text { TRN: STRENGTHS } & \text { TRN-PLUS } \\ \text { TRN: WEAKNESSES } & \text { TRN-MINUS } \\ \text { TRN: HOW MANAGEMENT PERCEIVES } & \text { TRN-MGT } \\ \text { TRN: HOW SALES REPS PERCEIVE } & \text { TRN-SALES }\end{array}$

IEARNER

IRN: COMPUTER BACKGROUND

LRN: ATTITUDE TOWARD SYSTEM

IRN: JOB AT CUSTOMER SITE

IRN: MOTIVATION

IRN: HANDS-ON ACTIVITY

LRN: RELATE TO EXPERIENCE
LRN-COMP/EXP
LRN-ATT
LRN-JOB
IRN-MOT
LRN-HANDSON
LRN-EXPER 
APPENDIX E

Interview Guide Used With Sales Reps

Reproduced with permission of the copyright owner. Further reproduction prohibited without permission. 
INTERVIEW GUIDE FOR SALES REPRESENTATIVES

1. Briefly describe the typical sales cycle for a sales rep in your company?

2. At what points in the sales cycle does marketing interface with the training department?

3. What do you perceive the relationship to be between marketing and training?

4. What types of problems do the trainers create for you once a system has been sold?

5. What problems do you think trainers might believe you create for them?

6. Do you have any suggestions for how the training/marketing relationship might be improved? 
REFERENCES

Alessandra, A. (1987) . Bite-sized training. Training Trends, 3 . Ball, S. (1983). Participant observation as a method of research. The conduct of fieldwork, Victoria: Deakin University Press.

Bell, C. (1984). Building a reputation for training effectiveness. Training and Development Journal, 38(5), $50-53$.

Bellman, G.M. (1984). What do we need to know about a group before designing training for it? Training and Development Journal, $\underline{38(9), 16-21 . ~}$

Bennis, W. G. (1971). A funny thing happened on the way to the future. In G. L. Lippitt, I. E. This, and R. G. Bidwell, Jr. (Eds.). Optimizing human resources: Readings in individual and organization development. Reading, MA: Addison-Wesley, $2-9$.

Bezdek, J. (1985). How to teach technical subjects to nontechnical learners. Training, 22(4), 73-80.

Biklen, S. K. and R. Bogdan (1986). On your own with naturalistic evaluation. In New directions for program evaluation, 30, San Francisco: Jossey-Bass.

Bogdan, R. C. and S. K. Biklen (1982) - Qualitative research for education: An introduction to theory and methods. Boston, MA: Allyn and Bacon. 
Borg, W. R. and M. D. Gall (1983). Educational research. New York: Longman Inc.

Bowman, B. (1985) - Assessing your needs assessment. Training, $\underline{22}(10), 30-34$.

Callaghan, D. R. (1985) - Realistic computer training. Training and Development Journal, $39(7), 27-29$.

Calvert, R. (1985) - Training America: The numbers add up. Training and Development Journal, 39(11), 35-37.

Cohen, L. and Manion, L. (1985). Research methods in education. Dover, NH: Croom Helm.

Cooke, P. and R. R. Bates (in press). Cause-and-effect evaluation: Sorting out the dilemmas. San Diego: University Associates.

Cross, K. P. (1983). Adults as learners. San Francisco, CA: Jossey-Bass.

Custer, G. E. (1986). Planning, packaging, and presenting training: A guide for subject-matter experts. San Diego, CA: University Associates.

Dailey, N. (1984). Adult learning and organizations. Training and Development Journal, 38(12), 64-68. 
Delaney, C. (1987). The organizational context of training evaluation for staff development. In L. S. May, C. A. Moore, and S. J. Zammit (Eds.). Evaluating business and industry training. Boston, MA: Kluwer Academic Piblishers, 41-56.

Deming, B. S. (1982). Evaluating job-related training: A quiuje for training the trainer,. Washington, DC: American society for Training and Development.

Employee training in America (1986). Training and Development Journal, $40(5), 34-37$.

Esty, K. C. (1987). Trainer and trainee: What role theory can teach you about training, training theory and practice. In Reddy and Henderson (Eds.). Training theory and practice. Arlington, VA: NTL Institute for Applied Behavioral science and San Diego, CA: University Associates.

Ettington, J. E. (1971). Which role for today's trainer? In G. L. Lippitt, L. E. This, and R. G. Bidwell, Jr. (Eds.). Optimizing human resources: Readings in individual and organization development. Reading, MA: Addison-Wesley, 407-411.

Frederiksen, L.W., J.B. Myers, and A.W. Riley (1986). A case for cross-training. Training, $\underline{23}(2), 37-43$. 
Gallegos, R.C. and J.G. Phelan (1975). Using behavioral objectives in industrial training. In D. L. Kirkpatrick, Ed., Evaluating Training Programs. Madison, WI: American Society of Training and Development, 125-130.

Gehrson, D. J. and C. A. Moore (1987). The role of training in implementing strategic change. In L. S. May, C. A. Moore, and S. J. Zammit (Eds.). Evaluating business and industry training. Boston, MA: Kluwer Academic Publishers, 3-18.

Goldstein, I.L. (1986). Training in organizations: Needs assessment, development, and evaluation. Monterey, CA: Brooks/Cole.

Goodell, F. C. (1971). Reflections of a training director. In G. L. Lippitt, I. E. This, and R. G. Bidwell, Jr. (Eds.). Optimizing human resources: Readings in individual and organization development. Reading, MA: Addison-Wesley, 401-406.

Greiner, L. E., D. P. Leitch, and L. B. Barnes (1971). Putting judgment back into decisions. In G. L. Lippitt, L. E. This, and R. G. Bidwell, Jr. (Eds.) - optimizing human resources: Readings in individual and organization development. Reading, MA: Addison-Wesley, 365-378.

Guba, E. G. (1987). Naturalistic evaluation. In Cordray, D. S., H. S. Bloom, and R. J. Light (Eds.). Evaluation practice in review. San Francisco, CA: Jossey-Bass, 23-43. 
Guba, E. G. and Y. S. Lincoln (1981). Effective Evaluation. San Francisco, CA: Jossey-Bass.

Guba, E. G. and Y. S. Lincoln (1983). Epistemological and methodological bases of naturalistic inquiry. In Madaus, G. F., M. Scriven, and D. L. Stufflebeam (Eds.). Evaluation models: Viewpoints on educational and human services evaluation. Boston, MA: Kluwer-Nijhoff.

Hahne, G. (1986) . How can subject matter experts prepare themselves to be trainers? Training and Development Journal $\underline{40}(8)$.

Hales, L. D. (1986). Training: A product of business planning. Training and Development Journal, 40(7), 65-66.

Hall, C. (1987). Why don't they ever ask for my suggestions? Supervision, $\underline{49}(12), 3-5$.

Hamblin, A.C. (1974). Evaluation and control of training. London: McGraw-Hill.

Hebert, Y. M. (1986) Naturalistic evaluation in practice: A case study. In Williams, D. D. (Ed.). New directions in program evaluation. San Francisco, CA: Jossey-Bass, 3-21.

Hiebert, M. B. and W. N. Smallwood (1987). Now for a completely different look at needs analysis. Training and Development Journal, $41(5), 75-79$. 
In search of missing skills (1986). The Economist, $\underline{301}(7477 / 7478), 93-94$.

Janov, J. (1986). How can subject matter experts prepare themselves to be trainers? Training and Development Journal, $\underline{40}(8)$.

Jones, R. A. (1985). Research methods in the social and behavioral sciences. Sunderland, MA: Sinauer Associates, Inc.

Kahman, V. S. and J. P. Mohr (1984). Training needs assessment in the eighties: Five guideposts. Personnel Administrator, 10, 47-53.

Kayloe, A.G. (1975). A method for evaluating the effectiveness of technical training. In D.L. Kirkpatrick, Evaluating Training Programs. Madison, WI: American Society of Training and Development, 97-103.

Kelley, A.I., R.F. Orgel and D.M. Baer (1985). Seven strategies that guarantee training transfer. Training and Development Journal, 39(11), 78-82.

Kemmis, S. (1983) A guide to evaluation design. In case study methods: The conduct of fieldwork. Victoria: Deakin University, p. 1 - 32 .

Kidder, L. H. and M. Fine (1987) - Qualitative and quantitative methods: When stories converge. In Mark, M. M. and $R$. L. Shotland (Eds.). Multiple methods in program evaluation. San Francisco, CA: Jossey-Bass, 57-75. 
Kirkpatrick, D.I. (1975). Techniques for evaluating training programs. In D.I. Kirkpatrick, Evaluating Training Programs. Madison, WI: American Society of Training and Development, 1-18.

Kirkpatrick, D. L. (1976). Evaluation of training. In R. L. Craig (Ed.). Training and development handbook. New York: McGraw-Hill.

Kliem, R. L. (1985). In-house training for microcomputer users. Administrative Management, $\underline{46(12), 50-51 .}$

Knowles, M. S. (1971). The leader looks at the learning climate. In G. L. Lippitt, L. E. This, and R. G. Bidwell, Jr. (Eds.) . Optimizing human resources: Readings in individual and organization development. Reading, MA: Addison-Wesley, $69-77$.

Knowles, M. S. and Associates (1984) - Andragogy in action. San Francisco, CA: Jossey-Bass.

Knox, A. B. (1986). Helping adults learn. San Francisco, CA: Jossey-Bass.

Laird, D. (1978) . Approaches to training and development. Reading, MA: Addison-Wesley.

Laird, D. and F. Belcher (1984). How master trainers get that way. Training and Development Journal, 38(5), 73-75. 
Lawrie, J.W. and C.W. Boringer (1975). Training needs assessment and training program evaluation. In D.L. Kirkpatrick, Evaluating Training Programs. Madison, WI: American Society of Training and Development, 291294.

Lerda, I.W. and L.W. Cross (1975). Performance oriented training: Results measurement and follow-up. In D.I. Kirkpatrick, Evaluating Training Programs. Madison, WI: American Society of Training and Development, 210215.

Lester, R.L. (1975) - Criteria for evaluating training results. In D.I. Kirkpatrick, Evaluating Training programs. Madison, WI: American Society of Training and Development, 33-36.

Lincoln, Y. S. and E. G. Guba (1986). But is it rigorous? Trustworthiness and authenticity in naturalistic evaluation. In D. D. Williams (Ed.). New directions in program evaluation. San Francisco, CA: Jossey-Bass, 73-83.

Lincoln, Y, S. and E. G. Guba (1985) . Naturalistic evaluation. Beverly Hills, CA: Sage Publications.

Lindo, D. K. (1987). Stop Employee Training. Supervision, $\underline{49}(7), 18-19$.

Lippert, F. G. (1984). Evaluate Training? Supervision, 46(12), 16-17. 
Lippitt, G. L. (1971) . Is training a profession? In G. L. Lippitt, L. E. This, and R. G. Bidwell, Jr. (Eds.) . optimizing human resources: Readings in individual and organization development. Reading, MA: Addison-Wesley, 393-400.

Lippitt, G. L. (1971). The neglected learner. In G. I. Iippitt, L. E. This, and R. G. Bidwell, Jr. (Eds.). Optimizing human resources: Readings in individual and organization development. Reading, MA: Addison-Wesley, 59-68.

Lippitt, G. L. (1971) . Trends affecting the future of training and development. In G. L. Lippitt, L. E. This, and R. G. Bidwell, Jr. (Eds.). Optimizing human resources: Readings in individual and organization development. Reading, MA: Addison-Wesley, 32-39.

Lott, 0.C. (1975) . Evaluating to reduce training costs. In D.I. Kirkpatrick, Evaluating Training Programs. Madison, WI: American Society of Training and Development, 244-246.

Luckett, D. (1985). Rate your training program traits. Training and Development Journal, $\underline{39}(4), 79-80$.

MacDonald, B. and R. Walker (1983) - Case study and the social philosophy of educational research. In perspectives on case study: Naturalistic observation. Victoria: Deakin University Press. 
Madaus, G. F., M. Scriven, and D. L. Stufflebeam, Eds. (1983). Evaluation models: Viewpoints on educational and human services evaluation. Boston, MA: Kluwer-Nijhoff.

Margolis, F. H. and C. R. Bell (1986). Instructing for results. San Diego, CA: University Associates.

Mayo, G. D. and P. H. DuBois (1987). The complete book of training: Theory, principles, and techniques. San Diego, CA: University Associates.

McConnell, J. H. and F. J. Setaro (1976) - Computer-related training. In R. L. Craig (Ed.). Training and Development Handbook. New York: McGraw-Hill.

Merwin, S. (1986). Effective evaluation strategies and techniques: A key to successful training. San Diego, CA: University Associates.

Meyers, W. R. (1981). The evaluation enterprise. San Francisco, CA: Jossey-Bass.

Miles, M.B. (1979). Qualitative data as an attractive nuisance. Administrative Science Quarterly, 24, 590-601.

Miles, M. B. and A. M. Huberman (1984). Drawing valid meaning from qualitative data: Toward a shared craft. Educational Researcher. 
Miles, M. B. and A. M. Huberman (1984). Qualitative data analysis: A sourcebook of new methods. Beverly Hills, CA: Sage Publications.

Moore, W.R. (1975). Training evaluation: It used to be so simple. In D.L. Kirkpatrick, Evaluating Training Programs. Madison, WI: American Society of Training and Development, 237-239.

Newsweek staff (1971). Motivating people: Money isn't everything. In G. L. Lippitt, L. E. This, and R. G. Bidwell, Jr. (Eds.). Optimizing human resources: Readings in individual and organization development. Reading, MA: Addison-Wesley, 314-317.

Olson, L. (1986). Training trends: The corporate view. Training and Development Journal, 32-35.

Parnell, E.M. (1987). Self-examination: The achilles heel of teams. Supervision, $49(2), 6-8$.

Patton, M. (1980) - Qualitative evaluation methods. Beverly Hills, CA: Sage Publications.

Paul, W. J., Jr., K. R. Robertson and F. Herzberg (1971) . Job enrichment pays off. In G. L. Lippitt, L. E. This, and R. G. Bidwell, Jr. (Eds.). Optimizing human resources: Readings in individual and organization development. Reading, MA: Addison-Wesley, 318-342. 
Peters, T. (1987). Thriving on chaos: Handbook for a management revolution. New York: Alfred A. Knopf.

Peters, T. (1987). Training neglect gives hardware edge over humans. San Diego Union, October 19, E-1.

Phillips, J. J. (1983). Training evaluation and measurement methods. Houston, TX: Gulf Publishing Company.

Ramsey, P. J. (1987) . System training - Not by the menu. Performance and Instruction, $7,20-22$.

Randall, L.K. (1975). Evaluation: A training dilemma. In Kirkpatrick, D.L., Ed. Evaluating training programs. Madison, WI: American Society of Training and Development, 186-190.

Reddy, w. B. and C. C. Henderson, Eds. (1987). Training theory and practice. Arlington, VA: NTI Institute for Applied Behavioral Science and San Diego, CA: University Associates.

Reynolds, D. (1982). The naturalistic method of educational and social research: A Marxist critique. In Perspectives on case study: Naturalistic observation. Victoria, Deakin University, 119-129.

Robinson, K. R. (1985) - A handbook of training management,. London, England: Kogan Page.

Roman, D. (1984) . Evaluation starts long before training begins. Computer Decisions, 16(7), 82-84. 
Rosenberg, M. J. (1987). Evaluating training programs for decision making. In L. S. May, C. A. Moore, and S. J. Zammit (Eds.). Evaluating business and industry training. Boston, MA: Kluwer Academic Publishers, 57-74.

Russ-Eft, D. F. and J. H. Zenger (1985). Common mistakes in evaluating training effectiveness. Personnel Administrator, 4, 57-62.

Sauer, S. F. and R. E. Holland (1981). Planning in-house training: A personal system with an organizational perspective. Austin, TX: Learning Concepts.

Schmidt, พ. H. (1971). Transforming knowledge into impact - Some thoughts on the teaching-learning process. In G. L. Lippitt, L. E. This, and R. G. Bidwell, Jr. (Eds.) . Optimizing human resources: Readings in individual and organization development. Reading, MA: Addison-Wesley, 78-83.

Schmidt, W. H. (1971), How to evaluate a company's training efforts. In G. L. Lippitt, L. E. This, and R. G. Bidwell, Jr. (Eds.). Optimizing human resources: Readings in individual and organization development. Reading, MA: Addison-Wesley, 379-391.

Schuerman, J. R. (1983). Research and evaluation in the human services. New York: The Free Press.

Simons, H. (1983) . Conversation piece: The practice of interviewing in case study research. The conduct of fieldwork. Victoria: Deakin University Press. 
Smith, J. K. (1983). Quantitative versus qualitative research: An attempt to clarify the issue. Educational Researcher, $12(3), 6-13$

Sokol, E. W. and J. C. Bulyk (1986). Truths of technology training. Training and Development Journal, 40(2), 43-45.

Sorenson, T. C. (1971). The revolutions of our time and their implications for training and development. In G. L. Lippitt, L. E. This, and R. G. Bidwell, Jr. (Eds.). Optimizing human resources: Readings in individual and organization development. Reading, MA: Addison-Wesley, 2-9.

Spaid, O. A. (1986). The consummate trainer: A practitioner's perspective. Englewood Cliffs, NJ: Prentice-Hall.

Stake, R.E. (1982). To evaluate an arts program. In Perspectives on case study: Naturalistic observation. Victoria: Deakin University, 27-44

Stake, R.E. (1983). The case study method in social inquiry. Case study: An overview. Victoria: Deakin University Press.

Stake, R.E. (1983). Program evaluation, particularly responsive evaluation. In G. F. Madaus, M. Scriven, and D. L. Stufflebeam (Eds.). Evaluation models: viewpoints on educational and human services evaluation. Boston, MA: Kluwer-Nijhoff. Strauch, R. (1984). Training the whole person. Training and Development Journal, 38(11), 82-86. 
Thiel, C. T. (1985) . Training starts with top-down acceptance. Infosystems, $\underline{L}_{1}, 60-64$.

This, I. E. and G. L. Lippitt (1971). Learning theories and training: An overview of learning theory implications for the training director. In G. L. Lippitt, L. E. This, and R. G. Bidwell, Jr. (Eds.). Optimizing human resources: Readings in individual and organization development. Reading, MA: Addison-Wesley, 41-58.

Tracey, W. R. (1968). Evaluation of training and development systems. American Management Association, Inc.

Tuckman, B. W. (1978) - Conducting educational research. San Diego, CA: Harcourt Brace Jovanovich.

Van Maanen, J., Ed. (1979). Qualitative methodology. Beverly Hills, CA: Sage Publications.

Van Maanen, J. (1973). The process of program evaluation: A guide for managers. Washington, DC: National Training and Development Service Press.

Van Maanen, J., J. M. Dabbs, Jr., and R. R. Faulkner (1982). Varieties of qualitative research. Beverly Hills, CA: Sage Publications. 
Walker, R. (1982). The conduct of educational case studies: ethics, theory and procedures. In perspectives on case study: Naturalistic observation. Victoria: Deakin University, 45-78.

Whyte, W. F. (1984). Learning from the field: A gide from experience. Beverly Hills, CA: Sage Publications.

Williams, D. D. (1986). When is naturalistic evaluation appropriate? In D. D. Williams (Ed.), Naturalistic evaluation. San Francisco, CA: Alfred A. Knopf, 85-92.

Wlodkowski, R. J. (1985). Enhancing adult motivation to learn. San Francisco, CA: Jossey-Bass.

Yin, R. K. (1984) - Case study research: Design and methods. Beverly Hills, CA: SAGE Publications.

Yoong, S. (1986). Guba as a vanguard of naturalistic inquiry: A harbinger of the future? Paper presented at Bergamo Conference on Curriculum Theory and classroom Practice, Dayton, OH, October 10-25.

Zemke, R. and T. Kramlinger (1987) . Figuring things out: $\underline{A}$ trainer's quide to needs and task analysis. Reading, MA: Addison-Wesley. 